\title{
Bristol as a Smart Local Energy System of Systems: Skills Case Study
}

\author{
Ruzanna Chitchyan, Caroline Bird \\ University of Bristol, UK \\ $\{$ r.chitchyan, caroline.bird\}@bristol.ac.uk
}

26 April 2021

\section{Contents}

1 Overview of the Context $\quad 6$

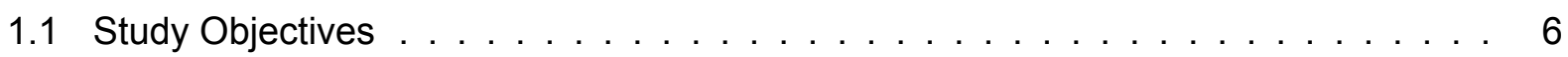

1.2 Framing of the SLE Notion $\ldots \ldots \ldots \ldots \ldots \ldots$

1.2.1 SLE as a System-of-Systems . . . . . . . . . . . . . . . . . . 7

1.2 .2 Local in SLE SoS . . . . . . . . . . . . . . . . . . . . . . . 9

1.2 .3 Smart in SLE SoS . . . . . . . . . . . . . . . . . . . . . . 9

1.3 Structure of the Report . . . . . . . . . . . . . . . . . . . . . 9

2 Methodology 10

2.1 Materials Review for Bristol's SLE Projects Identification . . . . . . . . . . . . . . . 11

2.2 Per-project Stakeholder Identification . . . . . . . . . . . . . . . . . . . . . . . . . . . . . . . . . . . . . . . . . .

2.3 Stakeholder Interviews and Focus Groups . . . . . . . . . . . . . . . . . . . . 11

2.3.1 Participant Recruitment for Study with Stakeholders . . . . . . . . . . . . . . 12

2.3.2 Participant Recruitment for Study with Citizens . . . . . . . . . . . . . . . . . 16

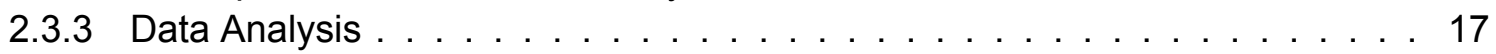

2.3.4 Treats to Validity and Study Limitations . . . . . . . . . . . . . . . . . . 17

3 Bristol's Energy Ecosystem 19

3.1 Background to the city of Bristol . . . . . . . . . . . . . . . . . . 19

3.2 Energy stakeholders . . . . . . . . . . . . . . . . . . . . . 20

3.2 .1 Community . . . . . . . . . . . . . . . . . . . . . . 20

3.2.2 Non-governmental organisations . . . . . . . . . . . . . . . . . . . 21

3.2 .3 Local Government . . . . . . . . . . . . . . . . . . . . . . . . . . . . 21

3.2 .4 Business . . . . . . . . . . . . . . . . . . . . . 22

3.3 Bristol Policies for Energy . . . . . . . . . . . . . . . . . . . . . . . . . . 23

3.3.1 One City Plan, SDGs and Climate . . . . . . . . . . . . . . . 23

3.3 .2 City Council Plans: SLES Impact . . . . . . . . . . . . . . . . . . . . . . 24 
4 Building and Retrofit Sub-System: Findings from Data Analysis 25

4.1 Factors affecting Bristol's Building and Retrofit sub-system . . . . . . . . . . . . 25

4.2 What Skills are Needed for the Building and Retrofit Sub-System Currently and in the Future? . . . . . . . . . . . . . . . . . . . . . . . . . 26

4.2.1 Engineering and design skills for the Building and Retrofit sub-system . . . . 26

4.2.2 Trades Skills for Building and Retrofit sub-system . . . . . . . . . . . . . . . 28

4.2.3 Managerial Skills for Building and Retrofit sub-system . . . . . . . . . . . . . 29

4.2.4 Energy Skills for Building and Retrofit sub-system . . . . . . . . . . . . . . 30

4.2.5 Finance Skills for Building and Retrofit sub-system . . . . . . . . . . . . . . . . 30

4.2.6 Policy Skills for Building and Retrofit sub-system . . . . . . . . . . . . . . . . . . . 30

4.2.7 Legal Skills for Building and Retrofit sub-system . . . . . . . . . . . . . . . 30

4.2.8 Soft Skills Shortage in Building and Retrofit sub-system . . . . . . . . . . . . 31

4.3 Training Needs for Building and Retrofit Sub-System . . . . . . . . . . . . . . . . . 31

4.3 .1 Areas of Training Needs . . . . . . . . . . . . . . . . . . . 31

4.3 .2 Modes of Training . . . . . . . . . . . . . . . . . . . . . . . . . . . . . . . .

4.4 Insights and Recommendations on Bristol's Building and Retrofit Sub-System . . . . 33

4.4.1 Motivating the current workforce to take up the available training and adopt modern building and retrofit practices . . . . . . . . . . . . . 33

4.4 .2 Attracting young people . . . . . . . . . . . . . . 36

4.4 .3 Navigating the transition path equitably $\ldots \ldots \ldots . \ldots . \ldots 37$

5 Local Authorities Subsystem: Findings from Data Analysis 37

5.1 Factors Affecting Bristol's Local Authority Subsystem . . . . . . . . . . . . . . . . . 37

5.2 What skills are needed for Bristol's Local Authority (energy) subsystem currently and in the future $\ldots^{2} \ldots \ldots \ldots \ldots \ldots \ldots \ldots \ldots$

5.2.1 Engineering Skills for the Local Authority Subsystem . . . . . . . . . . . . . . 39

5.2 .2 Trades Skills for Local Authority Subsystem . . . . . . . . . . . . . . . . . . . . 41

5.2.3 Managerial Skills for Local Authority Subsystem . . . . . . . . . . . . . . . . . . . 41

5.2 .4 Energy Skills for Local Authority Subsystem . . . . . . . . . . . . . . . . . . . . . . 42

5.2 .5 Finance Skills for Local Authority Subsystem . . . . . . . . . . . . . . . . 43

5.2 .6 Legal Skills for Local Authority Subsystem . . . . . . . . . . . . . . . . . . . . 43

5.2 .7 Policy Skills for Local Authority Subsystem . . . . . . . . . . . . . . . . . . . . . . 43

5.2 .8 Soft Skills for Local Authority Subsystem . . . . . . . . . . . . . . . . . . . . 44

5.3 Training Needs for Local Authority Subsystem . . . . . . . . . . . . . . . . . . . . . . 44

5.3.1 Areas of Training Needs within BCC . . . . . . . . . . . . . . . . . 44

5.3 .2 Modes of Training . . . . . . . . . . . . . . . . . . . . . . 45

5.4 Insights and Recommendations on Bristol's Local Authority Subsystem . . . . . . . 46

5.4.1 Creating the Local Regulatory Landscape . . . . . . . . . . . . . . . . . . . . . . 46

5.4 .2 Assessing Quality of City Leap Delivery . . . . . . . . . . . . . . . . . . . . . . . 46

5.4.3 SLE SoS Training Across All BCC Departments . . . . . . . . . . . . . . . . 47

6 Citizens' Subsystem $\quad 47$

6.1 Factors Affecting Bristol's Citizens' subsystem . . . . . . . . . . . . . . . . . . 47

6.2 Trust, Risk, Complexity and Loss of Control . . . . . . . . . . . . . . . . . . . . . 49

6.2 .1 Trust . . . . . . . . . . . . . . . . . . . . 49

6.2 .2 Risk . . . . . . . . . . . . . . . . . . . . 50 
6.2 .3 Technical Complexity . . . . . . . . . . . . . . . . . . . . . 50

6.2 .4 Loss of Control . . . . . . . . . . . . . . . . . . . . . . . . 50

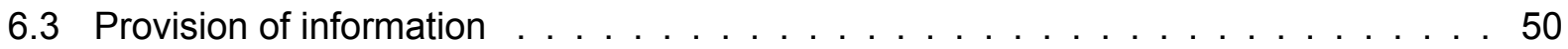

6.4 Training needs for the Citizens' Adoption of SLE . . . . . . . . . . . . . . 51

6.4 .1 Areas of Training Needs . . . . . . . . . . . . . . . . . . 51

6.4 .2 Modes of Training . . . . . . . . . . . . . . . . . . . 53

6.5 Insights and Recommendations on SLE SoS for Citizens' Subsystem . . . . . . . 53

6.5 .1 Citizens are the Foundational Subsystem . . . . . . . . . . . . . . 53

6.5 .2 Channels for Impact . . . . . . . . . . . . . . . . . . . . . . . . 53

7 Transport and Mobility Subsystem: Findings from Data Analysis $\quad 54$

7.1 Factors Affecting Bristol's Transport and Mobility subsystem . . . . . . . . . . . . 54

7.2 What skills are needed for the Transport and Mobility Subsystem presently and in the future? . . . . . . . . . . . . . . . . . . . . . . . 55

7.2.1 Engineering Skills for the Transport and Mobility subsystem . . . . . . . . . 55

7.2.2 Energy Domain Skills for Transport and Mobility subsystem . . . . . . . . . 57

7.2.3 Trades Skills for Transport and Mobility subsystem . . . . . . . . . . . . . . 58

7.2.4 Managerial Skills for Transport and Mobility subsystem . . . . . . . . . . 58

7.2 .5 Finance Skills for Transport and Mobility subsystem . . . . . . . . . . . . 58

7.2 .6 Policy Skills for Transport and Mobility subsystem . . . . . . . . . . . . . 58

7.2 .7 Legal Skills for Transport and Mobility subsystem . . . . . . . . . . . . . . . 59

7.2 .8 Soft Skills for Transport and Mobility subsystem . . . . . . . . . . . . . . 59

7.3 Training needs for Transport and Mobility System . . . . . . . . . . . . . 60

7.3.1 Areas of Training Needs . . . . . . . . . . . . . . . . . . . 60

7.3.2 Modes of Training . . . . . . . . . . . . . . . . . . . 60

7.4 Insights and Recommendations on Bristol's Transport and Mobility Subsystem . . . 61

7.4.1 Transport and Mobility - Core SLE SoS Subsystem . . . . . . . . . . . . 61

7.4 .2 Behaviour change . . . . . . . . . . . . . . . . 61

7.4 .3 COVID-19 Impact . . . . . . . . . . . . . . . 62

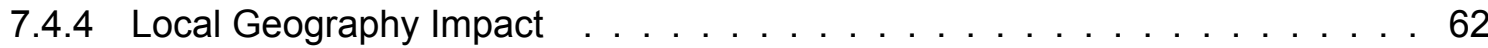

7.4 .5 Scale Up Concerns . . . . . . . . . . . . . . . . . . . 62

8 Community Energy Subsystem: Findings from Data Analysis 63

8.1 Factors Affecting Bristol's Community Energy subsystem . . . . . . . . . . 63

8.2 What skills are needed for the Community Energy Subsystem now and in the future? 65

8.2.1 Engineering Skills for Community Energy subsystem . . . . . . . . . . 65

8.2.2 Energy Domain Skills for Community Energy subsystem . . . . . . . . . . . 67

8.2.3 Finance Skills for Community Energy subsystem . . . . . . . . . . . . . . 67

8.2.4 Legal Skills for Community Energy subsystem . . . . . . . . . . . . . . . 68

8.2.5 Managerial Skills for Community Energy subsystem . . . . . . . . . . . 68

8.2.6 Policy Skills for Community Energy subsystem . . . . . . . . . . . . . . 69

8.2.7 Soft Skills for Community Energy subsystem . . . . . . . . . . . . . . . . 69

8.2.8 Trades Skills for Community Energy subsystem . . . . . . . . . . . . . . . 70

8.3 Training needs for Community Energy Subsystem . . . . . . . . . . . . . . . 70

8.3.1 Areas of Training Needs . . . . . . . . . . . . . . . . . 70

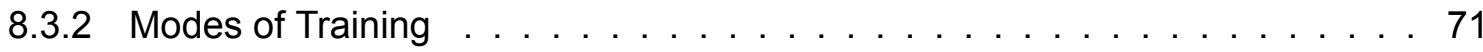


8.4 Insights and Recommendations for Bristol's Community Energy Subsystem . . . . . 72

8.4.1 Risks and Mitigation in Community Energy Projects . . . . . . . . . . . . . 72

8.4.2 Differentiated Support to Community Groups . . . . . . . . . . . . . . . . . . . 74

8.4.3 Skills to be Procured: Challenges and Recommendations . . . . . . . . . . . 74

9 Energy Sub-Sector: Findings from Data Analysis $\quad \mathbf{7 6}$

9.1 Factors Affecting Bristol's Energy Sector subsystem . . . . . . . . . . . . . . . 76

9.2 What skills are needed for Bristol's Energy Subsystem? . . . . . . . . . . . . . . . 77

9.2.1 Engineering Skills for Energy Subsystem . . . . . . . . . . . . . . . . . . . . 79

9.2.2 Trades Skills for Energy Subsystem . . . . . . . . . . . . . . . . . . . . . . . 81

9.2.3 Managerial Skills for Energy Subsystem . . . . . . . . . . . . . . . . . . . . 82

9.2.4 Energy Skills for Energy Subsystem . . . . . . . . . . . . . . . . . . . . . 83

9.2.5 Finance Skills for Energy Subsystem . . . . . . . . . . . . . . . . . . . 83

9.2.6 Legal Skills for Energy Subsystem . . . . . . . . . . . . . . . . . . . . . . 84

9.2.7 Policy Skills for Energy Subsystem . . . . . . . . . . . . . . . . . . . . . . . . 84

9.2 .8 Soft Skills for Energy Subsystem . . . . . . . . . . . . . . . . . . . . . . 85

9.3 Training needs for Energy Subsystem . . . . . . . . . . . . . . . . . 86

9.3.1 Areas of Skills and Training Needs . . . . . . . . . . . . . . . . . . 86

9.3 .2 Modes of Training . . . . . . . . . . . . . . . . . . . . 87

9.4 Insights and Recommendations for Bristol's Energy Subsystem . . . . . . . . . . . 88

9.4.1 Digital Innovation Drive . . . . . . . . . . . . . . . . . . . 88

9.4 .2 Practice of Systems Engineering . . . . . . . . . . . . . . . . 89

10 ICT for SLE Sub-System: Findings from Data Analysis $\quad 90$

10.1 Factors Affecting Bristol's SLE ICT sub-system . . . . . . . . . . . . . . . . . . 90

10.2 What skills are needed for the ICT Sub-System presently and in the future? . . . . . 92

10.2.1 Engineering Skills for the ICT sub-system . . . . . . . . . . . . . . . . . 92

10.2.2 Energy Domain Skills for ICT sub-system . . . . . . . . . . . . . . . . . . . . 94

10.2.3 Trades Skills for ICT sub-system . . . . . . . . . . . . . . . . . . . . . . . 94

10.2.4 Managerial Skills for ICT sub-system . . . . . . . . . . . . . . . . . . . . . . . 94

10.2.5 Finance Skills for ICT sub-system . . . . . . . . . . . . . . . . . . . . . . 95

10.2.6 Policy Skills for ICT sub-system . . . . . . . . . . . . . . . . . . . . . 95

10.2.7 Soft Skills for ICT sub-system . . . . . . . . . . . . . . . . . . . . . . . . . . . . . . . . . . . . . . . . . . .

10.3 Training needs ICT sub-System . . . . . . . . . . . . . . . . . . . . . . . . . . . . . . . . .

10.3.1 Areas of Training Needs . . . . . . . . . . . . . . . . . . . 96

10.3.2 Modes of Training . . . . . . . . . . . . . . . . . . . . . . 97

10.4 Insights and Recommendations on Bristol's ICT for SLE Sub-System . . . . . . . . 97

10.4.1 Reduce SLE Project Complexity through Good SE Practice . . . . . . . . . . 97

10.4.2 Scale Up Considerations . . . . . . . . . . . . . . . . . . . . . . 98

10.4.3 Capacity and Expertise . . . . . . . . . . . . . . . . . . . . . . 99

11 Skills Across SLE SoS Sub-Systems: Architecting through Interfaces 100

11.1 Challenges of SLE as a SoS . . . . . . . . . . . . . . . . . . . . . 100

11.1.1 Challenge 1: Lack of a Holistic View (Understanding) . . . . . . . . . . . . . 101

11.1.2 Challenge 2: Interconnection and Communication between SubSystems (In-

tegrating $\ldots \ldots \ldots \ldots \ldots$. . . . . . . . . . . . . . . . . . . . . . . . . 
11.1.3 Challenge 3: Governance of the SLE SoS in its Entirety (Operating) . . . . 104 11.2 Shaping the type of SLE SoS in Bristol . . . . . . . . . . . . . . . . 106

$\begin{array}{ll}\text { A Appendix: Grounded Theory Method } & 109\end{array}$

B Appendix: Organisations in Bristol SLE Ecosystem 110

C Appendix: Energy Projects and Initiatives in Bristol 113

C.1 System projects . . . . . . . . . . . . . . . . . . . . . . 113

C.2 Retrofit and energy efficiency . . . . . . . . . . . . . . . . . . . . . . . 114

C.3 Renewables and Heat . . . . . . . . . . . . . . . . . . . . . . 115

C.3.1 Microgrids . . . . . . . . . . . . . . . . . . . . . 115

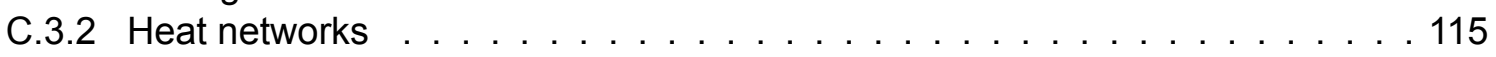

C.3.3 Solar . . . . . . . . . . . . . . . . . . . . . 115

C.3.4 Wind energy . . . . . . . . . . . . . . . . . . . . 116

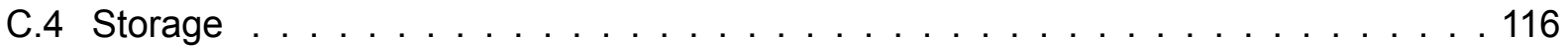

C.5 Transport and Mobility . . . . . . . . . . . . . . . . . . 117

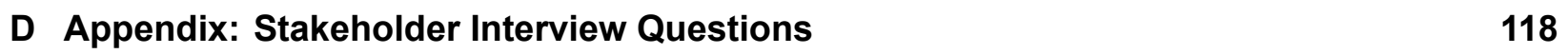

$\begin{array}{lr}\text { E Appendix: Citizen Interview Guide } & 120\end{array}$ 


\section{Overview of the Context}

The UK is decarbonising its economy, thus decentralised solutions are becoming an increasingly common part of the energy landscape. This shift can be seen in the energy industry (e.g. through the DNO-DSO transition), policies (e.g. in the Local Energy Teams across local and central governments) and innovations (e.g. UK Government Industrial Strategy challenges and the Prospering from the Energy Revolution (PFER) programme).

Smaller scale renewable and other technologies have become more readily available with the improved energy system, enabling a more localised generation and consumption approach. This is supported with technology-enabled solutions, such as smart meters and smart appliances, increasing electrification of transport, development of heat networks and increasing cross-sector interactions.

Concurrently, there is an increasing awareness of the potential to take action against climate change at a local level amid growing concerns over fuel poverty and societal inequalities.

This is the context in which we see "Smart local energy" (SLE) systems developing. SLE systems aim to manage and balance the supply of local energy, as well as its storage and use across all vectors (e.g. power, heating and transport), bringing efficiencies to energy supply and demand, and social, environmental and economic benefits to the given locality.

While the energy system is undergoing all of these changes at an unprecedented rate, the UK must also train the workforce that would be delivering and operating the new SLE system, as well as educating the citizens and communities who inhabit homes and environments where this system will be integrated. After this, what skills and training provisions are needed for the successful transition to smart local energy systems?

To answer this question, the Skills research team at the EnergyREV [1] project has set out to undertake several case studies at the localities where this transition is underway. This report presents the first of our case studies, i.e. that of the city of Bristol.

\subsection{Study Objectives}

The key research question addressed in this study is: What are the skills and training needed for transition to SLE systems?

This question has been further refined into the following set of sub-questions:

RQ1 What factors contribute to the skill shortages in SLE?

RQ2 How do the locality factors drive and differentiate the skills needs for smart energy (sub)systems?

RQ3 What skills shortages are the SLE (sub-)systems experiencing?

RQ4 What training is needed to support the availability of the skills that will be needed for SLE within the next few (5 to 10) years?

To explore the answers to these questions, a series of case studies will be developed, focusing on the study of the whole 'ecosystem' of a locality, establishing a clear focus on a place and a specific local system of systems (SoS). The first case study, for the city of Bristol, is detailed below.

We must note that previously well-established practices exist in the labour/job shortages assessment and planning for the whole economy (e.g. [2]) or well-defined regions, as well as for 
sectors of economy (e.g. wind energy sector [3]) with some work considering "green jobs" as a specific sector on its own [4, 5, 6, 7]. However, to our knowledge, there has been no previous work on addressing skills needs and shortages specifically for the domain of "smart local energy (sub-)systems".

\subsection{Framing of the SLE Notion}

While, in theory, the above description of SLE could cover any of the energy vectors and systems architectures, we also account for the following factors:

1. Zero-carbon economy targets: Given the UK's zero-carbon economy targets for 2050, one can clearly see that any investment other than that in carbon-neutral or carbon-reducing assets will either jeopardise the set targets, or potentially leave these assets stranded during the next 30 years. As a result, this study only considers green and renewables-based initiatives.

2. Decentralisation trend: most renewable energy technologies are dependent on the availability of locally distributed renewable sources. For instance, tidal energy can only be harvested on the shorelines, while sufficient solar generation can be expected from localities with sunny weather, etc. However, should these locally distributed sources be used to generate electricity and supply to the transition grid, the locality aspect of SLE will be disregarded. Thus, this study considers decentralisation as a key characteristic of SLE.

\subsubsection{SLE as a System-of-Systems}

A smart local energy system is itself a system of systems (SoS), the simplified overview of which is presented in a rich picture in Figure 1. In this figure, a set of individual sub-systems (such as local/national government, energy supply, building and retrofit provision, transportation and mobility services provision, local citizens and communities, the community energy groups and the ICT infrastructure for digital energy services) are integrated through a digital and physical infrastructure. These individual sub-systems have their own boundaries and behaviours, although they collaborate for the common goal of optimal use of local energy and carbon reduction. To achieve this, they exchange data and exercise control over the energy exchange itself (e.g. drawing on or storing into batteries, switching consumption equipment on/off, etc.).

Systems of systems are often defined by the set of traits that they exhibit $[8,9,10]$. The traits of key relevance to SLES are discussed below:

- Operational Independence of sub-systems refers to the fact that the sub-systems which comprise the SoS can usefully operate independently of SoS. For instance, with or without the rest of the sub-systems, the energy supply sector will deliver energy to its household or business customers.

- Managerial Independence of SLE sub-systems refers to the fact that the sub-systems are delivered and operated by independent commercial companies and organisations which not only belong to a wide set of different owners, but are also located within quite different industries (e.g. in transport, energy, government, etc.). While, as part of the SoS, the sub-systems collaborate towards a common goal ${ }^{1}$, each of the sub-systems must continue delivering its

\footnotetext{
${ }^{1}$ which, for SLE SoS is maximum utilisation of locally generated energy and net-zero carbon impact
} 


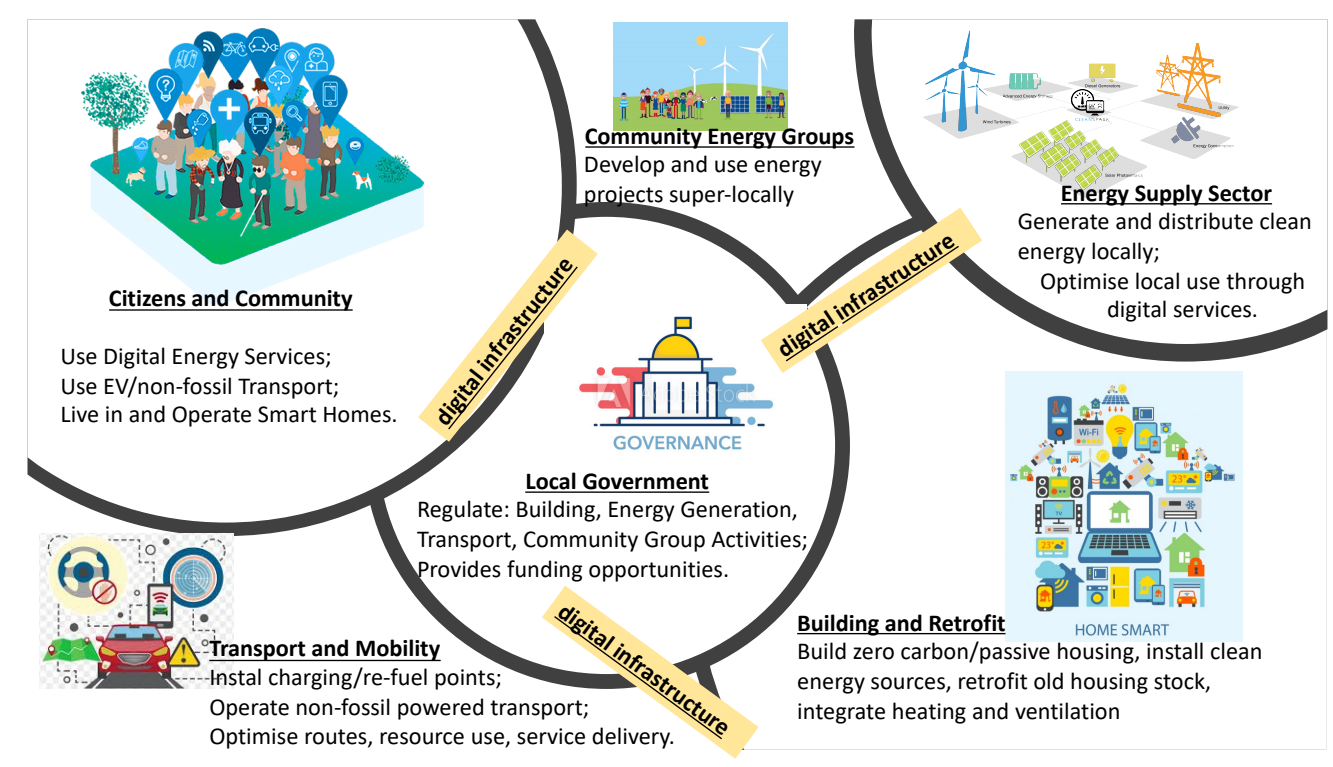

Figure 1: A (simplified) rich picture of a smart local energy system

own goal as well (e.g. a transport and mobility sub-system must ferry people and goods to the required destinations, even if it also stores and re-supplies electricity via EV batteries).

- Evolutionary Development of SoS implies that the SoS will be able to deliver useful services even before complete deployment of all its components. Conversely, sub-systems can be removed from the SoS with the SoS still remaining otherwise operational. For instance, a reduced form of SLE SoS can optimise the use of local energy and minimise carbon impact, even if there is no energy supply to citizens and communities from electric vehicles and fleets. This is to be expected because, given that the sub-systems are (at least partially) independent in their development and operation, there can be no guarantee of their continuous availability [8].

- Emergent Behaviour of SoS refers to the fact that, by working as the SoS, the sub-systems deliver more that the simple sum of their services - they are able to provide new (levels of) services (e.g. flexibility to grid via EVs from Transport sector and DSR services over citizens' household appliances).

- Geographical Distribution of sub-systems leads to looser coupling between the sub-systems (and their components), and may result in longer communication delays.

- Heterogeneity of sub-systems refers to the fact that the components would have very different compositions (e.g. each sub-system will own hardware components - from wind turbines to EV charge points, washing machines and software systems to monitor and control them); pursue different goals; serve different stakeholders; operate different economic models, etc.). As a result of this heterogeneity, as well as independent ownership and development of the sub-systems, the only way of architecting a SoS is through interfaces between the sub-systems. For SLE SoS, the main set of interfaces between sub-systems is presently 
delivered through the ICT infrastructure and electricity distribution network ${ }^{2}$.

Given the above properties of the SLE sub-systems, it is clear that we cannot expect to see a homogeneous set of skills, work practices, or educational environments across them. Consequently, we suggest that each sub-system must be studied in its own right, as well as part of the integrated SoS, with the relevant interfaces considered each time.

\subsubsection{Local in SLE SoS}

The "local" aspect refers to a defined geographical area where local energy initiatives take place. This also covers a range of organisations, including partnerships between public, private and nonprofit sectors.

Public authorities may take a coordinating role to leverage private sector investment in local energy provision [11]. The local energy landscape includes a range of energy-related activities including generating energy; reducing energy use through energy efficiency and behaviour change; managing energy by balancing supply and demand and purchasing energy. Local authorities can provide support for community-driven energy projects which deliver social benefits.

\subsubsection{Smart in SLE SoS}

The "smart" aspect of an energy system often implies digitally supported coordination of decisionmaking for (sub-)systems to optimise their resource use and waste reduction (both generation and consumption), fault tolerance and recovery from failures, support for human decision-making for efficiency and comfort. On the other hand, the smart energy system will not fulfil its potential without smart users, thus the household and business users also need to acquire skills in the functioning and use of digital energy systems [12, 13, 14, 15].

It should be noted that a number of relevant sub-systems, such as manufacturing and finance, are omitted from the rich picture in Figure 1 for simplicity. These sectors, while very important to the SLE SoS operation, do not require any dramatically new skills, as per our current case study analysis. However, where each of the discussed sub-systems requires finance, policy, regulatory, or other skill updates for successful operation within the SLE SoS, such skill categories will also be discussed.

\subsection{Structure of the Report}

The rest of this report is structured into 10 further chapters. Chapter 2 presents the methodology used in this study. Chapter 3 describes Bristol's energy ecosystem, based on the documentary analysis undertaken. The next seven chapters (from 4 to 10 inclusive) each address one of the seven above listed sub-systems of the SLE SoS (as per Figure 1). Finally, chapter 11 considers the cross-subsystem challenges and skills needs for the system of systems level.

Each of the seven subsystem-specific chapters (i.e. chapters 4-10) is structured into 4 subsections that address the above listed questions:

\footnotetext{
${ }^{2}$ Other interlaces, e.g. heat captured from ICT infrastructure to heat citizens' homes, can also be envisioned, although it is outside of the time-frame scope of this study.
} 
1. Sub-section one addresses $R Q 1$ and $R Q 2$ and details the set of factors and their impact on the given SLE sub-system, and uses a causal link diagram to illustrate these factors and their positive or negative interrelationships. We underline that the set of factors discussed are those elicited for Bristol's case study, and are from the set of data collected for this report. The models are also available for execution through URLs listed along with each diagram. We note that each diagram uses colour differentiation for Bristol-specific (purple colour) and general UK-wide (red colour) factors.

2. Sub-section two addresses RQ3 and details the skills that are in short availability within each sub-system. For each sub-system, we compile sets of such skills for their relevant knowledge areas: Engineering, Energy, Finance, Legal, Managerial, Policy, Trades (e.g. construction, electrical, etc.) and Soft Skills.

3. Sub-section three addresses RQ4 and details the training needs and modes, as noted by the study participants.

4. Finally, sub-section four presents a set of insights and recommendations for each sub-system.

We note that a number of quotes from the study participants have been used to demonstrate the perspectives on specific skills needs and other issues. To maintain a readable format, we use a single relevant quote at a time, and we do not list all interviewees who expressed the same or similar view. (In other words, the fact that only one quote is used per skill type or point does not mean that only a single source has expressed this opinion.)

\section{Methodology}

At the time of writing, the SLE SoS domain does not constitute a separate industry. Instead, as shown in Fig. 1 above:

- It comprises of a number of industries (such as building and retrofit, (renewable) energy generation, community energy, electric/fossil-free transport, etc.);

- However, it cannot be assumed that any company operating within the above listed industries automatically contributes to SLE SoS. For instance, a car manufacturer may produce EVs or diesel engines. Similarly, it is debatable if building centrally gas-connected building stock is relevant to SLE SoS.

- Given that SLE SoS is currently a fledgling area, many companies do undertake some SLE SoS projects for a time, while simultaneously delivering their mainstream (non-SLE) activities (e.g. vehicle fleet operators trialling EVs, or energy companies piloting demand-response or peer-to-peer trading services for local energy, while continuing to serve as mainstream fossilbased suppliers).

- Locality factors have a substantive impact on how a smart energy system is delivered in each given location, so it is likely that no two SLE SoS are identical.

Thus, in order to ensure that information on skills obtained from stakeholders who would prospectively operate in the SLE SoS sector is relevant, and that locality factors can be studied, we opted to: 
1. Carry out a case-study research, whereby some locations with substantial SLE-focused activities would be chosen as case study localities, and

2. Undertake data collection and analysis from projects that are directly identifiable as SLEfocused within the given locality.

The city of Bristol was selected as the first case study for this work, as it is one of the UK's energy champion localities (using rankings suggested by [7-9]) and reviews of 119 SLE demonstrator projects carried out by Flett et al. [16]. Thereafter, the following methods were used to carry out this case study:

1. Review of grey literature [17] and materials to identify the set of SLE projects undertaken in Bristol;

2. Per-project stakeholder identification [18] and [19], to build up the picture of the participants in Bristol's SLE scene and their roles;

3. Interviews and focus groups [18] with members of SLE projects from Bristol to obtain their perspectives on required skills and expected growth for such skills needs.

\subsection{Materials Review for Bristol's SLE Projects Identification}

In order to identify the SLE projects within the Bristol area, we undertook a grey literature examination, reviewing the:

- Web materials from the prominent local stakeholders within the energy sector (e.g. from Bristol City Council, Bristol Energy Network, etc.). We also integrated the stakeholders identified as being relevant to the SLE within Bristol from the dataset of the EnergyREV research on SLE businesses in UK [19].

- The databases on funded projects from the UKRI [20].

- Datasets of 119 energy system demonstrator projects collected by previous research [16]

The list of the relevant projects identified through this review is provided in Appendix $\mathrm{C}$. This review also resulted in a full picture of Bristol as a SLE locality, which is detailed in section 3.

\subsection{Per-project Stakeholder Identification}

Along with the project identification process, for each project, the set of relevant stakeholders were identified (see sample shown in Figure 2, thus developing a picture of those who engage with the SLE domain in Bristol. The list of Bristol SLE stakeholders is presented in Appendix B.

\subsection{Stakeholder Interviews and Focus Groups}

Primary data collection was carried out through:

1. Interviews with 24 stakeholders at 23 interviews (one interview was carried out with two interviewees present together); 
2. Two focus groups with 10 participants overall;

3. Writing of one collaborative reflective summary report with 7 participants;

4. Interview study with 30 citizens through 28 interviews (two interviews were carried out with two interviewees present together).

Given that the data collection took place in the period between Oct 2019 and Oct 2020, during which time COVID-19 restrictions were imposed on Bristol, some of the interviews were carried out face-to-face, while others were arranged through videoconferencing. The focus groups and reflective reports were carried out via videoconferencing.

Data was collected by researchers from the University of Bristol, in accordance with the University's ethics committee data collection and handling processes and rules. The participants either signed and returned a consent form, or (during the COVID-19 restrictions period) were emailed the study materials and consent forms and asked to confirm their consent verbally at the time of interview recording and to return the form by email. In all cases, the conversations were recorded and transcribed for qualitative data analysis. To ensure participant anonymity, the stakeholder data is segregated into two sections, whereby the participant roles are reported separately from the organisations interviewed.

\subsubsection{Participant Recruitment for Study with Stakeholders}

The process of project and stakeholder identification discussed in sections 2.1 and 2.2 above was carried out iteratively. A snapshot of this analysis is presented in Figure 2. Figure 2 demonstrates that a number of institutions have participated in more than one project, which indicates the presence of a longer-term interest and commitment to SLE SoS within these organisations.

Furthermore, as the stakeholder list in Appendix B demonstrates, Bristol SLE SoS stakeholders primarily belong to the following categories:

- Local authority (Bristol City Council, West of England Authority);

- Transportation with a focus on EVs or smart mobility (e.g. Esoterix and Travel West);

- Building and Retrofit (e.g. CHEESE, Urbane);

- Energy supply (e.g. Bristol Energy, Ovo);

- Digital solutions and infrastructure (e.g. Bristol is Open, Zeetta Networks)

- Community Energy (e.g. Easton Energy Group, Ambition Lawrence Weston wind and solar);

- Citizens and community support intermediary groups (e.g. Bristol Energy Network)

The repeatedly engaged organisations and the above stakeholder types are kept in mind, while undertaking stakeholder engagement for interviews:

- We aimed to recruit interview participants from within organisations with more than one SLE project engagement; 


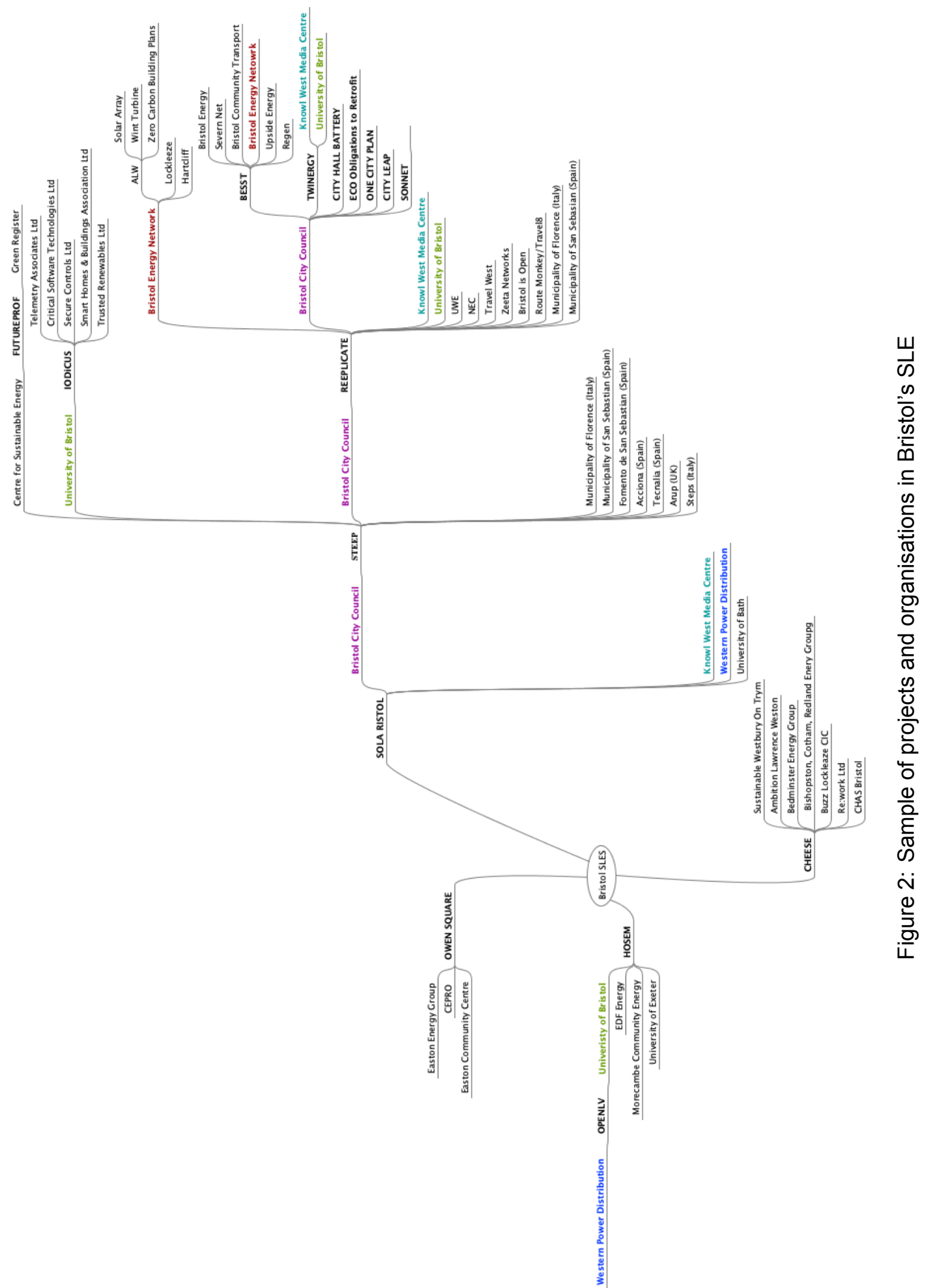


- We also worked on identification of those individuals within the organisations who, if at all possible, had themselves been part of more than one SLE project; this was done in the hope of obtaining more experience-based data from these particular participants;

- We then attempted to engage a mix of roles: a good proportion had hiring and project management responsibilities, as well as those who were directly engaged with the project delivery;

- Finally, the invitations to take part in the study were sent out to a set of organisations that covered the above-mentioned categories.

The summary details of the interview study participants are presented below, with the participating organisations listed in Table 1, and the participants in Table 2. Note that the organisations are listed in alphabetical order, while participants are listed in order of their (not shown in the table) names, to ensure the anonymity of the participants.

Table 1: Organisations that took part in Bristol City's Smart Local Energy Study

\begin{tabular}{|c|c|c|}
\hline \multicolumn{3}{|c|}{ Organisations } \\
\hline $\begin{array}{l}\text { 1. Ambition Lawrence We- } \\
\text { ston }\end{array}$ & 9. CEPro & $\begin{array}{l}\text { 18. South West Energy } \\
\text { Hub }\end{array}$ \\
\hline 2. Ascent Architecture & $\begin{array}{l}\text { 10. Centre for Sustainable } \\
\text { Energy (CSE) }\end{array}$ & 19. Trakm8 \\
\hline 3. Bristol City Council (BCC) & 11. EnergieSprong & 20. TUC \\
\hline $\begin{array}{l}\text { 4. Bristol Energy Network } \\
(\mathrm{BEN})\end{array}$ & 12. Energy4All & 21. University of Bristol \\
\hline 5. Bristol is Open (BIO) & 13. Esoterix & 22. Urbane Eco \\
\hline $\begin{array}{l}\text { 6. Bristol and Bath Regional } \\
\text { Capital }\end{array}$ & 14. Futureproof / CSE & $\begin{array}{l}\text { 23. Western Power Distri- } \\
\text { bution }\end{array}$ \\
\hline 7. Bristol Energy & $\begin{array}{l}\text { 15. Knowle West Media } \\
\text { Centre (KWMC) }\end{array}$ & 24. x-BCC, now Freelance \\
\hline $\begin{array}{l}\text { 8. Cold Homes Energy } \\
\text { Efficiency Survey Experts } \\
\text { (CHEESE) }\end{array}$ & 16. Lockleaze Loves Solar & $\begin{array}{l}\text { 25. x-Greenheart, Green } \\
\text { reg }\end{array}$ \\
\hline & 17. NEC Labs & \\
\hline
\end{tabular}

Table 2: Details of Bristol SLE Stakeholder interview Participants

\begin{tabular}{|l|l|l|l|}
\hline ID & Role within Organisation & Field of Work & Data Collection \\
\hline P1 & Software Engineer & ICT & FG \\
\hline P2 & SME Energy Project Developer & Energy & Interview \\
\hline P3 & Community Project Developer & Community Energy & Interview \\
\hline P4 & Regional Project Manager & Local Authority & Interview \\
\hline P5 & $\begin{array}{l}\text { Technical Developer, Commu- } \\
\text { nity Energy }\end{array}$ & Community Energy & Interview \\
\hline
\end{tabular}


Table 2: Details of Bristol SLE Stakeholder interview Participants

\begin{tabular}{|c|c|c|c|}
\hline ID & Role within Organisation & Field of Work & Data Collection \\
\hline P6 & $\begin{array}{l}\text { Local Authority Partnerships } \\
\text { Manager }\end{array}$ & Local Authority & Interview \\
\hline $\mathrm{P} 7$ & Retrofit Project Manager & Building \& Retrofit & Interview \\
\hline P8 & NGO Community Manager & Community Energy & Interview \\
\hline P9 & $\begin{array}{l}\text { Energy Company Innovation } \\
\text { Manager }\end{array}$ & Energy & Interview \\
\hline $\mathrm{P} 10$ & $\begin{array}{l}\text { Chief Marketing Officer: Smart } \\
\text { Mobility }\end{array}$ & Transport \& Mobility & Interview, FG \\
\hline P11 & Sustainable Building Consultant & Building \& Retrofit & Interview \\
\hline $\mathrm{P} 12$ & $\begin{array}{l}\text { Consultant for Business Case } \\
\text { Analysis }\end{array}$ & Building \& Retrofit & Interview \\
\hline $\mathrm{P} 13$ & $\begin{array}{l}\text { Community Energy Project Man- } \\
\text { ager }\end{array}$ & Community Energy & Interview \\
\hline P14 & $\begin{array}{l}\text { Building Company Managing Di- } \\
\text { rector }\end{array}$ & Building \& Retfrofit & Interview \\
\hline P15 & Trade Union Regional Secretary & $\begin{array}{l}\text { Trade Union, Commu- } \\
\text { nity }\end{array}$ & Interview \\
\hline P16 & Trade Union Education Officer & $\begin{array}{l}\text { Trade Union, Commu- } \\
\text { nity }\end{array}$ & Interview \\
\hline $\mathrm{P} 17$ & $\begin{array}{l}\text { Community Energy Develop- } \\
\text { ment Manager }\end{array}$ & $\begin{array}{l}\text { Community Energy, } \\
\text { Funding }\end{array}$ & Interview \\
\hline P18 & $\begin{array}{l}\text { Local Authority Investment Man- } \\
\text { ager }\end{array}$ & Local Authority & Interview \\
\hline P19 & Community Worker & $\begin{array}{l}\text { Community, Commu- } \\
\text { nity Energy }\end{array}$ & Interview \\
\hline $\mathrm{P} 20$ & $\begin{array}{l}\text { Research Associate: ICT for } \\
\text { Smart Mobility }\end{array}$ & $\begin{array}{l}\text { Academia, ICT, Trans- } \\
\text { port }\end{array}$ & Interview \\
\hline P21 & $\begin{array}{l}\text { Transport Technical Projects Di- } \\
\text { rector }\end{array}$ & Transport \& Mobility & Interview, FG \\
\hline P22 & Funding Associate & Community, Funding & Interview \\
\hline P23 & Architect & Building \& Retrofit & Interview \\
\hline P24 & $\begin{array}{l}\text { DSO and Future Networks Man- } \\
\text { ager }\end{array}$ & Energy & Interview \\
\hline P25 & $\begin{array}{l}\text { Data and Technology Architec- } \\
\text { ture Manager }\end{array}$ & ICT & FG, Reflect. Summary \\
\hline P26 & Network \& Developer Engineer & ICT & FG, Reflect. Summary \\
\hline P27 & $\begin{array}{l}\text { Sustainable Neighbourhoods } \\
\text { Manager }\end{array}$ & Community & FG \\
\hline P28 & Associate Professor: ICT & Academia, ICT & $\mathrm{FG}$ \\
\hline P29 & Project Manager: Smart Energy & Local Authority & FG, Reflect. Summary \\
\hline P30 & SLE Senior Researcher & ICT & FG, Reflect. Summary \\
\hline
\end{tabular}


Table 2: Details of Bristol SLE Stakeholder interview Participants

\begin{tabular}{|l|l|l|l|}
\hline ID & Role within Organisation & Field of Work & Data Collection \\
\hline P31 & SLE Senior Project Manager & Local Authority & FG \\
\hline P32 & SLE Project Researcher & $\begin{array}{l}\text { Academia, Community } \\
\text { Energy }\end{array}$ & Reflect. Summary \\
\hline P33 & Senior Lecturer: ICT for SLE & Academia, ICT & Reflect. Summary \\
\hline P34 & SLE Senior Researcher & ICT & Reflect. Summary \\
\hline
\end{tabular}

The interview questions were split into several sections:

- Participant and organisation background details;

- Activities within the SLE domain;

- Skills needed now (i.e. shortages);

- Future training needs.

\subsubsection{Participant Recruitment for Study with Citizens}

The citizens' interview study was carried out on 28 households (with two interviews carried out on couples, with a total of 11 males and 19 females). The interview questions were split into 3 sections:

- Participant background details;

- Current practices of appliance and energy use;

- Responses to the idea of automation for energy management.

Interviewees were drawn from households that had received smart appliances from BCC as a part of REPLICATE [21] Smart City project (16 in total) and households with no direct relationship to BCC or REPLICATE (12 in total).

In the recruitment of participants, an active effort was made to obtain a representative sample of participants, balancing for both demographic and owned/occupied property characteristics of the households.

Using the Grounded Theory analysis approach [22] (see Appendix A, we stopped the interview process when no new significant code categories emerged from the last 3 interviewees (i.e. theoretical saturation of the Grounded Theory Analysis method [22] was deemed as being achieved).

The participants' demographics are summarised in Table 3.

Interviews were carried out face-to-face in English; these were recorded, transcribed and analysed. The collected data was analysed and a set of relevant topics and skills were identified. 
Table 3: Characteristics of Citizens' Study Participants

\begin{tabular}{|l|l|l|l|l|l|l|l|l|l|}
\hline \multicolumn{2}{|l|}{ Age } & \multicolumn{2}{l}{ Income } & House Type & Household Size & \multicolumn{2}{l|}{ Gender } \\
\hline $16-25$ & 1 & $<25 \mathrm{~K}$ & 13 & Semi/Detached & 4 & Single & 4 & $\mathrm{M}$ & 11 \\
\hline $25-49$ & 17 & $25 \mathrm{~K}-50 \mathrm{~K}$ & 10 & Terraced & 20 & Couple & 3 & $\mathrm{~F}$ & 19 \\
\hline $50-65$ & 10 & $>50 \mathrm{~K}$ & 5 & Flat & 4 & House-share & 4 & & \\
\hline N/A & & & & & & Couple, adult kids & 1 & & \\
\hline & & & & & & 1 parent, young kids & 3 & & \\
\hline & & & & & & Couple, young kids & 4 & & \\
\hline & & & & & & Couple, young kids & 9 & & \\
\hline
\end{tabular}

\subsubsection{Data Analysis}

Data collected from both stakeholders' and citizens' studies was analysed using the constructivist strand of the Grounded Theory (GT) analysis methods [22] (see more detail in Appendix A). The interview texts underwent a line-by-line text analysis, resulting in a set of text codes during the initial coding stage (e.g. systems integration skills, lack of certainty on subsidies, etc.), which were then integrated into a set of main categories during the focused coding activity. These are:

- 7 main subsystem categories for the overall Bristol energy system (i.e. Local Authorities; Energy Sector; Community Energy; Transport and Mobility; Building and Retrofit; ICT sector and Citizens) with Barriers, Drivers, issues specific to Bristol, Skill Shortages, Training Needs and Insights sub-categories considered for each subsystem. In addition, the Stakeholders and Projects categories were populated for the Bristol's SLE system as a whole.

- 8 categories for the citizen's interview study: Practices, Appliances, Data, DSR Automation, Motivations, Concerns, Knowledge, Smart.

The theoretical coding then helped to establish relationships between these categories and formulate a cohesive theory of causal loops around each sub-area of SLE SoS (presented as section 1 for each sub-system in chapters 4-10 of this report). The detailed description of the theory derivation and coding activities is not presented in this report.

\subsubsection{Treats to Validity and Study Limitations}

\subsubsection{Treats to Validity}

We have made maximum efforts to engage with a representative sample of participants for both of the interview (and focus group) studies. However, we note that these are only representative of the community living in the city of Bristol, and the results are in the context of the SLE projects that have been taking place in Bristol.

In addition, the pool of participants was limited to those who responded to our invitation, and we note that this may imply a certain self-selection and self-reporting biases with those interested in SLE skills and energy management and energy efficiency coming forward more prominently. This concern, however, is mitigated to some degree by the fact that these are also the very same organisations and households that would likely engage with the broader SLE SoS adoption. 
To test the validity of our findings further, we draw on the notions of data, investigator, method and theory triangulation [23]:

- For data triangulation [23] we reached out across both the space and time. With respect to space triangulation, the interview participants were drawn from across the whole city, reaching out to stakeholders wherever the SLE projects were identified, as well as recruiting citizens from various areas of the city: both in areas where BCC had initiated the activities related to SLE SoS (16 households) and to those areas that are completely independent of formal SLE SoS initiatives (12 households). We also ensured that participants of varying demographics were engaged (see Table 3). With respect to time, the overall data collection span covered about a year, during which time we engaged with citizens' data collection in a more focused four-months period (mostly pre-COVID-19). Data from other stakeholders covers both pre-COVID-19 and COVID-19 periods.

- For investigator triangulation, two researchers worked on the GT coding and analysis, continuously double-checking and verifying each other's work, and discussing and resolving disagreements.

- For the data collection method triangulation, we used interviews, focus groups and a reflective writing method, so a variety of data inputs thus inform the analysis.

- Finally, for theory triangulation, we will be undertaking additional case studies and expert group feedback, which are planned as the next steps in this ongoing work.

\subsubsection{Study Limitations}

We note the following limitations:

1. No Generalisation: Given that this is a qualitative study, based on data obtained through interviews and focus groups, we do not claim that the findings are generalisable beyond the scope of this case study. Given that the GT results are grounded within the studied context and collected data, this is an expected limitation.

While further case studies will be designed to add to the evidence that could validate and generalise the results obtained from this case study (as indeed is our intention for future work), findings from such additional studies will not change the validity of the study for this given context.

2. Lack of Detailed sub-skills: The topics that relate to the skills are extracted from the interview records, and are named as the interviewees name them. We observe that, in many cases, such topics are quite general and can be interpreted in different ways by different people/sectors.

For instance, the commonly noted skill of "Data Analysis" can include a large set of sub-skills: from statistical analysis, to machine learning, and more. However, the uncertainty analysis skills within data analysis are very often missing, both in application, and in recognition of their need. In other words, data is often analysed without correctly quantifying (or even considering) the uncertainty associated with the data (say, when values are missing, defaults have been used to populate the data, or parts of the data could be missing due to communications failure, etc.). The sub-topics related to uncertainty in data analysis include: 
- measurement of uncertainty,

- decision-making under uncertainty,

- risk analysis if relying on (partially)incorrect data, etc.

Another example is that of Legal Metrology. Legal skills are mentioned in several sections, and a gap is often identified between legal skills and engineering skills. An important part of this gap is related to a lack of legal metrology skills, which are essential in SLE. To illustrate this:

- When smart meters are used, the power consumption is calculated using algorithms (instead of being measured, as with analogue meters). However, policies and regulations in relation to calculations transparency and methods have not been adequately updated with the introduction of the smart meters. These aspects are not adequately regulated because legal teams don't understand the differences and implications of possible mistakes as well as the wrongdoings.

- In SLE, the responsibilities in terms of power quality are not well-defined. Although power quality can be monitored, there are no clear procedures to determine who is responsible for providing acceptable power quality to all users, and who should be blamed in the case of poor power quality, etc.

Thus, in summary, we note that more detailed sub-skills can be enumerated for many of the skills identified in our study. However, given that our interviewees did not enumerate them, we are unable to list the (many) specific sub-skills in this report.

\section{Bristol's Energy Ecosystem}

\subsection{Background to the city of Bristol}

Bristol is one of the UK's Core Cities with a population of around 500,000 . It is the largest city in the South West of England and, along with the neighbouring authorities of Bath and North East Somerset (BaNES) and South Gloucestershire, it is a member of the West of England Combined Authority (WECA).

Bristol was the first local authority area to declare a climate emergency in November 2018 [24] and has set a target of carbon neutrality by 2030 . Actions against this ambitious target have been developed through a series of workshops, consultations, reports and analyses.

Preceding the declaration, the city council had already published other climate and energy strategies, notably 'Our Resilient Future: A Framework for Climate and Energy Security' (2015) [25].

From the business perspective, Bristol was recently named as the UK's most productive technology cluster. One third of the FTSE 100 companies have a base in the region. It was named as one of the top ten city regions in Europe by The Financial Times and the highest performing 'Core City' in England.

At the same time, the city faces many systemic challenges; the disparity in accessing higher education is almost $80 \%$ between local government wards and nearly $16 \%$ of Bristol's population live in deprived areas. This means that access to technology, training and opportunity is very uneven. 
Bristol is the home of a number of national 'green' organisations, such as Sustrans (the Centre for Sustainable Energy, The Soil Association), amongst others. It also has a strong community energy sector working alongside some significant anchor organisations across the neighbourhoods of the city.

Bristol's energy approach is widely distributed with many small initiatives taking root around the city. This is partly due to a strong community ethos and well-established community energy groups. The city council is also very active, with an energy service employing around 40 people, which is significantly more than most other local authorities.

The "Energy Service", whilst part of the city council, also sits at arms-length and is connected to Bristol Energy which was set up as a wholly-owned energy supply company. The idea behind this was to deliver better energy products to the city (and beyond) with a strong innovation team exploring smart energy approaches.

There are also two universities in Bristol, and a range of small technology companies or arms of larger businesses, alongside green builders and entrepreneur social enterprises.

\subsection{Energy stakeholders}

There are numerous organisations across the city which are involved in developing SLE SoS approaches. The full listing of organisations that we have either engaged with or researched for this case study is provided in Appendix B. The grouped categories of such organisations are discussed below:

\subsubsection{Community}

\section{Community Energy Groups}

There are several city-wide community-focused organisations operating in the non-profit space, with a small number of paid staff. These are the organisations that have started to scale up successfully and develop business models which are increasingly less reliant on grant funding. Examples of this include: Bristol Energy Network (BEN); Bristol Energy Co-operative (BEC); Cold Homes Energy Efficiency Survey Experts (CHEESE).

At the neighbourhood and community levels, there are community energy organisations and other community groups which are developing hyper-local approaches to energy management and are working on a voluntary basis. An important function at this level is engagement and the buy-in of the local communities. These groups are connected together, and also to larger organisations, through the Bristol Energy Network which forms an 'umbrella' and has been instrumental in helping to facilitate connections and supporting the upscaling.

Examples of this include: Bedminster and Fishponds energy groups, Bishopston, Cotham and Redland Energy Group and ReWork in Knowle West.

\section{Anchor organisations}

Beyond energy groups, the city has an extensive network of local and 'community anchor' organisations. These perform a multiplicity of roles to meet the needs of their communities and have an important place in the city's ecosystem for reaching and engaging with citizens through connections of place or interest. Prominent examples of anchor organisations embracing community energy are Ambition Lawrence Weston (ALW), and the Hartcliffe and Withywood Community Partnership (HWCP). 


\subsubsection{Non-governmental organisations}

\section{Non-profit and Charitable Organisations}

Bristol is strongly represented in the NGO space with the Centre for Sustainable Energy (CSE) being a notable energy organisation. CSE has grown from its founding as the Centre for Urban Technology in 1979 to an organisation of around 70 employees. Although CSE operates nationally, it is strongly rooted in Bristol and works to address fuel poverty, energy efficiency and other aspects of the energy system. Regen, which is a not-for-profit centre of energy expertise and market insight whose mission is to transform the world's energy systems for a low carbon future, also works at both a local South-West level and nationally from its base in Exeter.

Sustrans is another national organisation with a strong Bristol presence. It was founded to develop and promote sustainable transport, and it now manages a national network of cycle routes and collaborates with other city partners to improve the uptake of walking and cycling and reduce vehicle carbon emissions.

\section{Education}

Tertiary education in Bristol is represented by two well-regarded universities (the University of Bristol and the University of the West of England). There are seven FE colleges serving the Bristol area (including one in Bath and one in Weston super Mare), alongside 12 school-based sixth form centres. Additionally, there are a range (a total of 36 are listed) of post-16 training providers which are recognised by BCC as providing short courses, apprenticeships and trainee placements.

\subsubsection{Local Government}

Local government, here represented by the Bristol City Council (BCC), is a key component in a city (or regional) approach to SLE SoS. Bristol has taken a proactive approach by developing the Energy Service team which has around 40 employees. The Energy Service was initially established through the European investment funding ELENA - European Local ENergy Assistance - run by the European Investment Bank, to 2015. It now aims to set up a city-wide approach to energy generation and efficiency. Alongside this team, other parts of the city council are also important, e.g. the innovation and sustainability teams, planning, estates, and property and finance. Bristol has an elected mayor and cabinet, alongside the elected councillors representing different wards of the city.

A further layer of local government comes from the West of England Combined Authority (WECA) with an elected West of England Mayor, alongside the Local Enterprise Partnership (LEP).

Within these structures, some energy responsibilities sit at a city level and some in the region. Notably, WECA has powers over spending on the region's transport, housing and adult education and skills.

The South West Energy Hub (one of five hubs across England) covers seven LEP areas from Swindon to Cornwall and is funded by BEIS (The Department for Business, Energy and Industrial Strategy). WECA is the lead partner and hosts the hub team of 8 in the Bristol office. The aim of the Energy Hub is to [26]:

"encourage investment into energy infrastructure, connect local institutions and share best practice across the five Hub regions to increase the number, scale and quality of energy projects. Projects supported by the Energy Hub will improve the way that energy is used, supplied or distributed." 


\subsubsection{Business}

The business category encompasses a whole range of for-profit organisations, from big multinationals operating in the city to sole traders, and from energy supply to finance, to technology, and to building. Below is a short summary and examples across this spectrum.

\section{Energy supply and distribution companies}

In (and around) Bristol, there are several energy supply companies: Bristol Energy (BE) was the wholly-owned energy company set up by BCC in 2015, although it was recently sold to Together Energy after failing to make a profit. BE had an order book of approximately 155,000 customers of whom around $20 \%$ were local to the Bristol area. Ovo energy, meanwhile, has grown substantially over the 10 years since its founding, absorbing SSE (and 3.5 million new customers) in 2020.

Beyond Bristol, yet still based in the region, are the green energy pioneers of Ecotricity in Stroud in Gloucestershire, and Good Energy in Chippenham in Wiltshire.

Western Power Distribution (WPD) is the network operator for the Bristol area, playing a key role in the SLE SoS transition as it also moves from the traditional role of Distribution Network Operator (DNO) to Distribution System Operator (DSO). WPD manages the electricity supply network, connections and capacity.

\section{Clean Energy development}

Clean energy development covers a spectrum of activity from large-scale renewables to microgrids to batteries. CEPRO has been operating in the Micro-grid space for a while, although it is largely reliant on grants.

At a more commercial level, Aura power is based in Bristol and is a global developer of renewable and clean energy projects. Aura has two energy storage projects in Bristol, namely $15 \mathrm{MW}$ in Lockleaze and 20MW in development at Feeder Road.

DNV-GL is also a global company which includes Garrad Hassan, one of the pioneers in wind energy technology and design.

Bristol is also home to several solar installers such as One World Solar.

\section{Technical Innovation Companies}

Alongside these more traditional players in the energy sector, a number of technology companies, including start-ups, each have a role to play in developing the 'smart' side of local energy systems. As an example, we have seen a number of different organisations in the REPLICATE project, such as the Bristol Toshiba innovation lab, in transport Esoterix, and the University of Bristol and BCC co-developed Bristol is Open (BIO) initiative (which, since September 2020 has been wholly owned by the BCC).

\section{Energy Efficiency and Retrofit}

Energy efficiency plays an important part in the energy ecosystem, both in terms of building efficiency and human behaviours (see community above).

In the retrofit sphere, a number of local eco-retrofit companies are key, alongside the Green Register, which brings these builders and architects together and provides training. It has also recently started to provide certification of retrofit trainers through its Futureproof project.

Many building companies are micro SMEs, i.e. sole traders or businesses which have two or three people working for them. "They're not big companies, but they are the sort of people that do most house refurbishment projects" [P7]. There are particular challenges in engaging and upskilling this distributed workforce for domestic retrofit. Also in this category are electricians, plumbers, other building trade-workers and solar installers, etc. 
For new builds, national housing developers have generally been slow to engage in anything beyond building regulations. However, there are smaller developers who are experimenting with low carbon developments e.g. Bright Green Futures, which is working on building housing estates with their own microgrids (e.g., Waterlilies microgrid) and fostering self build and Greenheart, which specialises in near-Passivhaus new builds.

\section{Transport}

Alongside energy supply and domestic usage, transport plays an important role in the energy system with efficient transport planning, access to real time public transport information and electric vehicle charging being amongst the local initiatives. Some examples of innovations in this sector include Bristol's First Bus, which has been running a city-wide bus service operated on biofuels, and Travelwest which provides a comprehensive repository of travel advice and includes journey planning to show the sites of car clubs and charge points.

City car clubs ${ }^{3}$, including electric vehicles, have hourly hires available across the city, mostly in the central and Northern areas. There are 3 operators, Enterprise, Zipcar and Co-wheels. Most of the centrally located hire cars are co-located with their own charge points.

\section{Legal and Planning Support}

The Law firm, TLT, has developed expertise in the clean energy sector and has organised, hosted and sponsored numerous events to support the industry, as well as providing advice across the range of technologies ${ }^{4}$. This company was also involved in the Avonmouth battery project.

Bevan Britton, Burgess Salmon and others also use their company Corporate Social Responsibility commitments to provide pro-bono support for non-profit parts of the local energy system.

\section{Finance}

Bristol hosts Triodos Bank UK, which is recognised as one of the most ethical and sustainable UK banks. Triodos works with local organisations such as BEC (4.2MWp solar PV at Lawrence Weston) to support financing for the local energy system.

Thrive Renewables, based in Bristol and formerly part of Triodos, provides a platform for investment funding by individuals into clean energy projects. Avonmouth Wind Farm (four turbines) is a Thrive-supported project.

Bristol and Bath Regional Capital CIC is supported by the universities, voluntary sector and BCC, and seeks to connect enterprise with investment.

\subsection{Bristol Policies for Energy}

As already noted, Bristol is known for being at the forefront of the local authority energy activity in many areas and has produced a number of plans over the last 10 years at least to drive sustainability and responses to climate change as well as incorporating these into other core strategies.

\subsubsection{One City Plan, SDGs and Climate}

Bristol's One City Plan ${ }^{5}$ was launched in 2019 , and it takes a year by year look at how city partners will work together to create a 'fair, healthy and sustainable city'. This is the key strategy document

\footnotetext{
${ }^{3}$ https://journeyplanner.travelwest.info/?poi=carClubs

${ }^{4}$ https://www.tltsolicitors.com/expertise/sectors/energy-and-renewables/

${ }^{5}$ https://www. bristolonecity.com
} 
shaping the city's activities for the future with a cross-city sign up by partners including and beyond the city council.

The One City Plan was developed through extensive consultation with citizens and stakeholders and is meant to provide a collective vision for organisations and individuals across the city, rather than serving as a plan for city government alone. A commitment to the UN Sustainable Development Goals (SDGs) is integrated into this plan and Bristol, as a city, is a signatory of the global SDGs. The Bristol SDG Alliance has undertaken the UK's first Voluntary Local Review of SDG progress. The review has assessed progress against all 17 SDGs and includes data from over 140 indicators. It reflects a whole city approach to tackling the SDGs, making links to the One City Plan as the core city document ${ }^{6}$.

In taking the One City Plan and climate strategy forwards, cross-sectoral boards have been set up to lead on different aspects of the plans, monitor progress and bring actions together.

\subsubsection{City Council Plans: SLES Impact}

The Corporate Strategy (2018-2023) sits within the context of the One City Plan and sets out the council's own ambitions and objectives for the period.

The Corporate Property Strategy 2020-23 covers land and building management; Bristol City Council owns a significant amount of property and, by area, owns approximately $40 \%$ of the land in the city. A significant part of this is controlled by third parties under long term leasing arrangements. Operational property includes around 2600 hectares of land and 733 buildings (e.g. schools, libraries, offices and depots) ${ }^{7}$. One of the six visions in the strategy says: 'our estate leads by example in the contribution it makes to making Bristol carbon neutral and climate resilient by 2030'.

The Transport strategy ${ }^{8}$ covers all aspects of transport and has, at its core, aims to improve the city's connections, reduce inequalities and improve sustainability. It says: "The use of technology to help us move around has increased rapidly and will continue to do so. Technology is helping people to make their journeys door-to-door in a seamless way through measures such as journey planning tools, smart ticketing and mode sharing apps that allow citizens to access various modes of transport, reducing the need to own individual cars. We will embrace the use of technology that enables more efficient movement around our city and this is embedded throughout this strategy." The Smart city strategy ${ }^{9}$ 'Connecting Bristol' also talks about inclusion, which places people at the core of smart activity in the city.

\footnotetext{
${ }^{6}$ http://www.bristolonecity.com/sdgs/

${ }^{7}$ https://www. bristol.gov.uk/documents/20182/4565824/Corporate+Property+Strategy+2020-23.pdf / $3 a 0 c 2739-1 e 6 a-b 101-092 a-e a 37 e e d 149 b 3$

${ }^{8}$ https://www.bristol.gov.uk/policies-plans-strategies/bristol-transport-strategy

${ }^{9}$ https://www. connectingbristol.org/wp-content/uploads/2019/09/Connecting_Bristol_300819_WEB.pdf
} 


\section{Building and Retrofit Sub-System: Findings from Data Analysis}

\subsection{Factors affecting Bristol's Building and Retrofit sub-system}

Drawing on the interview data analysis, we have formulated the causal model of the building and retrofit sub-system in Bristol, as shown in Figure $3^{10}$, and is briefly explained below.

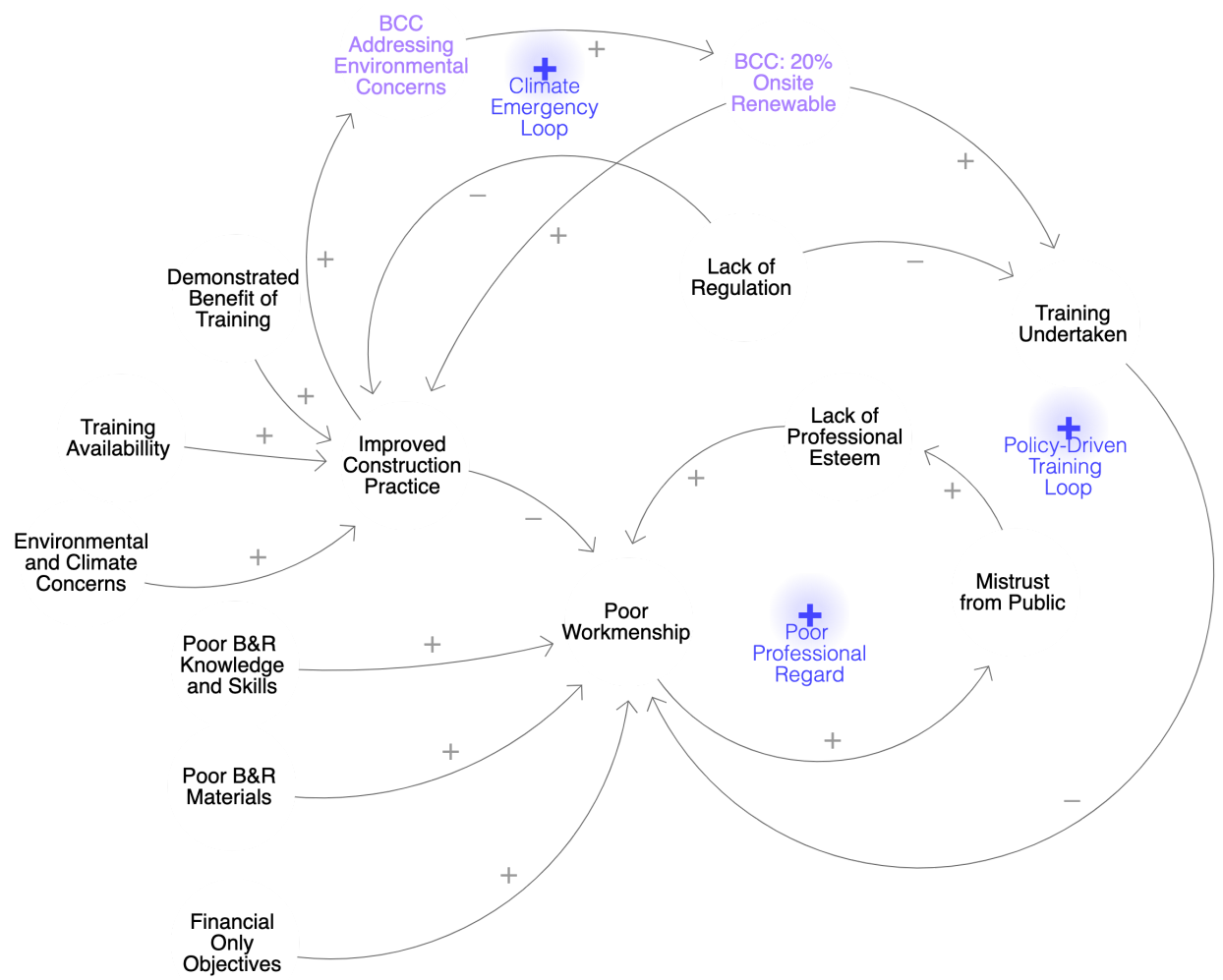

Figure 3: Causal model of Bristol's Building and Retrofit Sub-system (factors local and specific to Bristol are presented in purple).

The Building and Retrofit sector in Bristol has flagged two key factors of influence:

(a) the ethos of the UK building and retrofit industry, of which Bristol is a part, and

(b) the climate emergency challenge driven by national agenda and reinforced by the local city council.

The study participants describe the UK's Building and Retrofit sector as very conservative and lagging behind modern building knowledge in materials and methods. As stated by P11: "We seem very bad in this country about learning lessons about it from other countries. We're often trailing behind in terms of materials specification technologies. ...we seem incredibly resistant to perhaps stopping and looking and learning, and we plough on with our almost unique way of building ...". This is exacerbated by money-driven priorities, especially within the large building companies. This culture of building to the minimum specifications, and as cheaply and quickly as possible, leads to a poor quality of workmanship where the "...let's build quick and deal with

\footnotetext{
${ }^{10}$ This model can be simulated through this url: https://energysystems.blogs.bristol.ac.uk/2021/03/08/ retrofit/
} 
the problems later" (P11) attitude results in storing up problems in the new build. Thus, "because things don't get built properly,"(P14) “...in 20 years' time we'll be retrofitting houses that were built ...today." (P11).

This culture of poor workmanship leads to mistrust by the public towards the builders and retrofit providers "...a lot of the construction industry is not particularly well perceived by the general public. There are major trust issues around who you want to do work on your house ..." (P7). This reinforcing of poor practices also results in a poor view of the profession in that it is "...not seen as being glamorous or interesting or well paid enough ..." (P14).

However, the climate emergency challenge is a positive factor in driving change in the building and retrofit industry. In Bristol, the city council has introduced rules such as $20 \%$ of energy to be generated locally from renewable sources for each new build property and a ban on gas boiler installations in Bristol from 2030. Similarly, as part of the City Leap project, BCC will set up a joint venture for scaling up project delivery with qualified delivery providers. All these factors, along with the funding available from the central government for energy efficiency measures are encouraging training, the uptake of new technologies, and modernisation of work practices in the local building and retrofit industry.

To support training delivery, the Green Register [27] and Futureproof [28] projects have initiated training delivery activities in Bristol, although much still remains to be done.

\subsection{What Skills are Needed for the Building and Retrofit Sub-System Currently and in the Future?}

The skills deemed relevant by our interviewees to each of the areas of Bristol's Building and Retrofit ecosystem are summarised in Figure 4 and detailed below, while also being aggregated into generic types.

\subsubsection{Engineering and design skills for the Building and Retrofit sub-system}

- Architects with current retrofit knowledge: while we have not observed a shortage of architects per se, several of the study participants noted that the architects lack knowledge of, and experience in, undertaking retrofit projects. As noted by P14, "the architect I chose, ... is about one of two accredited building biologists in the whole of the UK". Furthermore, while builders can undertake much of the retrofit work, the architect should be involved with the quality assurance, as noted by P23: "... internal insulation would be undertaken by the general builder, and their workmanship would be inspected by the architect". Furthermore, P11 suggested that a new role should be considered for an architectural technician, who would fill the "...space [between] builder and the architect. There's a space in the middle ...to fill ...because, going back to the building science, building physics side of it, if you're a bricklayer, clearly you don't need to understand building software that's going to thermally model a house, for instance."

- Heating and Ventilation Engineering (also referred to as Mechanical and Electrical, or M\&E) is a skill set which "will play a bigger part in housing in the next few years ..." (P11), and relates to the integrated design of heat pump sizing and integration of heat recovery and ventilation systems. While the installation of these systems could be considered to be a trade skill, an integrated design for these is more of an engineering endeavour: "need to know where all 


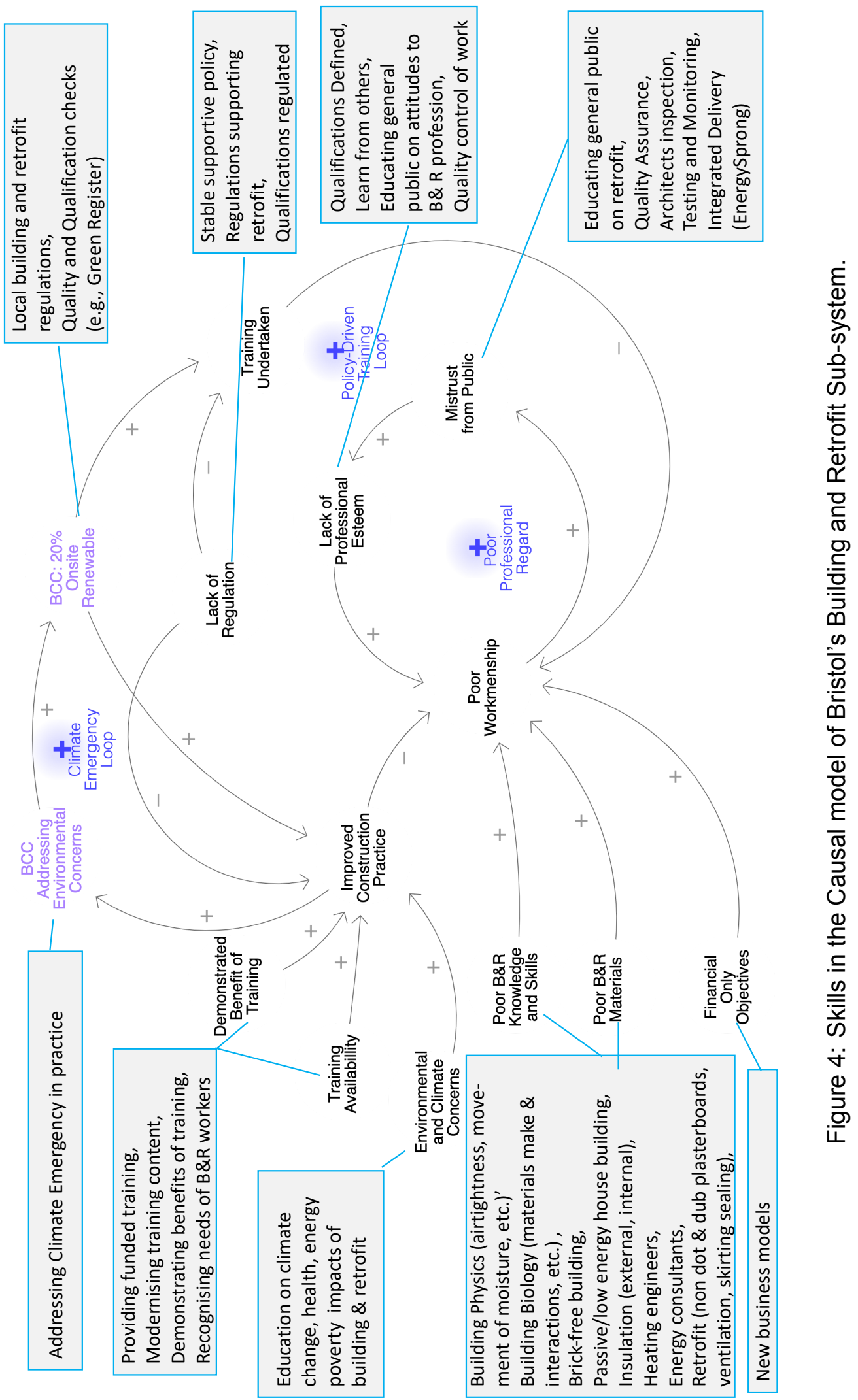


the kit is going to go. It's all very well designing it and then ready to go and then you think, 'Well I haven't got a big enough room to put all of the kit and we haven't allowed for cabling or duct work."' (P11).

- Software: smart buildings and controls are expected to take a more central role with the automation of energy systems, "...to guarantee the performance, you need much more detailed monitoring and controls than are typical." (P12).

\subsubsection{Trades Skills for Building and Retrofit sub-system}

The most notable lack of skills and knowledge within the Building and Retrofit trades seems to originate around the lack of desire to modernise the techniques and processes, and the materials used. The UK B\&R industry is said to cling to traditional building methods which are incompatible with both the carbon neutrality objectives and the SLE transition.

- Building Physics skills (i.e. " ...the knowledge of how buildings operate" (P7), such as an understanding of how to make a building airtight, yet providing a sufficient movement of moisture, regulating airflow and temperature across various areas of the building, etc.) are reported to be severely lacking. "That's the education around the difference between traditional construction and modern construction and the fact that they should be treated differently." (P7)

- Building Biology skills, (i.e. knowledge of building and retrofit materials, their make, interactions and impact on those living around these materials) is noted to be very poor. While building biology is "... long established in Germany" it is still "...a very niche thing in this country" (P14). As a result, "some builders that don't really understand are maybe specifying inappropriate products for the purposes ..." (P7).

Importantly, skilled use of building biology affects both the quality of the building (e.g. due to "...absorption and desorption of moisture" (P14)), as well as the health of their inhabitants (e.g. "...it's quite shocking how much stuff is toxic that people use. Most carpets have got all sorts of horrible chemicals in for fire retardant. And there's lots of people that are allergic to that and they get really ill." (P14))

- Installations of Alternative Heat Sources is the area of largest trades skills needs in Bristol (and elsewhere), as " ...the government are saying that no new houses will have a gas boiler from 2025. So they're going to have to all have heat pumps in them" (P18), and technologies such as solar water heaters and district heating projects are also growing.

- Gas boilers decommissioning must go along with the new heat source installation (noted above), as we "...need to rip out those gas boilers, and the scale and the pace that we need to move at to get to 2030 " [is very rapid] (P6).

- Brick-free building works with “...clay blocks and they don't have a mortar course as such; they've got an adhesive course. And so it's not traditional bricklaying by any stretch ...it has to be laser perfect" (P14). While this technology is well used regularly in the continental Europe, and is both faster and much more energy efficient, the UK builders so far, have so far, resisted from adopting it. 
- Retrofit skills, while available, substantially vary in the quality of delivery. Thus, simple draught proofing could often address sealing the gaps around windows, doors and letterboxes, yet leave out sealing around skirting boards. Installation of internal wall insulation often results in interstitial condensation and dampness due to a lack of ventilation and the use of non-breathable materials, as well as thermal bridging problems. The current use of "dot and dub plasterboarding" leads to cold air enveloping the rooms just outside of the plastering layer, and slipping in from under the skirting. Therefore, though retrofit skills are generally available, there is a lack of well qualified retrofit delivery professionals, or "retrofit consultants" (P23) which would " ...be one-stop shops that ... are able to explain, survey, analyse, liaise with the customers as part of a firm that's also able to deliver" (P23). This kind of approach looks at the whole house rather than individual measures.

- Quality Assurance skill is said to be completely lacking in construction and retrofit: "the whole kind of quality assurance bit during installation, through the whole process but installation in particular, which the construction industry doesn't really do." (P12). While managers could address this by setting up testing procedures and the tradespeople themselves could also upskill, there still needs to be a mechanism for checking the quality of the installation. In addition, architects could inspect the workmanship (P23) (which is sometimes done in construction, yet rarely in retrofit).

- Although passive/low energy house building is not a new method or process, it is still an under-represented skill in the UK building and retrofit industry (P23).

\subsubsection{Managerial Skills for Building and Retrofit sub-system}

Given that construction and retrofit projects work with large teams, and in the UK, these teams are often made up from individual builders who act as subcontractors, project management skills are particularly important. Within this context, the most relevant noted skills are:

- Building a core trusted team of tradespeople who are "...signed up to ... the whole idea of saving energy and the importance of trying to stabilise the climate and prevent global warming" (P14). When the managers were successful in this, the subcontractors, " ...even though they were self-employed, it was all but in name, they were essentially [company name] employees" (P11), preferring to work for a company that shared their approach and where their values and skills were recognised.

- Delivering Quality Assurance in an environment where the "supply chain is all split into architects, contractors and main contractors ..." (P12). For this, the manager needs to ensure that tests and checks are carried out, e.g. " ...the usual kind of co-heating and air tightness tests ..." (P12).

- Sourcing modern materials for the right price should not really be a specific skill; it should be as simple as "...phone in an order" (P7). However, modern materials are often not available at local building merchants, "... delivery costs quite often make it non profitable" (P7) to order these materials from afar, and "...SMEs they don't have storage facilities to order in the bulk that they need, and keep in storage". Thus, " ...if other products aren't readily accessible, then most builders ...just ...fall back on what they know" (P7). Thus, this skill of sourcing, 
or proprietary supply chain set up is considered to be a relevant and in-shortage managerial skill.

\subsubsection{Energy Skills for Building and Retrofit sub-system}

- Energy Surveyor role is often conflated with the building surveyor's. Furthermore, though general advice on roof insulation and draught proofing around windows is easy to give, the specialist energy surveyors who are able to use dedicated survey tools (such as thermal imaging) are still in short supply. As noted by P13, "There are one or two people in the country who are doing thermal imaging with pressure reduction" which is the most up-to-date energy surveying technology.

\subsubsection{Finance Skills for Building and Retrofit sub-system}

- Ability to work with new business models is considered as particularly relevant, if property owners are to be voluntarily committed to retrofit. As noted by P12, "...landlords need more re-skilling internally around kind of business model really, and what needs to be done to the properties to make them fit for purpose ...". This means being able to take a longer term view of costs and savings relating to retrofit measures.

\subsubsection{Policy Skills for Building and Retrofit sub-system}

While building and retrofit providers are not expected to follow the delivery policy and regulation directly, the policy concerns below were noted as being directly relevant to the industry:

- Delivery of Clearer Regulations: while Bristol City Council has declared a climate emergency and aims to transition to carbon neutrality by 2030, some parts of BCC act inconsistently, e.g. the Planning team prohibits certain PV installations (P7), or only allows for external wall insulation to be done at the back of the buildings to preserve the front decorations (P23).

- Stable supportive policy is necessary, as shown by the recent policy changes "I think ...the degree of retrofit going on has dropped by $80 \%$ since 2012 . ... That's because the plug was pulled by Cameron on all sorts of what he called 'the green crap'." (P13).

- Quality and Qualification regulations would ensure that building and retrofit providers undertake the relevant training and get "Some sort of certification that they can go: 'Look, I've got this certificate."” (P7). This "...pushing government to be stricter on the regulations ..." (P12) will improve the quality of the delivered workmanship as well.

\subsubsection{Legal Skills for Building and Retrofit sub-system}

While the building and retrofit providers are not expected to deliver the legal skills directly, the legal concerns below were noted as being directly relevant to the industry:

- Legal interpretation skills are very relevant when undertaking retrofit activities, because contradictions must be resolved at certain times, as noted by P7: “...they've declared a climate emergency and we must do this," yet later going on to say, "No, you can't put solar panels 
on your roof because you're in a conservation area, even though that's not what the planning guidance says. The planning guidance says you're not allowed to put it on your wall, and yet Bristol City Council interpret it as your roof."

- Furthermore, to help resolve most of the above-mentioned contradictions, P7 suggested that the UK must Legislate for Energy Efficiency of all Building and Retrofit work.

- Finally, a new legal requirement for an Energy Report for each house was suggested: “...everybody having a really good quality energy report on their house that needs to stay with the house? Yes, I know you need to change legislation in order to do this, but if everybody could get a good quality energy audit which provides a roadmap for achieving zero carbon, and the order that you would do it in to avoid doing something and then having to change it assuming that no extensions take place etc., and that gets passed onto the next occupants. Still have the EPC to determine what has changed since the last time is was sold, but that's your roadmap ..." (P7). Such a report would prevent made-up claims by "cowboy builders" on the work needed for energy efficiency improvement of a house, and would help the house owners in planning and realising the necessary improvements.

\subsubsection{Soft Skills Shortage in Building and Retrofit sub-system}

- Willingness to learn from others is a key missing skill, as noted by P11: "We seem very bad in this country about learning lessons about it from other countries. We're often trailing behind in terms of materials specification technologies." Similarly, the compulsory licensing of building and retrofit providers prior to giving them access to the work is mandatory, e.g. in Portugal, although UK still persists in "...not looking abroad and seeing how it's done differently and trying to learn from that." (P11).

- The skill of Valuing Own Work and Profession is said to be underdeveloped in building and retrofit professionals. This also leads to a low motivation to improve. Thus, building and retrofit professionals must learn that "...they're doing something quite important" (P11) by themselves, and they also need to communicate this message to the general public.

- Educating general public on:

- retrofit,

- attitudes to building and retrofit profession and its link to

- Climate change, health and energy poverty

is another key missing skill. Such an education would help the uptake of the retrofit activities, and would also help the general public to value the professionals who deliver these services.

\subsection{Training Needs for Building and Retrofit Sub-System}

\subsubsection{Areas of Training Needs}

The key areas in B\&R where training is considered to be particularly necessary are: 
- Building Physics, i.e. the understanding of the movement of heat and moisture in buildings, so that the resultant (retrofitted) buildings are more comfortable, energy efficient and healthy.

- Building Biology, i.e. the understanding of health hazards in the built environment: from chemicals in building materials, to allergens, mould and so on. This will help the B\&R professionals to choose the right materials and deliver healthy dwellings.

- Delivery of retrofit, including insulation (ensuring the avoidance of condensation and mould), thermal bridging, non-dot-and-dub plastering, sealing the edges of insulation and seams around joists, and alike. This includes an overview of the whole house in relation to a number of retrofit measures and their likely benefits and sequencing.

- Heat Pump and Heat Technology Installation, such as solar water heaters, ground and airsource heat pumps, district heating, etc.

- Maintenance " ...to turn up in somebody's house that's got some dodgy wiring and weird plumbing ....and how you remove .... lead pipe or some nasty lime scaled thing off the wall without destroying it." (P7) This is a particularly relevant skill as all fossil-fuel-based infrastructure (e.g. gas and diesel) must be decommissioned at scale.

- Building with new methods, such as brick-free building, passive and low energy house building.

- Work Ethic, i.e. conscientious approach to work, with respect to their own occupation (which has a paramount impact on energy efficiency, health and the environment), as well as those who will use the resultant buildings.

\subsubsection{Modes of Training}

When discussing how training should be delivered, the respondents noted that a variety of training modes will be relevant:

- Higher education for theoretical and science-based professions (such as architectural engineers or data analysts);

- Further education colleges: while "NVQs and HNDs in building services are generally focused on new build" (P7) and these skills need updating, trainees also need to learn about retrofitting older buildings;

- Internal Training at a Company where the innovation delivered is new and specific, such as thermal imaging with air pressure use for energy surveying at CHEESE [29]: “ ...nobody else is doing what we're doing so we're training people. We run at least one training course a year" (P13); this might also include training delivered by the manufacturer of a particular product to ensure correct installation;

- Learning-by-doing where the content "... is not complicated but it does require patience. And it does require you to want to learn and not to rush it" (P11), such as laying insulation or learning to be a "draught buster" (P13); 
- Online Courses, such as those from the Association for Environment Conscious Building (AECB) [30] on retrofit are available, yet are limited in content, and new material (e.g. on building Physics and Biology). Green Register [27] has also set up online training, in addition to its in-house provision. This mode, however, is less suited for practical skills development, although AECB uses photographic evidence of completed practical tasks as part of its assessment.

- Peer-Learning, i.e. learning from colleagues, either from within the same company, or from peers outside of one's own organisation, is another well-established method. The Toolbox Talks programme was recently started by Green Register through the Futureproof project, whereby if " ... builder would like an hour's training on site from another builder about a particular area ..." a Futureproof qualified (FAB: Futureproof Associate Builder) peer will be invited to deliver the training.

- In Community Training is delivered by local community organisations and for the community benefit " ...skilling up of local people who might be unemployed" (P13). It is aimed at developing the sense of ownership and engagement within the local community, as well as upskilling the local residents "...it's not a company coming in and just doing it and leaving again. But you can have that ownership ..." (P18).

\subsection{Insights and Recommendations on Bristol's Building and Retrofit Sub-System}

The key challenges faced by Bristol's B\&R sector in support of the transition to smart local energy systems arrive when:

1. Motivating the current workforce to a) take up the available training and b) adopt modern building and retrofit practices;

2. Attracting young people to the sector;

3. Navigating the transition path equitably, i.e. avoiding obsolescence of the sector workers.

\subsubsection{Motivating the current workforce to take up the available training and adopt modern building and retrofit practices}

Knowledge of modern building and retrofit techniques as well as training providers are readily available in Bristol (including through two universities, several FE colleges, online training delivery organisations (such as AECB [30]), as well as local professional development initiatives (such as Futureproof [28] with Green Register [27] and CHEESE [29])). As it is, the challenges are in:

a) motivating the current workforce to take up this training, and

b) applying the said training into their remaining practice.

We suggest that both of these challenges need to be addressed simultaneously by, on the one hand, removing the barriers, and, on the other, creating demand for the upskilled, modern building and retrofit services.

\subsubsection{Overcoming Barriers to Training Uptake}


Barriers to training uptake are both economic, cultural and personal, and so the means for overcoming them must be of a similar nature:

- Paid-for Training is necessary, as many of the B\&R workers are "one man bands" (P14) and cannot afford to take time off work. However, where the worker is employed by an SME, payment of the salary to the worker is insufficient, and the overheads (e.g. costs of the company's bookkeeper, warehouse, manager, etc.) to the SME also need to be accommodated.

- Difficulty of New Methods Uptake is due to the inertia against change: "people are so used to doing something for so long that it's quite a struggle to introduce something new even though it's really simple/straightforward" (P14). Thus, when introducing new methods, the $B \& R$ professionals would require additional support, such as a trainer, or a peer network to help out.

- Providing Funding for Trainers is necessary for both enabling the training organisations to continue to function as a training provider (e.g. "FE colleges ... are absolutely strapped for cash and ...sometimes they don't have enough money to run the courses" (P7)), nor for the development and delivery of modern (hands-on practical) and relevant training content. When funding is limited, the training providers could be forced to work with what they have: "Kingfisher and Knauss give FE colleges free products. Well, if you go and learn how to put Kingspan in ...you go into a shop and you see Kingspan, oh, I used that in school so that'll be fine. But what you don't know about is the twenty other different insulant types that might be fine or even better for the purposes you use them." (P7)

- Professionalise Vocational Education: given that the present regulations do not require any qualifications for the B\&R trade, there are not many incentives for those already in the profession to undertake additional training. This could be mitigated if there is "...some certification element attached to it that makes those people that have made the effort stand out in some way" (P7). This certification can then be used to signal to customers the skill levels of various B\&R workers.

\subsubsection{On Supply and Demand for Building and Retrofit Training at Bristol}

While removing obstacles to training uptake makes training accessible, it does not really motivate the already busy builders to upskill themselves. This is the challenge that a Bristol-based CSE has advocated to target through "locally focused market orchestration" [31].

The locally focused market orchestration approach observes that the technology adoption curve (see Fig.5) is led by innovators who take risks. These risk takers have already been adopting the new methods and practices, both as builders and as homeowners. The innovators are followed by the "early adopters", who would not take the risk of trying the unknown, but would look for examples and references from the innovators. The early adopter home owners "...won't take 'innovator' risks so need to get recommendations for builders and to see homes like theirs already done completed before taking action" [31]. Once the early adopters take up the new technology, the early and late majority will follow (under the right financial conditions). However:

- the early adopter homeowners (the demand for skills) will not invest into extensive energy efficiency measures (beyond the easy draught proofing and roof insulation), unless they are confident that they can find a good builder and have seen what the end result would be. Meanwhile, 


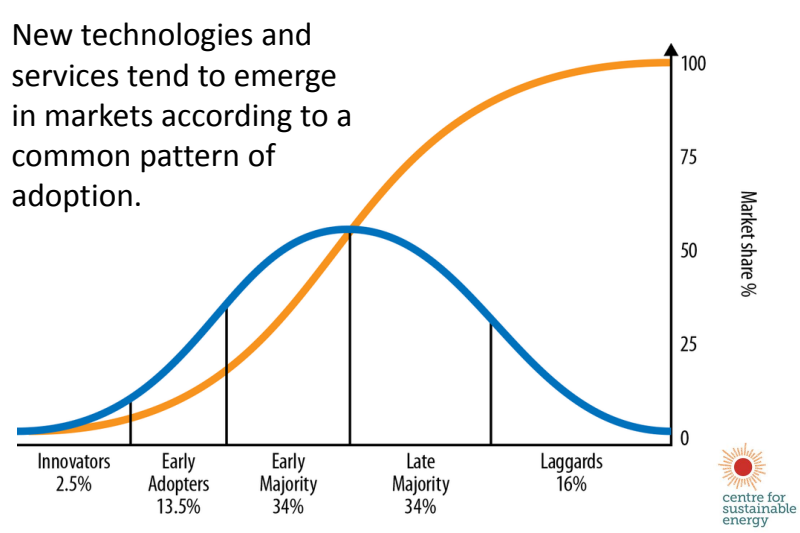

Figure 5: Technology Adoption Curve [31]

- the early adopter builders (supply of skills) will not invest in skills development if they don't think that there is a local demand which will give better margins than their current skills.

The locally focused market orchestration approach addresses this by stimulating demand on the one hand, and supply on the other.

CSE, in collaboration with other partners, have already started this process in Bristol:

- The Green Open Homes project [32] (active in Bristol since 2010 as 'Bristol Green Doors', and now a national network) provides an opportunity for people who have completed retrofit activities to open their homes to interested peer-homeowners, who may wish to do a similar upgrade. This gives the early adopters a chance to see the end products and to hear about builder recommendations.

- The Green Register [27] organisation (founded in 2000 and based in Bristol) provides a register of qualified building and retrofit professionals for each locality. This allows for the early adopters to find a local builder to employ.

- Bristol Energy Network (BEN) provides training in understanding the energy efficiency opportunities for Bristol's communities, which on the one hand, creates more demand. On the other hand, BEN works with the Futureproof project in the identification and engagement of builders and retrofit providers with the training programmes, thus boosting the supply side.

- At the same time, the demand is stimulated further through the nationwide Green Homes Grant funding [33].

- The Futureproof project [28] (which has been active in Bristol since 2019): a) provides funded training on modern technologies and techniques for building professionals, and b) provides an opportunity for building retrofit professionals to build peer networks for mutual learning and support.

- The CHEESE project [29] provides comprehensive energy audits for citizens as well as training community members in undertaking energy audits with cutting edge proprietary technology solutions which use thermal imaging to identify heat loss in buildings. 
While all of the above are supporting the uptake of both training and retrofit, the local authorities (and, in particular, Bristol City Council) can take a proactive role in amplifying their positive impact. The following aspects would strengthen this approach further:

- Formal regulation to make specific qualifications a required pre-requisite for access to building and retrofit work (similar to the prerequisites of qualifications to work as an electrician) would be particularly useful. This can be both a local policy and a national regulation. For instance, Bristol City Council could contract only those registered with the Green Register, or qualified to the minimum of Futureproof's Level 1 for work within city-owned properties, strengthening the reputation of these qualifications. Such a regulation seems to be currently on the way with the Retrofit Academy's PAS 2035 accreditation expected to be a mandatory requirement "...for all projects in the long-term" [34]. However, BCC does not need to wait for the 'long-term' to act locally.

- Support with local supply chain provision is particularly relevant for the SMEs and sole traders who wish to build to the Passive House standard, and with modern materials and processes:

- The vast majority of the energy efficient components and natural materials (such as triple glazed windows and clay building blocks) are imported from Europe: "...the supply chain is all from Europe, we just don't make this stuff" (P14). This, already fragile, supply chain can be easily broken down with changes in trade rules and tariffs due to Brexit. Thus, we suggest that BCC sets up a Building and Retrofit Suppliers Network or Conference that meets up regularly to facilitate supply chain and relationships building between the EU and Bristol companies. Moreover, an investment into distribution service set up (either funded through contributions from SMEs, or privately with agreement of SMEs to trade with the given distributors for the specified items) would be very desirable.

- Competitions for Supply Chain Development is another avenue available for facilitating the transition of the sector. Such competitions have previously been funded, e.g. through the EU " ...we did a design competition back in October and so we got some of our prospective landlords to submit buildings which they're thinking about retrofitting. And the design competition, we had some funding so we offered that to consortia of supply chain companies to deliver [specialised retrofit] design for those case study buildings." (P12).

- Supply Chain Development per Design Archetype: given that there are many landlords that own properties of the similar design, i.e. "same housing archetypes" (P12), a solution "...that is designed is also suitable for other landlords down the line so that they benefit from the cost reduction rather than having dozens of separate pilots ..." (P12). Here, the 'solution' refers to both of the retrofit designs, and also to the supply chain drawn upon to implement the said designs. Here too, BCC could draw together the landlords of the archetypal properties from across Bristol and orchestrate a common solution for each type (e.g. through a pilot competition/tender, where the winner, or most successful pilot, is awarded the contract for the archetype).

\subsubsection{Attracting young people}

As previously noted, the B\&R sector currently has a poor image and is mistrusted by the general public. However, the scale and pace of the required transition necessitates attracting new building 
and retrofit professionals. A number of directions to tackle this challenge have already been noted and are briefly summarised below. Much of this can be carried out by the professional bodies, as well as by the local authorities:

- The training providers and employers can improve the image of the profession within the current workforce by demonstrating the value of the work and its impact on the environmental as well as public well-being (e.g. through Building Biology and Physics, Valuing Own Work and Work Ethics modules).

- Local and national authorities can increase the confidence of the public in the profession through certification of qualifications and quality assurance clauses for post-delivery of the work.

- The training providers and employers can engage with young people at schools to demonstrate the value of the profession and create an early interest (e.g. through acting as guest speakers at lessons, such as on Building Biology as part of the Biology curriculum, or Building Physics for Physics sessions, or Architecture in Product Design, etc.): “ ...go into my old school in Bristol and give a talk or two to the sixth form. I mean, it's a major issue we have to deal with." (P14)

\subsubsection{Navigating the transition path equitably}

Given the scale and pace of the necessary change to meet Bristol's agenda of becoming a carbon neutral city by 2030 , the city needs to train up a number of tradespeople to take on the immediately relevant jobs, such as at-scale gas boiler decommissioning and property retrofit. Unfortunately, these jobs will not have a long-term future in that, once the city is carbon neutral, the gas system decommissioning professionals will be obsolete. This poses a challenge of, on the one hand, training up the tradesmen in large numbers for such jobs while, on the other hand, planning for their post-2030 transition into other specialisms or jobs.

In order to avoid mass redundancies and joblessness in Bristol's B\&R workforce in the postcarbon neutrality future, we advocate:

- avoiding a single-skill professionalisation/training provision. For instance, gas decommissioning tradesmen can also be trained to undertake heat pump installations. Thus, should the demand for work on decommissioning reduce, the installation skills could continue to remain relevant.

- maintain the continuous professional development and ensure that training in a new, mid-tolong-term relevant skill is made available to the B\&R workers, as the demand for one of their previously relevant skills declines.

\section{Local Authorities Subsystem: Findings from Data Analysis}

\subsection{Factors Affecting Bristol's Local Authority Subsystem}

The local authority opinions presented in this work are those obtained through interviews with the members of Bristol City Council (BCC) and the West of England Combined Authority, supplemented with views expressed by other interviewees. 
Drawing on the interview data analysis, we have formulated the causal model of Bristol's Local Authority subsystem in relation to SLE, as shown in Figure $6^{11}$, and briefly explained below:

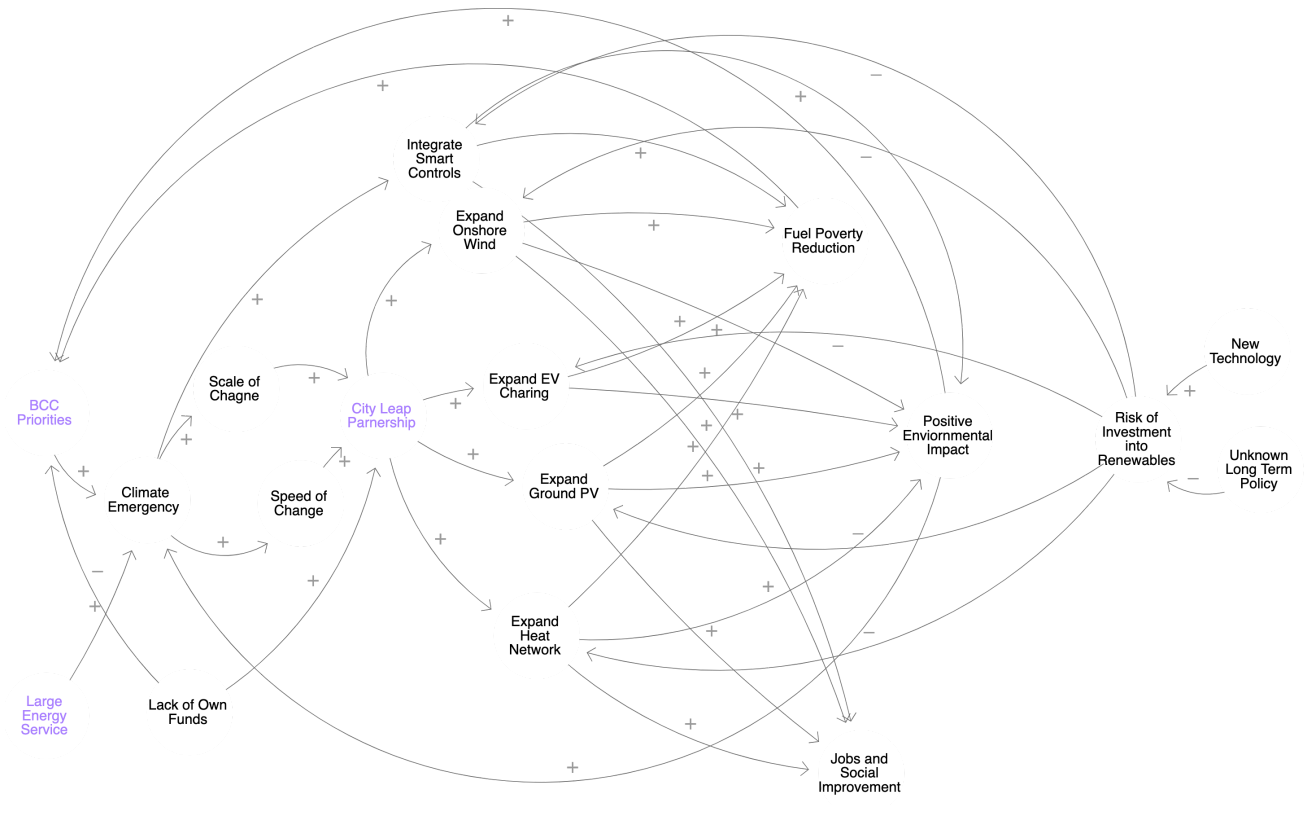

Figure 6: Causal Loop Diagram of Bristol's Local Authority Subsystem (factors local and specific to Bristol are presented in purple).

Bristol is the first city within the UK to have declared a climate emergency. While the city has a number of priority areas to address as identified in the One City/City Leap documents [35, 36], the climate emergency challenge is the key focus for the city and its council.

As part of its addressing the climate challenge, BCC has set up the City Leap [36] programme of work, one key area of which is the transition to clean energy systems. This work is supported by BCC's large Energy Team, which currently consists of approximately 40 employees. This is an unusually privileged position for a UK city council, as most councils have lost their energy teams altogether (due to the austerity-induced budget cuts) or have managed to retain only a small team of energy managers.

The BCC's Energy Team has been supporting a wide set of energy transition projects, such as the development of ground-mounted PV arrays, onshore wind turbines, energy efficiency projects for council-owned housing, micro-district heating development and electrification of vehicles in the city. However, on declaration of the climate emergency, BCC observed that the scale and speed of energy transition needed to be scaled-up to levels that could not be sustained by the council's currently available human and financial resources, as noted by P6:

....in light of the climate emergency .... We know it's just not enough, and we know that, with the council's ability to deliver on the scale and at the speed that we need, it's just impossible. So, we've done some calculations on our ambitions for the next 10 years in terms of our energy projects for things like expanding our existing heat network, ...low

\footnotetext{
${ }^{11}$ This model can be simulated through this url: https://energysystems.blogs.bristol.ac.uk/2021/01/19/ localauthority/
} 
carbon and affordable heating ...more onshore wind, more ground-mounted PV, more EV charging, all of those bits of infrastructure, we've essentially looked at our ambition and we've looked at the cost of that ambition .... And it came to around a billion pounds, about $£ 950,000,000$, so much more than the council's got .... And with ever-shrinking public budgets we know we're not going to be able to deliver that over the next 10 years solo.

This massive scaling-up of the transition activities was planned and set in motion through the City Leap project, whereby BCC has initiated a tender process for a private-public partnership, inviting innovative, clean energy companies to bid for an opportunity to deliver various services to the city of Bristol on 50 - 50 partnership terms. The winners (single companies or consortia) will form joint ventures with $\mathrm{BCC}$ to deliver large-scale transition activities.

The joint ventures between $\mathrm{BCC}$ and the commercial companies are intended both as a way of scaling-up the investment as well as, on the one hand, reducing the risk of BCC's investment in the new technology and, on the other, reducing the risk of lost investments due to policy changes by the commercial investors. By investing with established technology-providing companies, the council gains a level of certainty that the said technology has been tried and tested in previous projects. Similarly, the commercial investors gain a level of certainty of a return for their investment, even if the national policy on these technologies within the UK is rather unstable.

Along with its fostering transition to a zero-carbon economy by 2030 (a target set by BCC), the City Leap project will support job creation, societal improvement for the citizens of Bristol and the reduction of fuel poverty.

\subsection{What skills are needed for Bristol's Local Authority (energy) subsystem cur- rently and in the future?}

The skills deemed relevant to each of the areas of Bristol's Local Authority ecosystems by our interviewees are summarised in Figure 7. We note that the City Council has a number of teams that are focused on addressing various issues of the city's administration. However, the key focus of the City Council is to design the projects and relevant policies, and then to commission their delivery through tenders and procurement of skills from commercial partners, rather than just developing in-house skills for tackling all areas of the various projects' delivery.

\subsubsection{Engineering Skills for the Local Authority Subsystem}

BCC already owns a substantial number of clean energy resources (such as wind and solar generation, rooftop PV on council-owned buildings, electric charging stations and vehicles). These assets will continue to grow (both through the City Leap joint ventures and through the Council's own investment) and will need to be maintained and operated. Furthermore, the City Innovation team engages in technology research and directly employs engineers as well; thus, as per P6:

...we're transitioning to a smarter energy system. Things are becoming more automated and more interconnected, which is fantastic. With that, there are undoubtedly going to be some skills challenges ...the clever individuals that come up with the algorithms that allow your in-house heat pump to talk to your central heating and your battery to talk to your PV ...Some of that work is becoming rapidly automated but there 


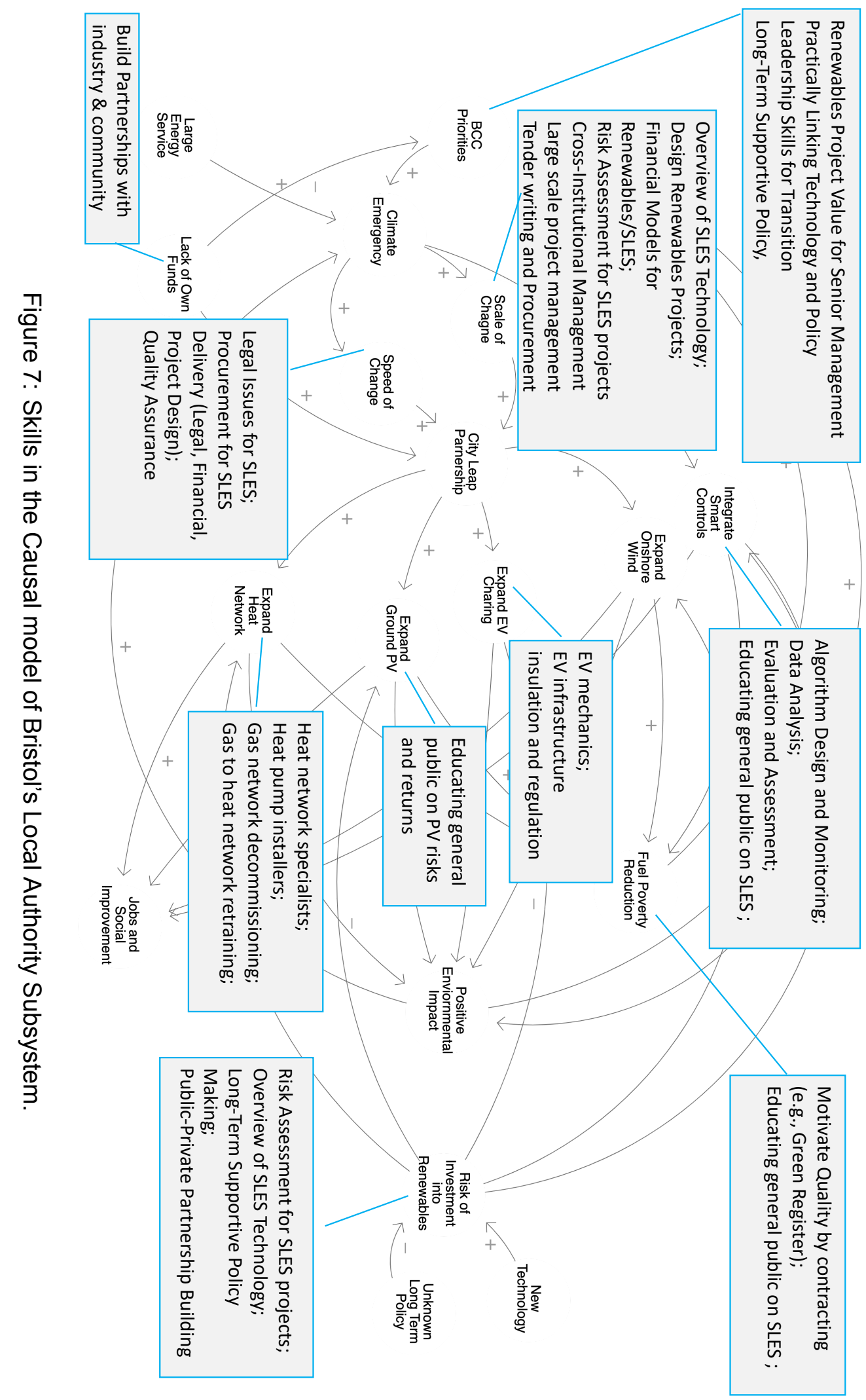


still needs to be ....an individual, or a team of individuals, in an operation centre looking at the data flows and screens and saying, okay, something's gone a little bit awry there; we need to tweak the provisions.

- Data Analysis to evaluate performance of the BCC SLE SoS and identify ways of optimising it;

- Algorithm Design and Monitoring, primarily to operate and maintain the council's resources, optimise their performance, as per input from the data analysis, and undertake innovation and pilot projects.

- Heat Network Specialists are needed to support the district heating program roll out, which is a new and growing area of BCC's energy transition.

- EV Infrastructure Installation and Regulation Compliance Checks skills are required for BCC's charge point installation projects. Some aspects of this work require innovative solutions, e.g. P18 states that during the installation of charge points they learned that the width of the pavement, can be no less than 1.2 metres wide to ensure that pushchairs can go down it. "So, when you put in a charge point you have to say, 'Hold on, the pavement's not wide enough. ...we had to put the charge point in the road. Wow OK, how do you do that? Well, we need to put bollards. We will need to put a tree next to it to protect it and all this. So, the Highways team, it was totally new to them doing a charge point. And their electrician, who's always a very busy man, spent weeks and weeks trying to get him engaged on the project."

\subsubsection{Trades Skills for Local Authority Subsystem}

BCC does not directly employ a large number of tradesmen, except where specific work must be carried out by the BCC employees (e.g. installations on the highway must be carried out or overseen by the BCC Highways team). Nevertheless, BCC procures the skills of tradesmen in undertaking all of its projects. The trade skills listed below were noted to be of particularly growing relevance:

- Charge Point Installation Engineering, e.g. as per P6: "Maintenance of a charge point if a charge point broke."

- EV Mechanics Skills to maintain the growing number of the council's and citizens' EVs;

- Heat Pump Specification and Installation Skills, e.g. P18: " size heat pumps correctly to the size of the room ...there's quite a lot of design features with heat pumps.";

- Retrofitting Skills for Energy Efficiency, as per P18: "How to insulate a house properly. .... heat pump only works if the building is brilliantly insulated."

- Gas Network Decommissioning, as per P18 "we want to take every gas boiler out”;

\subsubsection{Managerial Skills for Local Authority Subsystem}

The main focus of BCC's activities is to develop projects, procure their delivery and manage them to completion. As noted by P29: 
The skill is for us to be able to unlock the skills where they lie with our partners and out there. Because undoubtedly there will be people who have the technical skills somewhere to do the stuff we want to do.

While the usual array of managerial skills is clearly relevant to BCC as well, here we note the issues noted as specifically relevant to the large and multi-stakeholder project management, due to the nature of the City Leap initiatives:

- Cross-Institutional Management is particularly relevant within the City Leap context; as noted by P6, BCC has to see that: "...City Leap as a joint venture will sit outside the council. We need that interface with the council in a sensible way ...";

- Large-Scale Project Management with Multiple Stakeholders, as noted by P9: SLE SoS "...requires such an interplay by so many different systems and players, not just the Council but telecoms; all of the utilities will have to play into that."

- Procurement for SLE SoS Delivery (Legal, Financial, Project Design) is noted (by P4) as "... becoming a key element for us ..." since the many large projects cannot be designed and delivered solely by the city council's internal staff;

- Tender Writing for energy systems. As noted by P4, poor tenders lead to loss of funds and poor project delivery: “...there isn't that knowledge, as one fairly senior local authority person said, we wrote this tender and we wrote it very lightly to allow the market to innovate. And I said, 'What you actually allowed your market to do was to take all your money and not deliver what you wanted."

- Building Partnerships with the Industry and Community so that BCC can "...make the most of partner organisations' capacity ..." (as per P29).

\subsubsection{Energy Skills for Local Authority Subsystem}

- Overview of SLE Technology An understanding is necessary if local authorities are to embrace these technologies. As noted by P4: "I would hazard a guess that most levels of local authorities ... wouldn't know one end of a heat pump from the next ...A lot of my projects are dealing with our solar PV, solar thermal, heat recovery systems - a heat emitting system whether an air source, ground source or biomass - and then you make all that work together with software, a building management system, how it all integrates and works together, and then how it integrates with the grid. ...Not many people with the specialism to cover all of that ..." (P4).

- Senior Management's Ability to Value Renewables Projects is currently very weak, as noted by P18: “...directors and the senior management team haven't really quite bought into it ...A lot of people at senior officer level ... have been in economic development and think in that way. It's all about productivity and GDP ...And now that they're to deliver energy and climate change elements ...It's not necessarily cost efficient to do it, but it's carbon efficient to do it."

- Designing Renewables Projects: given that carbon reduction is a key consideration in all BCC projects, there must be a plan for the use of clean energy. However, it is noted (by 
P18) that "the council doesn't really have the skills to look at the planning reports. So all the planning officers in my mind should be going on energy awareness courses. I mean really that solar design, what is possible on a roof to do solar panels?"

\subsubsection{Finance Skills for Local Authority Subsystem}

- Development of Finance Models for Renewables / SLE is a critically missing skill (as per P18), finance people at BCC currently have: "this little formula built in a spreadsheet that if the payback is more than five years, it comes up with an error." Given that most energy projects have a much longer payback time, financial services are often the bottleneck in transition projects.

\subsubsection{Legal Skills for Local Authority Subsystem}

- Contract Writing for SLE projects is complicated by the fact that the legal teams are not very well familiarised with the SLE technologies: “...So legal people don't really understand solar panels. They're certainly not going to understand batteries. If we tried to put a battery in someone else's building, we'd be there for months, with the lawyers having arguments about it." (P18)

- Risk Assessment skills for SLES projects are lacking as the clean energy equipment is new and unfamiliar to many. As stated by P18, they worry: "...what is this box on the wall? I don't know what it does. Do I need to maintain it? What happens if it goes wrong?". They need to become accustomed to treating these as they would any other equipment which "...just comes with a manual and a warranty." (P18).

\subsubsection{Policy Skills for Local Authority Subsystem}

- Practically Linking Technology and Policy: "It's about understanding the application of it [energy technology]. Understanding the integration of that panel into a number of different building types. But However, also, how to translate that into local policy." (P18).

- Long-Term Supportive Policy Making is necessary both at central and local government levels. As noted by P4: “...some local authorities ...got an idea of a project ... [that] would take ...three to four years. ...And you could see them just getting a bit jittery, because they know they've got local elections between that time etc. etc. etc. ...then, commitment falls away."

- Motivate Quality by Contracting Qualified Delivery Partners (e.g. Green Register), as suggested by P4: "I think there needs to be some form of certification at the highest level of accreditation for companies ...especially if they use public money."

- Quality Assurance of renewable projects suffers as "The operation and maintenance isn't covered within contractual elements at the beginning, so nobody will come back and fix it." (P4). Local authorities need to develop quality assurance skills and integrate these into local policies and contracts. 
- Evaluation and Assessment for Continuous Improvement is centred on integrating the current learning into planning for the future. In other words, accounting for "...that measurement piece, that evaluation, that kind of continuous improvement" (P6). While local authorities do not always need to carry out measurement and evaluation by themselves (e.g. this can be carried out by academics or other sub-contractors), they need to be able to plan for this and integrate the learned results into future projects.

- The BCC teams need to be ready to do their review quickly on Infrastructure Regulations as the transition poses previously unforeseen situations. For instance, installing an EV charge point "...has to satisfy all these regulations about, for example say, the width of the pavement..." (which must be 1.2 metres or wider) (P18).

\subsubsection{Soft Skills for Local Authority Subsystem}

- Leadership for Transition is to be assumed by BCC as it is one of the better resourced and innovative local authorities in the South West of the UK: "there are a lot of eyes on Bristol in terms of us in a leadership role and the ability to share knowledge, best practice, share mistakes with our local authority counterparts." (P6)

- BCC has engaged in the City Leap, which is essentially a project to Build Partnerships, “...establishing a long-term, very flexible, very innovative partnership to bring in that investment, to bring in a billion pounds over the next ten years through public and private partnership." (P6). Thus, partnership building skills are essential to all teams across BCC, as well as to all other local authorities who wish to replicate a similar transition approach.

- Skills for Educating the General Public on various topics of SLE (e.g. SLE overview and risks and benefits of PV/other technology installations) are also necessary within the local authority, as the general public must engage with the local authority plans to have these delivered successfully.

\subsection{Training Needs for Local Authority Subsystem}

\subsubsection{Areas of Training Needs within BCC}

The key areas in the Local Authority in Bristol where training is considered particularly relevant are:

- A basic Overview of SLE SoS and Renewable/Energy Efficiency Technologies is necessary to enable BCC employees to handle SLE SoS concerns in all areas of the council's activities (e.g. integrating energy efficiency measures by the planning department, installation of charge points by the Highways department).

- Evidence-Based Policy Making skills are critical in practically linking the policy to the renewable technology and commercial delivery opportunities (e.g. given the evidence of EV and the performance of bio-gas fuelled buses, a policy of electrification of Bristol's transport can be put in place). 
- Managing a Large Set of Stakeholders on a Project is likely to become the daily practice in $\mathrm{BCC}$, as within the SLE SoS environment, the interconnected subsystem stakeholders become relevant for other subsystem projects (e.g. time of vehicle charging within the Transport and Mobility Subsystem becomes relevant to heating within the Energy Subsystem).

- Engineering Skills for Management of SLE Projects are essential, as the technically knowledgeable manager is able to make decisions based on facts, rather than on a third party's interpretations and opinions (e.g. which generation technology will best fit the local environment? Is the given platform suited for the data analysis task at hand?).

- Building Partnerships is another critically pertinent skill for BCC, as, given the scale of investment and speed of change necessary for the SLE SoS transition, BCC must work with both private and public organisations, as well as with the citizens directly.

\subsubsection{Modes of Training}

- Learning by Doing is particularly relevant for acquiring the relevant background technical skills (e.g. heat pump installation, etc.) that are then drawn upon for policy/project decision making: "...you really gain that by delivering and installing. ...knowing whether or not that company's good at installing heat pumps ....and how they manage the project is a little difficult to discern from a classroom-based training exercise" (P4). Thus, a short-term secondment of the BCC Energy and Policy team within SLE companies could be very beneficial.

- Peer Learning is both valued and a well-practised mode in BCC: "the Head of Highways [at $B C C]$ is actually willing to send his electrician to London and spend time with the electrician in London 'cause it's about peer-to-peer learning. They wouldn't trust getting this from a manual and they definitely don't trust the manufacturers" (P18). This mode is also supported through groups and bodies set up specifically for this purpose, such as the UK's Core Cities Group [37] and the Association for Public Service Excellence [38], where peer groups for experience exchange and mutual support are regularly convened. In addition, external peers, such as consultants, are often invited to help with learning specific skills, e.g. "... if you need to know other tools then maybe you need to go and get a consultant" (P18).

- Conferences and Workshops are often used to learn about technology and practice: “...the most useful thing I found was going and engaging at conferences ...hearing people talk through live use cases from different companies or research institutes, that was far more useful to me than reading things online because you could go and have a conversation with those people afterwards" (P29).

- Demonstrators are particularly relevant in reducing uncertainty for the planning of novel projects, risk, and the decision making as "...you could go and see this working" (P18).

- Online Courses are also used by BCC staff, where they feel they need to fill some knowledge gaps. These tend to be done voluntarily, in their own time, e.g. "So, for my own benefit I did an IOT course, just to try and get fundamentals and understanding of what that was because it was completely new to me. ...just six-to-eight week courses ..." (P31). To support this further, BCC could select and recommend specific providers to interested staff, as well as account for the necessary learning time within the workload allocation. 
- Internships at BCC are used to support specific scoped project needs (e.g. community engagement; peripheral software development). These provide a valuable opportunity for collaboration between the Council and the City's universities and colleges, as interns are often (yet not exclusively) taken in from these institutions.

\subsection{Insights and Recommendations on Bristol's Local Authority Subsystem}

Having decided that carbon-neutrality by 2030 is a key target for the city, the local authority now has to ensure that the right ecosystem is in place to enable realisation of this target.

\subsubsection{Creating the Local Regulatory Landscape}

The key role of a local authority, such as BCC, is to create the right regulatory landscape within their locality, aiming to deliver against local goals. Given Bristol's decarbonisation agenda, the local authority needs to both address its own skill shortages for the energy transition, and also to create regulations designed to prevent shortages in all other SLE SoS subsystems. This implies that sector-specific regulations need to be delivered for all noted SLE SoS areas (see Fig. 1), and include:

1. Review of all local training provisions for modern SLE content (e.g. brick-free building, financing renewable energy projects)

2. Per Subsystem regulatory review, e.g. for Building and Retrofit Subsystem:

- Clean energy sources to be integrated in all new build (aiming for fully self-sufficient sourcing, instead of the current $20 \%$ rule);

- Clean energy generation and energy efficiency pre-conditions for planning approval of all renovations of the existing housing stock;

- Incentives for energy efficiency retrofit, beyond the current UK-wide funding (e.g. through novel financing and cost sharing models);

- Certification of all involved in building and retrofit activities to ensure the quality of workmanship (e.g. through required upskilling via Futureproof [28] and Green Register [27]);

- Activation of professional position uptake in a variety of roles such as a certified retrofit specialist or a heat pump installer (as these professions are expected to be in high demand in the short-to-medium term) with clear professional progression for the longer term.

\subsubsection{Assessing Quality of City Leap Delivery}

BCC has started the transition to SLE SoS in a strong position, with a competent Energy Service team of approximately 40 in number and an impressive record of innovative energy project delivery and decarbonisation. However, given the estimated need of over "...£1 billion of investment towards Bristol becoming a zero-carbon, smart energy city by 2030" [39], BCC has identified the need for external investment and has initiated the City Leap program of setting up a joint venture to leverage the said investment on a $50 \%-50 \%$ private-public contribution basis. 
A procurement exercise for a Strategic Partner for City Leap was initiated in September 2020. The Strategic Partner (i.e. an organisation or consortium that will work with the council to deliver the investment for energy transition) appointment will be concluded in 2021. The current shortlist for the potential partners (following the review of applicants) consists of [40]:

- Ameresco Limited, with Vattenfall Heat UK Limited as an Essential Sub-Contractor.

- ENGIE Services Holding UK Ltd and Sumitomo Corporation (acting as a consortium), with Abundance Investment Ltd as an Essential Sub-Contractor.

- E.ON UK PLC and Marubeni Corporation (acting as a consortium).

While the joint venture and scaling-up of the investment into SLE SoS transition is an inspiring initiative, BCC needs to ensure that well qualified staff and partners are in place to monitor, access and support the delivery of the City Leap project. As noted above, a practical technical background is strongly desirable for objective assessment of such activities (e.g. assessment of the quality of heat pump installations or retrofit for energy efficiency). Thus, we recommend that $a$ City Leap Quality Assessment team is set up (made up of trained BCC members, as well as independent assessors, such as academic and industry representatives skilled in data analysis and power systems, heat networks, and renewable energy etc.) in order to help the project succeed.

\subsubsection{SLE SoS Training Across All BCC Departments}

With the declaration of the climate emergency in 2018, BCC has effectively committed to full energy transition to SLE SoS by 2030. Within this energy transition project, BCC must also tackle fuel poverty, refurbish the housing stock within the city, reduce transport emissions, bolster the workforce in energy efficiency and engineering areas for the said transition while also maintaining and promoting equitable conditions for the citizens.

The transition requires upskilling the traditional "non-energy" departments at BCC to get them involved with the SLE SoS agenda. Thus, there is a substantial shift in the knowledge and skills underway in most of BCC's departments. Therefore, there is a need for additional crossdepartmental local authority-wide training on SLE technologies, as well as on area-specific issues. (Examples of specific issues are: how to calculate return on investment for finance team members and how to support upgrades for energy efficiency in protected areas for the city planning teams.)

\section{Citizens' Subsystem}

\subsection{Factors Affecting Bristol's Citizens' subsystem}

Drawing on the analysis from the interview data, we have formulated the causal model of Bristol's citizen system, as shown in Figure $8^{12}$, and briefly explained below.

Our citizen data is drawn from interviews and workshops exploring citizens' views and motivations relating to the changing energy system and, more specifically, to aspects of energy demand

\footnotetext{
${ }^{12}$ This model can be simulated through this url: https://energysystems.blogs.bristol.ac.uk/2021/01/08/ citizens-bristol/
} 


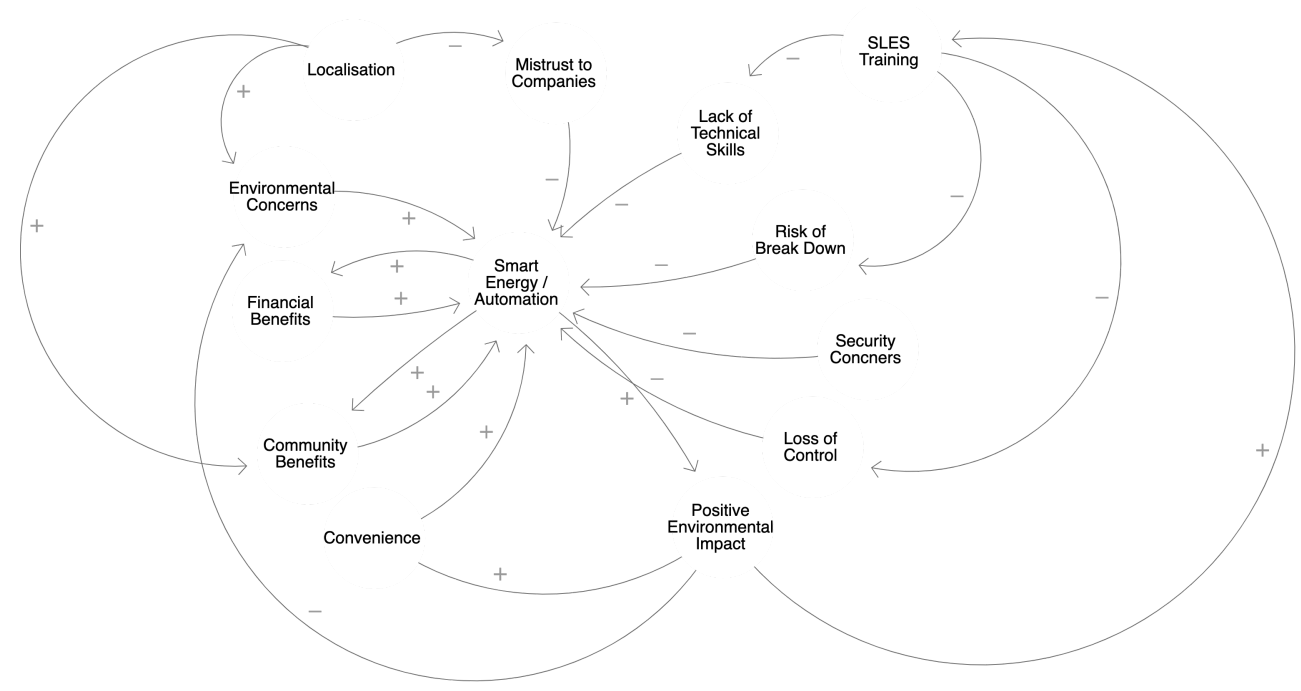

Figure 8: Causal model of Bristol's Citizens' Subsystem.

management and automation of domestic systems. Overall, the respondent Bristolians were motivated by environmental, financial and efficiency outcomes for signing up to energy management and automation.

Many of them said that the environment was a primary motivator, because they want to be supportive of environmental protection as long as is practical within their household arrangements. Some participants said that they were even prepared to cope with disruption and inconvenience if there were positive environmental outcomes, for instance:

"I would sacrifice, you know, if something was maybe a bit disruptive or not perfect, then I would rather sacrifice that to reduce the energy consumption" (PE5).

"I would be very willing to change the way that I do stuff, even at the cost of convenience or money, if that's really going to make a difference" (PE9).

However, given that the personal impact on the environment due to smart energy system use is both intangible and indivisible, the respondents were worried that their actions were not "...really going to make a difference", and many asked that the system should provide feedback on the actual environmental impacts.

Where energy efficiency is a core ambition for users, they are aiming for a better use of resources. Here, the respondents consider automation to be a positive force, as the energy management system can make decisions based on the availability of renewable energy, which will then help the grid to be used more efficiently. Some respondents also noted that energy storage for use at peak demand times and that ensuring electric vehicles are charged when renewable energy is plentiful should be part of the future automation.

Most interviewees wanted to have financial savings, even when their primary motivation was environmental, for example:

"Obviously I do want to save the world. But I don't want it to cost me" (PE7).

"I suppose environmental issues which would be the main driver and benefit, save me money as well, that'd probably be a second factor" (PR11).

Some interviewees noted that financial return is expected in recognition of the effort put in by 
the householders, the disruption of their routines, and for getting to grips with a new system, e.g.:

"It doesn't sound like it will be that inconvenient. If it was massively inconvenient, then 'no'. l'd want more of a financial incentive. So 'yes', it's a sliding scale of inconvenience" (PE6).

Here, they also noted the parallels with other sectors:

"It's a bit inconvenient, but l'll have the food delivered at 10 o'clock at night. Oh, l've got to stay up, but it's $£ 2$ cheaper" (PE10).

"That's kind of the standard model for a lot of things, isn't it? It's like flights or you know, Uber" (PR2).

Furthermore, a number of participants recognised a degree of social responsibility to engage in managing energy better, both for supporting current users and future generations, e.g. Participant PE9 notes "...if you're looking socially irresponsible to not do it then that would motivate me."

\subsection{Trust, Risk, Complexity and Loss of Control}

In our discussions of the likely benefits and problems envisaged due to the use of an automated system, the main themes emerging were related to trust, complexity and risk. Some themes found from the interviews are reported below:

\subsubsection{Trust}

Through the interviews, trust came up in different guises:

\section{a. Trusting a system to work properly}

Lack of trust that the system would work as expected seems to be backed up with direct experience of technology use and by other people's stories of things going wrong. For instance: "I just don't trust computers generally, and their ability to continue doing the right thing. You know? Because they go wrong, don't they?" (PE7). "I only like to use that when I'm there because recently my friend's dishwasher set her house on fire" (PE6).

Clearly, once such a story is embedded into "common knowledge", it is difficult to change and it gets repeated and spread around.

\section{b. Trust in the operator}

The 3rd party system and service providers must be trusted to make the right decisions for the benefit of the users, although such a trust still needs to be earned, e.g. "I don't think l'd trust an outside authority to make those decisions for me" (PR4).

Respondents were more inclined to trust the local authorities or academic research, rather than the big businesses who were seen as chasing profits. "I'm with Bristol Energy so I trust them. If I was with one of the big six, I might be a bit reluctant to let them have it [energy data]. Yeah it probably depends who's supplying my energy" (PR11).

\section{c. Trust in use of data}

Data privacy was an underlying concern, but it was also one that most participants didn't feel that they had much control over.

Many respondents accepted the idea that energy companies could hold and use detailed data, especially if it helped them to manage supply and the grid better, thus doing good for the planet: 
"for the common good, not for the private benefit" (PE1) "if the main aim is to save energy, it's about doing something good" (PE10).

However, to others, the need to make data available might be a demotivator for participation in energy management:

"I can't say l'm enthusiastic about it, no. It would act as something of a demotivator. If I thought the whole thing was a really great idea, maybe l'd accept that, but I don't really like the idea" (PE9).

\subsubsection{Risk}

Participants were concerned about several aspects of the risks involved:

\section{a. Risk of Financial Loss}

The respondents wanted to have some assurance that the smart energy system either generated rewards or, at the very least, ensured than no penalties were passed onto the households.

\section{b. Risk of System Malfunction}

The risk of system malfunction (e.g. causing appliance failure, overheating, or damage) or incorrect operation (e.g. starting up a remotely controlled appliance at an inappropriate time of the day) was noted by several participants. To counter this (to some degree), the respondents suggested that the smart system should be able to inform users of various issues which could cause malfunction/failure (e.g. need to deep clean appliance and filters; detection of a power surge or burnout; over-capacity loading, etc.).

\subsubsection{Technical Complexity}

The respondents were concerned about technical complexity and their own technological literacy (e.g. "I'm not techno savvy so I probably wouldn't do it anyway because I just switch things on and let them do their thing." (PR7); "I just don't trust computers generally, and their ability to continue doing the right thing. You know? Because they go wrong, don't they?), which impairs their willingness to engage with the smart energy systems.

\subsubsection{Loss of Control}

The respondents were worried about losing control over their daily lives and their ability to use the appliances as and when they wanted (e.g. "like you're kind of losing control over what it's doing, that you don't know" (PE 2) and "I don't kind of like the way that's sort of managed and how everything speaks to - you know, there's a lot of wireless technology involved in that isn't there, which is slightly worrying?" (PE12)).

\subsection{Provision of information}

The participants said they wanted more information on how much energy is used, on savings, on environmental impact, etc. Feedback is thus extremely important for engagement. The system should show energy / CO2 savings and potential benefits, enabling users to think differently about their consumption. Greater knowledge should mean that energy is used more consciously, thus enabling people to make changes and improvements to their own practices. 
"Information about those peak times and how much energy is being used nationally at those times, and my average daily and weekly usage. Information like that would be good, because I haven't got a clue." (PR3).

Other information might include how much energy is wasted when using standby or leaving lights on. The system could suggest the best way to use appliances, give an overview of how energy has been used and how these compare with (relevant, comparable) others.

"I think there should me more sort of advice about how you can be more efficient and that sort of thing. And maybe sort of tailored to you, rather than just random" (PE7).

\subsection{Training needs for the Citizens' Adoption of SLE}

\subsubsection{Areas of Training Needs}

The SLE SoS skills deemed relevant by our interviewees to the citizens of Bristol are summarised in Figure 9 and are briefly explained below:

- SLE overview, uses, implications and engagement processes: what the SLE SoS are, why are they replacing the traditional energy system, what could householders do to benefit best from the SLE SoS (e.g. invest into battery or roof-top PV, etc.) and how.

- Opting in and out of SLE services: where SLE SoS provide optional services, the households should be able to choose which services to take up or refuse.

- Preferences setting: what the customisation options when participating in SLE SoS are (e.g. demand side response, peer-to-peer trading, etc.)

- Manual override for automation options: where 3rd parties control any in-house appliances, what can be manually overridden and how, if necessary.

- Security Procedures for successful SLE SoS participation: where the security threats are and how to avoid pitfalls.

- Privacy Settings with SLE technologies: where the privacy concerns are, and how they can be handled (e.g. data sharing and ownership).

- Knowledge of who to contact for which issues and where to find this information is necessary to help alleviate the worries of the householders.

- Knowledge of what warranty and guarantee provision is available for SLE SoS services and activities and how to access these will be equally relevant in alleviating financial loss concerns.

- A set of "How to" procedures to help householders navigate the concerns on how to:

- monitor company activities;

- observe the environmental impacts of SLE;

- monitor their own financial gains and losses due to engagement with the SLE SoS;

- observe the impact of SLE SoS on the community. 


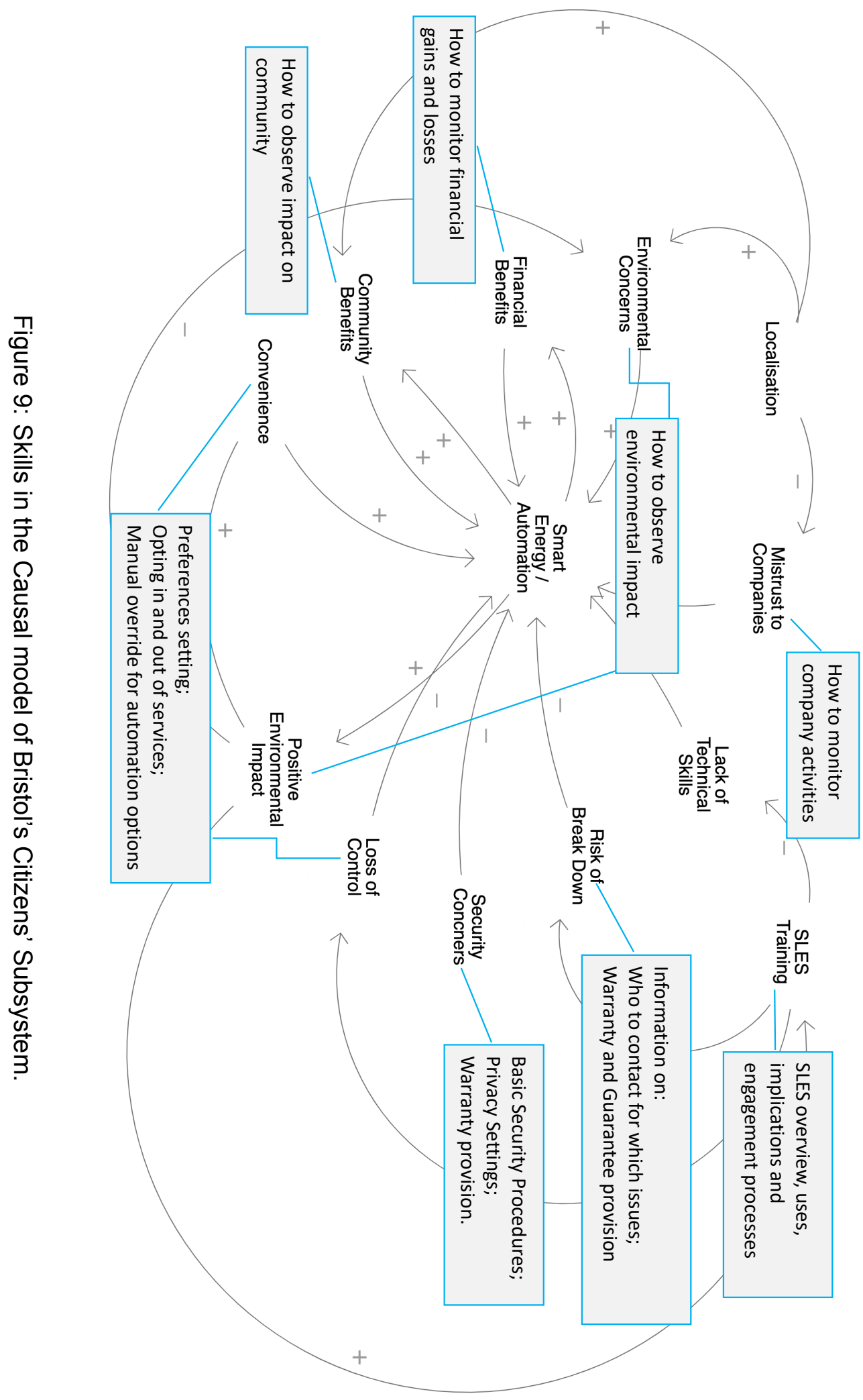




\subsubsection{Modes of Training}

Given that the knowledge of and willingness to engage with the SLE SoS needs to be communicated to citizens of all parts of Bristol (including the current minors who will become adults by 2030, current property owners and investors, as well as tenants of all ages), the training modes must be adapted accordingly. Thus, training should be delivered:

- To all, via media campaigns, explaining the structure and aims of the SLE SoS, overview of technology, opportunities and impacts, as well as where and how to look up further information. This can be achieved through television, radio and social media advertisements (akin to the UK-wide 'Don't Drink and Drive' campaign);

- To school children: more detailed understanding of the SLE SoS as a system, its key technologies, their roles and their impacts. This can be integrated within various areas of the school curriculum (from science to citizenship);

- To property tenants, explaining the available SLE SoS services' opportunities, costs and benefits, via energy service delivery companies, citizens' advice services, the council website, post and community groups.

\subsection{Insights and Recommendations on SLE SoS for Citizens' Subsystem}

\subsubsection{Citizens are the Foundational Subsystem}

While the Citizens' subsystem is the most "informal" (i.e. least organised institutionally) out of all the SLE SoS subsystems identified in Fig.1, it is also the most fundamental one: ultimately all professionals (including those in other SLE SoS subsystems) as well as those outside of the current workforce, are citizens. Thus, if the citizens, as a whole, are well-informed, willing and able to engage with the SLE agenda, the progress of this agenda across all other subsystems is also assured. Consequently, all efforts and costs committed to engagement with and the education and training of this subsystem are well worth the investment for all involved.

\subsubsection{Channels for Impact}

Several channels for access to citizens within this ecosystem (as noted above) are the broadcast media (i.e. television and radio) at the local and national levels, and their related social media outlets; citizen information and advice services, as well as utility providing companies. However, additional channels within Bristol can be engaged for the maximum impact, including Bristol's:

- Citizen Assembly;

- Extinction Rebellion and other environmental groups;

- Community / neighbourhood groups;

- Museums (such as We the Curious, where permanent art and technology exhibits can be commissioned on SLE SoS and their technologies for children and parents);

- City events, whereby activities (such as art competitions or Treasure Hunts) can be arranged around SLE SoS projects, etc. 
All of these channels will require the appropriate engagement materials to be prepared and shared. This report contains a set of simulation models, which is the kind of engagement and exploration material that could be informative for a wide set of users. However, much more of the relevant material must be developed and distributed at speed.

\section{Transport and Mobility Subsystem: Findings from Data Analysis}

\subsection{Factors Affecting Bristol's Transport and Mobility subsystem}

Drawing on the interview data analysis, we have formulated the causal model of Bristol's transport and mobility subsystem, as shown in Figure $10^{13}$, and briefly explained below.

Our interviewees note that, whilst the common perspective is that a smart transport and mobility system implies the adoption of electric vehicles (EV) across private and public transport, this does not quite hold within the transport and mobility sector in Bristol. In fact, alternative fuels, such as bio-gas (as used by Bristol's First Bus company) and hydrogen are perceived to be more viable solutions for local public transport (e.g. P10: "Biofuels in Bristol are quite big; they've got quite a few biofuel buses. When I say 'they', I'm talking about First Bus because they're a predominant operator."). This is motivated by the state of practice in the EV battery sector, as well as by the local geographical characteristics of Bristol. As noted by one interviewee (P10):

...We've had lots of problems with electric vehicles ... when we put the bid in, there were several electric minibuses on the market. By the time the project started, most of them had been withdrawn from the market because of battery life issues; and in Bristol particularly, it's very hilly. Within the bus industry, there's some scepticism about whether electric buses will ever really become mainstream.

EV adoption for private and fleet use (e.g. for car clubs or delivery fleets) is also impacted by concerns about battery life, as well as by the availability of charging points and the overall vehicle price. Furthermore, while fleet operators opt to install their own charging points (so as to maximise asset utilisation and reduce risk of dependency on others), private EV ownership is impeded by the lack of charge points around Bristol. Similarly, a lack of qualified EV engineers for vehicle maintenance is a concern for both private and fleet operators.

On the other hand, many citizens of Bristol are very concerned about the environmental impact on their lifestyles (including the use of fossil fuels for transportation), and this motivates their transition to electric bikes and vehicles. The BCC policy of a clean air zone in Bristol city centre, as well as the drive to address Climate Emergency challenges, drives adoption of EVs within taxi services and other car fleets.

Another hurdle for Bristol's car fleet operators' adoption of EVs is in the challenge of formulating a business model that would deliver sufficient value. This is challenging in Bristol, in particular due to the insufficient population density with large distances and non-grid road layout, both of which render the multipoint-to-multipoint (i.e. shared taxi) and other similar models unworkable. Clearly, additional revenue streams (e.g. from selling energy to the grid or providing frequency response services) would be a welcome addition to such fleet businesses.

\footnotetext{
${ }^{13}$ This model can be simulated through this url: https://energysystems.blogs.bristol.ac.uk/2021/03/08/ transport/
} 


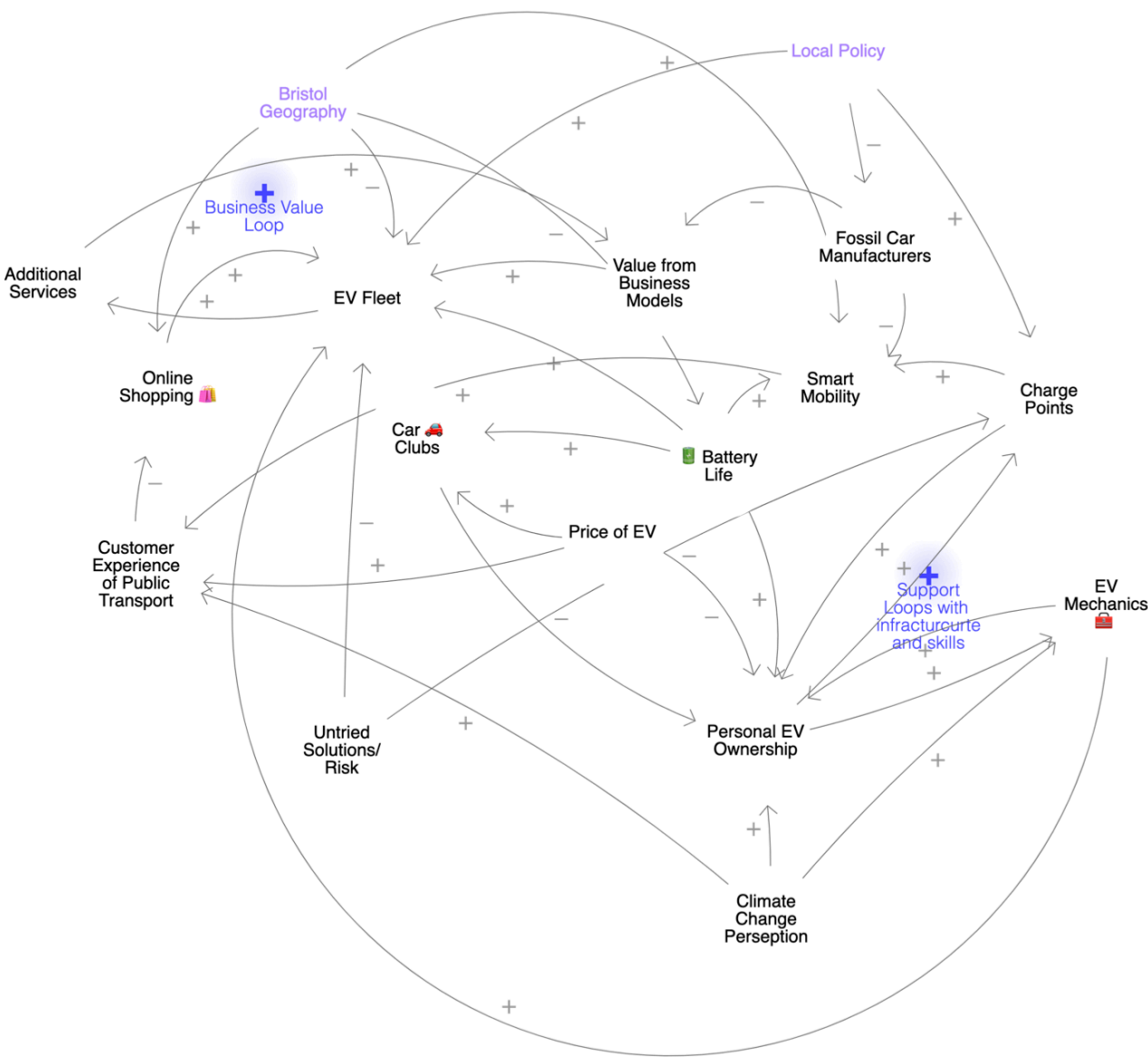

Figure 10: Causal model of the Bristol's Transport and Mobility Subsystem (factors local and specific to Bristol are presented in purple).

\subsection{What skills are needed for the Transport and Mobility Subsystem presently and in the future?}

The skills deemed relevant by our interviewees to each of the areas of Bristol's Travel and Mobility ecosystem are summarised in Figure 11 and are detailed below, while also being aggregated into generic types.

\subsubsection{Engineering Skills for the Transport and Mobility subsystem}

Engineering skills are noted to be the most in-demand and hard to come by within the Transport and Mobility sector. Here, a wide range of Engineering skills are required:

- Software Engineering skills are short across all areas of the software life cycle, including:

- Requirements Engineering, where the engagement for requirements elicitation is often carried out by non-technical people which leads to a "big decoupling" of what is expected and what the technology can deliver (P20); 


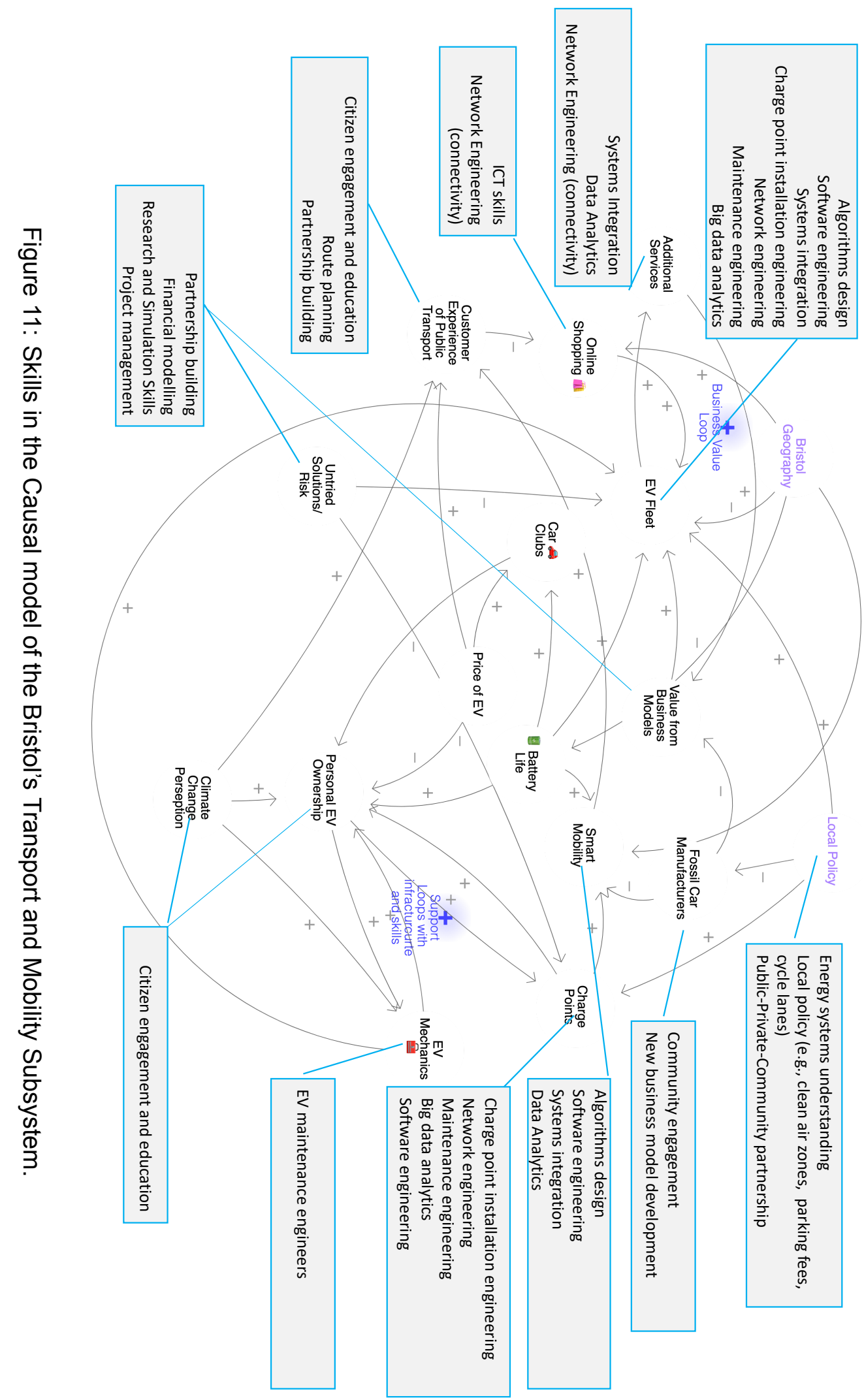


- Software Systems Architecture, where various components must be integrated to construct a software system;

- Programming, where fluency in various programming languages is expected, e.g. "Node developers are quite a premium" (P21),

- Deployment, where dependency on external conditions and user experience must be accounted for "putting a big burden on the user and ...that's what you want to avoid" (P20), etc.

- Systems Engineering and Integration requires accounting for interoperability between technologies (e.g. P21: “...connect it to this and it will be easy-peasy and then when you actually get to do it, actually these little challenges pop up."), their reliability, maturity, security, as well as their adherence to the expected (industry or company) standards, e.g. "The charge points that we looked at, they all claimed to be OCPP 1.6 compliant ....the reality is they didn't" (P21);

- Algorithms are designed for a wide variety of activities: from route planning to resource use and optimisation, e.g. "...our algorithms can be used to forecast the energy demand and then match that to when the vehicles need charging, but also in terms of when they need to do their deliveries" (P20);

- Data Analytics learn about the "big data and ...behaviour" (P10) of software system users, and publicise the results, etc.

- Networking and Telecommunications skills ensure that the various devices (such as EVs, charge points, energy pricing system, etc.) are able to connect and exchange data in a secure way.

- Electronics Engineering skills are deployed in hardware components design and integration (e.g. microchip integration into electric bikes (P20)), etc.

- Multidisciplinary Collaboration skills are also required of engineers in this domain, as EV systems pool together skills from various areas: e.g. "you might be a mechanical engineer, but you're also working in software electronics ..." (P21).

- Research and Simulation Skills should be applied to evaluate possible scenarios both of technical viability and of societal behaviours as well as their impacts.

\subsubsection{Energy Domain Skills for Transport and Mobility subsystem}

- Understanding of Energy Domain and Technologies is considered relevant to those working in T\&M domain, as "...in effect, an electric vehicle is just a mobile battery on wheels" (P21), and when not used for transportation, would serve as a battery to both supplement the owner's income and help with the energy system demands. Although much of the engineering knowledge and skills in the energy domain remain unchanged (e.g. how to measure current), a whole host of new renewable energy technologies have emerged and the public should be acquainted with these as well (P20). 


\subsubsection{Trades Skills for Transport and Mobility subsystem}

- Installation engineers are required for installing telemetric units, cameras, charge points, etc.

- EV Maintenance skills are growing in demand as more fleets and private car owners are moving away from fossil-fuelled to electric cars.

\subsubsection{Managerial Skills for Transport and Mobility subsystem}

- Partnership building is essential as there are many stakeholders involved who need to trust and coordinate with each other: "you've got people like charge point manufacturers, you've got energy utilities and you've got vehicle manufacturers. ...I think if we can try to remain technology agnostic ... we could be a little bit more credible when we say, perhaps you should consider this type of charge point ...So I think in terms of forging those relationships ....we're going to have to do that as well as the actual technical delivery" (P21).

- Technical Project Management is "...desperately lacking from industry, ..." but where this is in place and "...the engineers [are] also the project managers ..." (P20), the project runs better and more smoothly.

\subsubsection{Finance Skills for Transport and Mobility subsystem}

- New Business Model Development is imperative for many stakeholders within the T\&M section, as the traditional route operation or car/taxi services are becoming less and less viable on their own“ ...Via, for example, has a tie-in with Mercedes Benz who are looking at creating a new market for their vehicles because they see car ownership as reaching a point where perhaps it's going to go down ..." (P10). Thus, various income streams are to be considered and combined into a business model.

- Financial modelling is relevant when planning on revenue stream integration (e.g. from car clubs, multipoint-to-multipoint taxi service, to using EV batteries for vehicle-to-grid energy trading and grid frequency support). Since the geography of a given locality will have an impact on the viability of the smart mobility model (e.g. the low population density and nongrid layout of Bristol make multipoint-to-multipoint service unprofitable (P10)), the income, costs, and constraints of each service would need to be modelled in order to set up a viable T\&M business.

- Creating Value from Data is a "challenge and a skillset" (P21) of identifying monetisation opportunities of data while keeping to the privacy and security regulations (GDPR) and other organisational constraints.

\subsubsection{Policy Skills for Transport and Mobility subsystem}

Here, the respondents noted the impact of local policies as well as identifying several areas where necessary regulations are missing:

- Local policy (e.g. clean air zones in Bristol, restricting parking and increasing parking fees, building city-wide cycle lanes and networks) provides a positive impetus for transition away 
from the fossil-fuelled transport. Thus, linking up such policies to the local needs and changes is a valuable skill.

- Compliance with the Regulations on Charge Point Standards is, at present, voluntary. This makes it impossible to ensure that all the various charge points within Bristol are interoperable, which increases the risk to EV asset utilisation and forces the EV fleet owners to invest in their own charge points. This, in turn, makes the transition to the EV project even more expensive. Thus, a regulation for installing only OCPP (Open Charge Point Protocol) standard compliant chargers within a given locality (i.e. Bristol) could help break this barrier to a better local EV adoption.

- Lobbying for SLE SoS Transition in Transport and Mobility is about engaging with pressure groups (e.g. Transport Focus), understanding travel habits, constraints, and opportunities so as to influence the local and national authorities to foster SLE SoS transition in the T\&M sector.

\subsubsection{Legal Skills for Transport and Mobility subsystem}

- Regulation on Cybersecurity is noted as a key open issue to be addressed for the smart EV charging and control: "...cyber security is a bit of an open door that they [the regulators] haven't really considered ..." Should a charge point be hacked, it would lead to "...huge reputational damage". The current state of cybersecurity controls within T\&M is said to be "...the equivalent of just leaving a window open and a ladder" (P21).

- The skill of Transferring Previous Learning is missing, e.g. in transferring learning on regulation around smart meters and their security to the EV charge point domain. Such learning and transfer of skills could help to legislate for a deregulated, yet also interoperable and trustworthy solution, for EV charge points.

- Handling User Data in a GDPR-compliant way is another missing key skill: T\&M companies must learn to share, exchange and monetise user data while also complying with the GDPR. The current lack of skills to interpret this regulation leads to a lack of collaboration and business development around the data sharing/use opportunities.

\subsubsection{Soft Skills for Transport and Mobility subsystem}

- Communication with Citizens on Technology is often challenging, as there is a gap in understanding between technologists and non-technologists, and communication is often undertaken by people who do not understand the technology well themselves. This can be overcome by undertaking communication through a " ...team of people who are not just doing the technology, but are also doing the engagement” (P20).

- Engaging People with Engineering is another critical skill set, as the ever increasing need for engineers is a certain trend for transition to SLE SoS. Although this is challenging, such an engagement can be carried out through "...engineering outreach and trying to engage with ...the wider public" (P20). 


\subsection{Training needs for Transport and Mobility System}

\subsubsection{Areas of Training Needs}

The key areas in T\&M where training is considered to be particularly necessary are:

- Engineering, or more specifically, Software Engineering, Electrical and Electronics Engineering and Systems Engineering. This is not surprising, as within the SLE context, Transport and Mobility is one of the core subsystems, which both provides transportation service, and also acts as a massive distributed battery system which stores electricity generation, provides flexibility services (e.g. by deferring or pushing forward the charging times) and regulates grid frequencies. Thus, engineers must be trained to deliver and maintain this smart subsystem. A highlighted focus is placed on such skills as:

- Requirements Engineering (so that the right system is built);

- Systems integration (so that the various components, such as EVs, charge points and pricing systems, can exchange data and exercise control);

- Programming, so that various monitoring, learning, control, and evaluation solutions are developed.

- SLE SoS and Renewable Energy knowledge, helping to show how T\&M interacts with and contributes to the SLE SoS agenda at large;

- New Business Model Development, so that commercially viable organisations are set up and endorse the agenda for T\&M in SLEs;

- Developing Local and National Policy that furthers T\&M in SLES agenda (e.g. clean air zones; charge point installation only for OCPP standard products with cybersecurity considered essential).

\subsubsection{Modes of Training}

When discussing how training should be delivered, the respondents noted a variety of training modes and levels, given that both highly-skilled and generic trades skills are needed. However, under the SLES, the T\&M sector is becoming more skilled and more digital:

- Higher education degrees are considered to be prerequisites for many roles. For example, the algorithm developers (e.g. for resource/route optimisation problems) are expected to have PhD degrees; those working with telemetries and data analysis would have an MSc or a Bachelor's level qualifications - mostly in ICT or Electronics Engineering and Power Systems/Energy. However, university education is also sometimes considered to be too theoretical and graduates are expected to supplement the degrees with practical experience.

- Further education colleges and HND qualifications are relevant for those employed on the "shop floor" (P21) of the manufacturing sections of the T\&M firms;

- Internal Training at a Company is utilised where there is a "business case" (P21) for extra training and external training providers are invited to deliver short courses. However, in SME's “...there aren't enough people for everyone to have a specific task" (P20) so each worker tends to be trained in a few specialities; 
- Placements and Secondments are considered to be a good way (for undergraduates) to supplement their theoretical university degrees. The sandwich year/year with industry programmes are considered to be particularly beneficial, as these allow for the students to get a good grasp of the jobs they could step into following their graduation. Shorter term placements (e.g. 6 weeks to 3 months) are considered to be less productive.

- Online Courses, such as those from Linked-In Learning, are noted as a way of keeping upto-date with relevant topics, as is "micro training" (P10) through listening to Blinkist which "abbreviates books on all sorts of topics into a 15-minute précis of the key ideas and just gives you an insight into all of that value" (P10).

\subsection{Insights and Recommendations on Bristol's Transport and Mobility Subsystem}

The transport and mobility sector is comprised of a large set of assets including the road and rail networks, traffic control equipment, vehicles, refuelling and maintenance stations, public transport etc. When transitioning to the SLE SoS context, much of the assets and infrastructure stock will remain, although the vehicle stock, refuelling and maintenance stations would have to be replaced. In addition, a new control infrastructure would need to be developed to integrate the EVs and their charging stations into the core of the Smart Local Energy System.

\subsubsection{Transport and Mobility - Core SLE SoS Subsystem}

As previously noted, EVs are "batteries on wheels" (P21). Presently, these 'batteries' and their charging stations are becoming tightly integrated into the electricity grid, both as electricity consumers, and as a distributed storage, flexibility providing and frequency regulating component. The intersection of these two subsystems (i.e. electricity and T\&M) has already begun to grow. In the medium to long term future, these subsystems are likely to become very tightly coupled with transport and mobility becoming a core part of the electricity grid.

From the skills perspective, such a tight integration will lead to the emergence of new professionals: those with strong backgrounds in both Energy and Transport/Mobility. Demand for such professionals has already emerged in smart mobility companies, and will continue to grow.

\subsubsection{Behaviour change}

Decarbonising transport is one of the biggest challenges we face in the transition to SLE SoS. Unlike transitioning to renewable electricity which has been mostly hidden from consumers, transport decarbonisation requires both significant behavioural change to shift away from vehicles powered by diesel and petrol, and the development of a new infrastructure.

\subsubsection{Infrastructure Development}

To support infrastructure development, many local authorities have already committed substantial investments into charge points. However, given that vehicle asset utilisation is dependent on charge point availability, and EV car mechanics, the car fleet operators see risks in the likely unavailability and lack of compatibility and security in the type of charge points they'd need. Therefore, they find it necessary to invest in their own charging stations, which increases the cost of EV adoption by fleet operators and businesses. 
In addition, the transition requires development of new safe walking and cycling networks, as well as new ride-sharing models.

From a skills perspective, the ability to define local (and national) policies that de-risk investment into EVs, as well as reducing the cost of transition, is highly sought after. In addition, engineers and tradesmen who will install, maintain and operate the infrastructure will need to be trained.

\subsubsection{Change of Vehicle Stock}

The change of fossil-fuelled to electric car types in private ownership is mostly impacted by the high price of electric and hybrid cars, concerns about the lack of charging point availability, as well as worries about costs and availability of car maintenance services.

Indeed, EV car maintenance skills are expected to be in high demand by all respondents, and thus, are an area of a high training need.

Furthermore, the better integrated the EVs become with the electricity grid, the more positive impact they can have on the decarbonisation agenda of Bristol. Thus, a wide-spread training and education initiative is necessary for informing and engaging the general public (see more in section 5 ) with the transition agenda via exchanging their personal cars to EVs, electric bikes and alike.

\subsubsection{COVID-19 Impact}

While the recent lockdowns and restriction of mobility within the UK has affected all transport and mobility businesses, it has also served as a growth impetus to many areas of smart mobility. In particular, areas that work with retail delivery (optimising resource use and route planning) have continued to grow.

For the T\&M skills from SLE SoS perspective, there has been a notable increase in demand for algorithm designers and programmers who would understand both the transport and the electricity subsystems' state and dependencies.

\subsubsection{Local Geography Impact}

Given the current properties of the commercially available EV batteries, we observe that the local geographies have a profound impact on whether, and if so, what kind of EV ecosystem would develop within a given area.

For example, with the low population density and 'hub-like' structure of Bristol's roads, multipoint-to-multi-point ride sharing schemes would not be viable in Bristol. Moreover, the hilly physical landscape would poorly suit electric vehicles that carry large loads. Thus, the hilly landscape of Bristol makes it more likely that bio-fuels/bio-gas/ or hydrogen are more likely to be adopted for bus services and city service vehicles (e.g. recycling and refuse collection).

\subsubsection{Scale Up Concerns}

While the T\&M sector in Bristol is well placed in the transitioning to SLE SoS agenda, our study participants noted several factors that might impede this transition, namely:

- The hardware within the SLE T\&M sector is still somewhat immature, in that many charge point manufacturers do not keep to the OCP (Open Core Protocol). This, in turn, both complicates interoperability between various charge point makers, and also impedes provision of sufficient security guarantees to the infrastructure users. 
- Scale Up through Public-Private Partnership for local authorities was discussed in section 5. A similar set of partnerships (e.g. for charge point operators and EV fleet operators) can be initiated within Bristol's City Leap project for the T\&M sector too. This will help to scale up investment, as well as de-risk longer term returns for such an investment for the industrial partners.

- A Pro-Active Local Regulation which promotes the SLE SoS T\&M agenda (i.e. more clean air zones in the city, parking charges and space regulation, opportunities for participating in "battery services to grid" initiatives for the EV owners, collaboration with local universities and colleges on teaching and training provision targeting local needs, etc.) will also foster a smoother and speedier transition.

\section{Community Energy Subsystem: Findings from Data Analysis}

\subsection{Factors Affecting Bristol's Community Energy subsystem}

Drawing on the interview data analysis, we have formulated the causal model of Bristol's community energy system, as shown in Figure $12^{14}$, and briefly explained below.

Community Energy groups are engaged in a wide variety of energy projects: from wind turbine and solar PV array installations (e.g. Bristol Energy Co-operative, Ambition Laurence Weston) to building and installing home retrofit for energy efficiency (e.g. ReWork, Owen Square Community Group) and offering advice for fuel poverty alleviation (BEN). Consequently, the set of occupations and skills relevant to the success of these groups is also very broad, in that it ranges from builders and project planners to legal experts and entrepreneurs.

At the same time, there is "quite a lot of knowledge lying around from the renewables boom" and "people that had their own businesses" (P4), who can all join community energy projects. Thus, many of the skills needed for such projects can often be found within the communities themselves (as in the positive link between Local Skills and Community Energy Projects in Fig 12).

Nevertheless, community energy groups would always have to invest in some skills. When such needs arise, many smaller community groups face skills gaps in their daily activities, despite the skills being available on the market. This is because the smaller groups do not have the finances available for procuring such skills. As stated by P19: "we just cannot provide the few thousand pounds that it would cost". Skills noted as available yet expensive within Bristol's context are:

- Consultancy support (focused on tender/project proposal writing);

- Legal advice;

- Neighbourhood planning with architects and city planners;

- Marketing support.

\footnotetext{
${ }^{14}$ This model can be simulated through this url: https://energysystems.blogs.bristol.ac.uk/2021/03/08/ community-energy/
} 


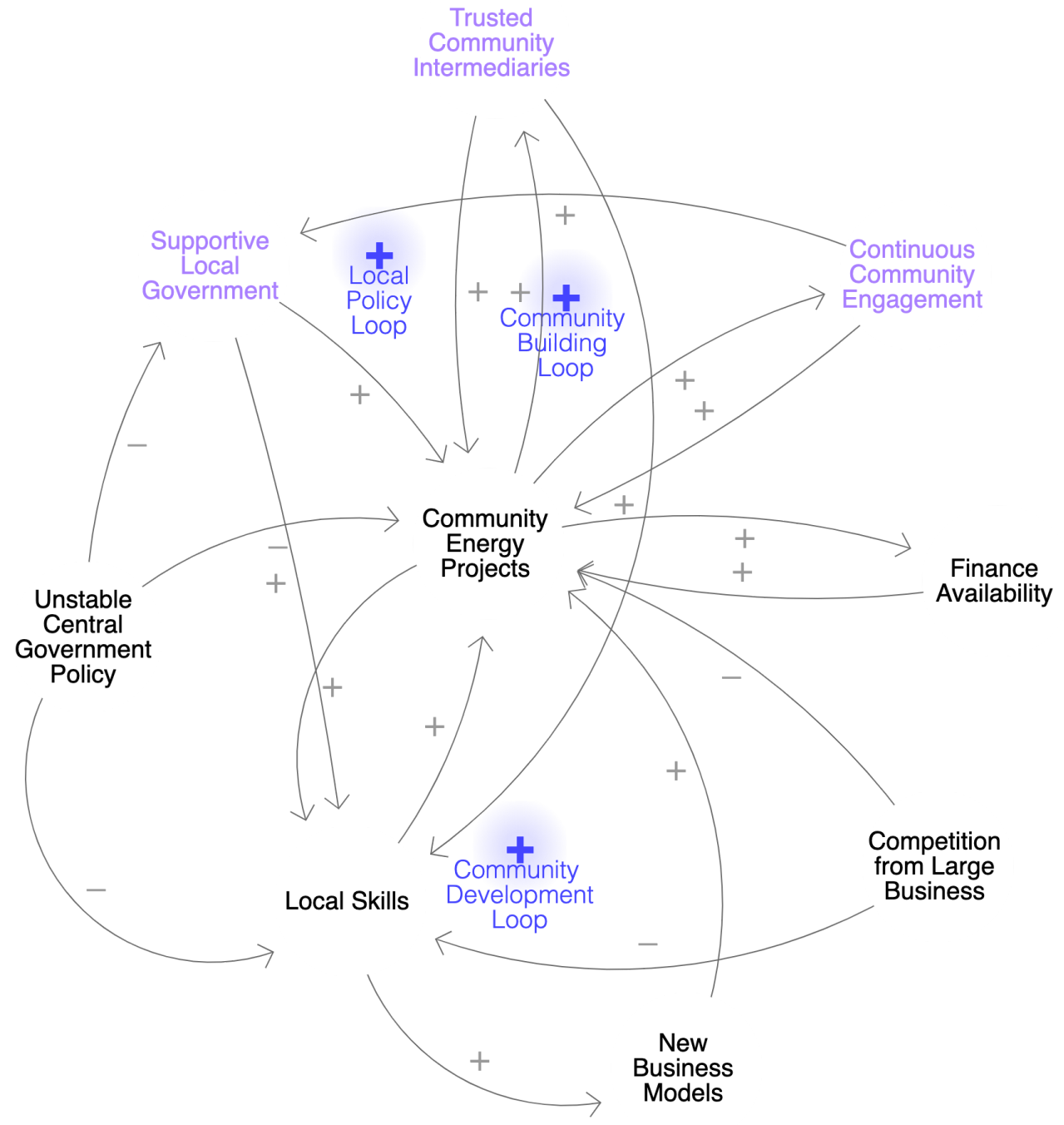

Figure 12: Causal model of Bristol's Community Energy Subsystem (factors local and specific to Bristol are presented in purple).

In Bristol, some of these services are made available to community groups in a limited supply on pro-bono (e.g. legal support) or subsidised (e.g. CSE consultancy) basis. However, these are insufficient to meet the need and therefore, the availability of such services is lacking, and negatively impacting on community energy projects.

Furthermore, community energy projects face continuous competition from larger, better funded developers in a variety of areas. For instance, larger developers are able to offer better terms and conditions to landowners for renting land for energy generation installations, where they get better terms for financing from investors and are perceived to be more credible service providers to customers.

Unstable policy directions taken by central government with regards to renewables and community energy sectors have a negative effect on local skills as well as on the success of community energy scheme. For instance, many skilled solar PV and onshore wind turbine installers are cur- 
rently out of work, as the cut in tariffs has resulted in reduced demand for their skills; wind turbine production businesses have also moved out of the UK. Growth of many community energy projects that focused around the installation of community generation assets for income from the Feed-in Tariffs (FiT) scheme has also stalled.

However, the community energy groups in Bristol are now looking for ways of utilising their skills to develop new local partnerships and new business models which, in turn, lead to further skills development within the Bristol community (e.g. the CHEESE project partnering with the city council to deliver energy efficiency audits for local residents and train local unemployed young people to work as energy surveyors for their communities). (This is marked as Community development loop in Fig 12.)

Of particular note in the case of Bristol city is the role that the trusted community intermediary organisations (such as Bristol Energy Network and Centre for Sustainable Energy) play. They nurture the community energy groups and projects by bringing together like-minded people at various networking events, which sparks collaboration and new project ideas, providing workshops and training sessions, information sharing, advice and coordination services. In short, they foster the development of the energy communities within the city of Bristol. (This is marked as Community building loop in Fig 12.)

Finally, we must note the impact of local policy, (as exercised by Bristol City Council and WECA) upon the local community energy scene. The city council (from setting up its dedicated Energy Team in 2010 to having declared a climate emergency in 2018) takes a very supportive stance towards community energy groups (e.g. making land available for community energy such as ALW wind turbine development, entering into long-term PPA agreements with energy community groups, etc.). This support de-risks investment into community energy projects and allows them to develop, as well as leads to more informed and engaged citizens within the city. (This is marked as Local policy loop in Fig 12.)

\subsection{What skills are needed for the Community Energy Subsystem now and in the future?}

The skills deemed relevant by our interviewees to each of the areas of Bristol's Community Energy ecosystem are summarised in Figure 13 and are detailed below, while also being aggregated into generic types.

\subsubsection{Engineering Skills for Community Energy subsystem}

The majority of community energy (generation) projects have at least one engineer in them. This is not surprising as such groups are set up for energy generation and therefore try to find a suitably skilled technical lead. The engineering skills in the projects vary, including, for example:

- Software engineering;

- Mechanical engineering;

- Power Systems engineering;

- Network Engineering, etc.; 


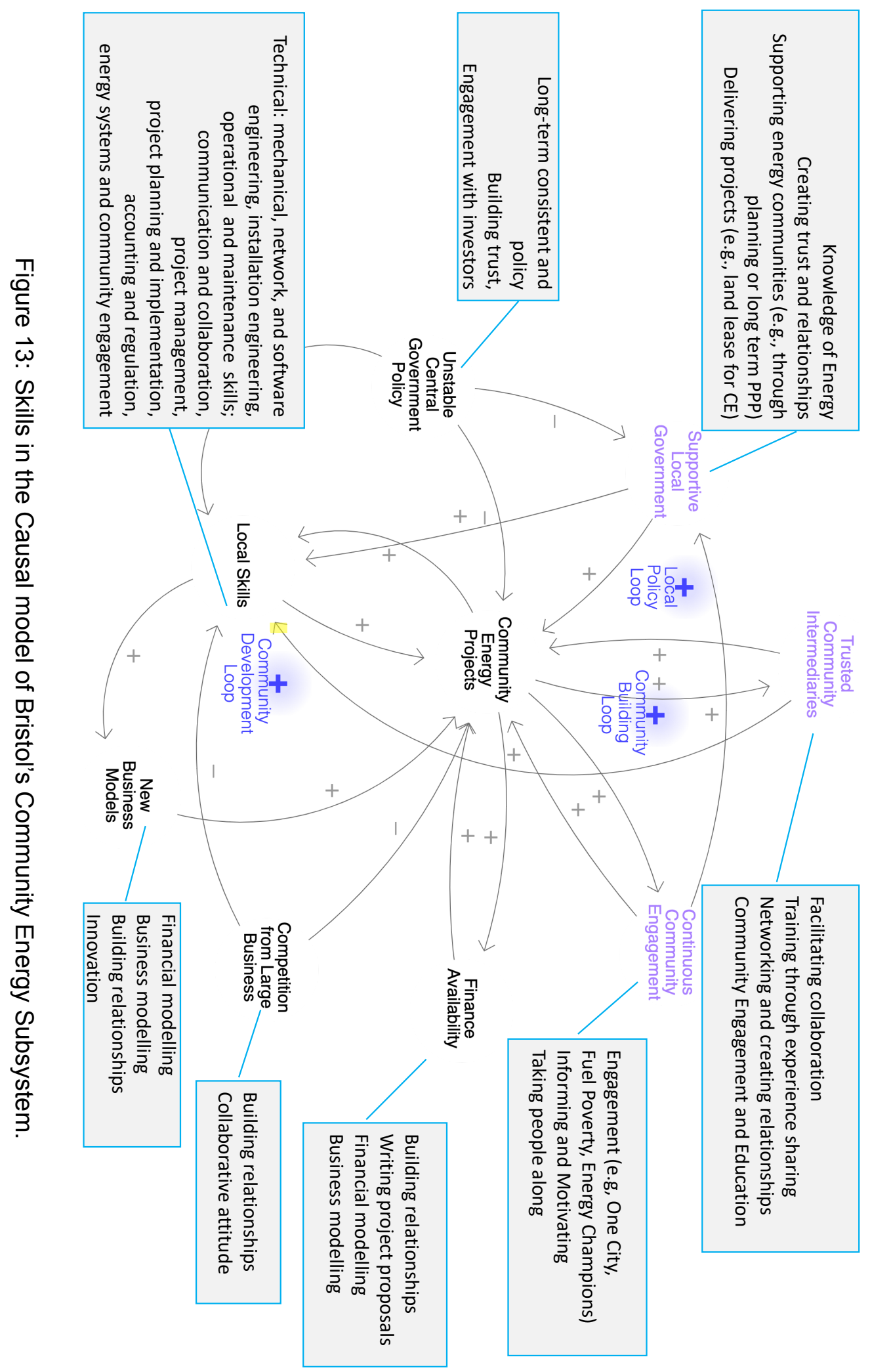


However, it is also not essential for all of these skills to be always fully integrated into the community energy group. Often these (professionalised) skills would be procured by the community groups as and when needed. Nevertheless, one skill which is often mentioned as desirable for the group to have is that of systems integration, so that the group has a clear idea of how their project would link up with the wider energy system:

- Systems Integration skills are lacking within the systems engineering area: "projects are getting more complex. It's not just one stand-alone technology ...how it all integrates and works together, and then how it integrates with the grid. So you've got a multifaceted, dynamic project. And there's not many people ... with the specialism to cover all of that." (P4).

\subsubsection{Energy Domain Skills for Community Energy subsystem}

- Energy Audit skills are essential where community undertakes a retrofit project, "we've got surveyors on board, energy surveyors" (P7). It is also noted that many current energy surveyors do not have up-to-date training, e.g. "my kids were saying to the guy doing the EPC, you've got to look for the draughts. And they were saying, draughts are nothing to do with energy"(P3).

- Delivering Advice on Energy Efficiency is one of the key activities of many community energy groups. However, they also need " really serious investment in our skillset" (P19) to be able to deliver better diagnostics (e.g., for thermal efficiency of homes) and advice.

- Understanding of the localisation of Renewable Technologies: knowledge of renewable technology in general can be sufficiently present within community energy groups, although the localisation perspective is not understood very well. As stated by P19: community energy groups "probably have quite a traditional knowledge of you put up a renewable energy project and it just goes to the grid ....and hopefully we're going to move away from that and keep it in local micro grids".

\subsubsection{Finance Skills for Community Energy subsystem}

- Financial modelling, i.e. "taking on a load of investment and then managing, paying that back" $(P)$, " " there's very poor training on the discounted cash flow analysis and financial assessment of different projects" (P2).

- "Accounting expertise is difficult to find" (P19), though it is not specifically an energy skill, community energy groups cannot operate without it.

- "Understanding and Putting together a Business Model, exposure to a completely new level of risk" (P8) is a particularly desirable skill to community groups in the post-fit world.

- Engagement with investors/Fundraising is another critical point of many community energy projects. While it is easier to raise funds for the better established and well-recognised community energy groups (e.g. Bristol Energy Cooperative can issue shares for a new (investable) project), this presents a real challenge to the newer groups. P 17 "communities need to find that early stage money and that's really, really hard to find because it's obviously 
very risky money." While some community projects generate a return - e.g. through renewable energy generation, others rely on grant funding, volunteers or donations e.g. in giving fuel poverty advice.

\subsubsection{Legal Skills for Community Energy subsystem}

While the community groups, in their majority, buy in (at least some) legal services, they do need to have an overview of some aspects of the legal domain, including:

- Legal Registration Process for groups to get started is scarce, and groups often struggle with "how do we make ourselves official?" (P8). More support in getting started could help with increasing the community group numbers.

- Understanding the Legal Framework in general is another challenge that community groups face, e.g. P19 "there's a lot of different actions involved and a lot of uncertainty around regulations, which are also a big challenge. Understanding the regulatory framework, I find difficult". However, the community groups must also " manage lawyers because ...they'll just keep clocking up the hours" otherwise (P17).

- Reading and Interpreting Contracts is necessary for both choosing the right contractors (e.g. P17: "contractors are terrible as well at coming in with a price and finding all sorts of wormy ways out of it and adding extras"), and striking the best agreements, yet "It is quite complex because you're talking about power purchase agreement from the community group to an energy supplier, power, megawatts ..." (P22).

\subsubsection{Managerial Skills for Community Energy subsystem}

- "Technical management skills and also the technical support skills to support the energy infrastructure" (P19) are needed along with Project planning and implementation skills.

- Writing Project Proposals and tenders, e.g. community groups do not know "how to stand back and to do an overarching consultancy report" (P4). Yet, nearly all interviewed community energy projects in Bristol that are successful have had some grant funding, which has enabled their progress. As previously noted by P17, "communities need to find that early stage ...very risky money" and grants provide an opportunity for handling such risks.

- Risk management requires the community groups to be able to handle " exposure to a completely new level of risk" (P8) as the community energy scene is very dynamic and must continuously adapt to the changing regulations and income/funding opportunities.

- Whole Life cycle Project Management is another relatively unique feature of community energy projects. In these cases, a project manager must get involved in most activities and have a versatile set of skills: from undertaking a feasibility study on identifying a site for potential project development through to commissioning and completion. The project manager must be able to manage lawyers, contractors, as well as having sufficient technical knowledge, and community and customer engagement skills. 


\subsubsection{Policy Skills for Community Energy subsystem}

\section{Policy skills for the community groups:}

- Engaging with policy makers and lobbying skills are currently scarce within the community energy sector, if compared to what industry/large companies possess. Up until now, it is unsurprising that this has not been the focus of community energy groups. To gain more influence though, the groups must learn to exercise these skills more.

Skills required from (local) authorities for successful community energy projects are:

- Long-term Consistent Government Policy which supports community energy activity, would allow for the development and maturation of this sector, as suggested by P4: "there needs to be a clear policy from government, ...there needs to be a roadmap outside of political timeframes. It needs to be a 20,30-year roadmap, so the commercial sector and local authorities and everybody can actually plan for a longer period". This is relevant for both national and local levels. For instance, the BCC policy to discontinue gas boiler installations from 2025 supports the community energy projects focused on energy efficiency in decarbonisation.

- Skills to Integrate Community Energy Activities into Local Authority Plans, or, in other words, driving a local authority policy of involvement and support for community energy projects. This can be achieved through a variety of avenues, such as providing council land for lease by community energy groups at low cost and/or signing long-term power purchase agreements with the CE groups to de-risk investments into them (e.g. as per Bristol's ALW wind turbine project). As stated by P17: "City Leap ... in Bristol is ....an example of the council really taking the bull by the horns and wanting to get the whole city carbon neutral by 2030 and that's going to create loads of opportunities for communities"

\subsubsection{Soft Skills for Community Energy subsystem}

- Confidence is needed for community members to initiate an energy group. However, "people that may be unemployed ... don't have the ...confidence" to start up the projects or engage (P8).

- Leadership is another key quality necessary to initiate a community energy project. As noted by P4 "I think you need that leadership drive. I think you need that person to build it around."

- Engagement (which includes both informing and motivating participation) is essential, and is carried out widely in Bristol (e.g. One City, Fuel Poverty, Energy Champions programmes). However, the community energy groups are "desperately short of engagement and of skilled engagement" (P19).

- Building Trust and Relationships with people is a key skill present in all community energy groups. Trust needs to be present both between the group members, the wider community which is served by the group, and between the group and the contractors with whom the community energy project works. As noted by P8: "Communities ... are very different but can have a key role to play in terms of trust, in terms of using their own social capital to create a transition". Although this particular skill is not considered to be in short supply, it is flagged as a key ingredient for community energy projects by nearly all of our interviewees, and so is noted here. 
- Communication and Negotiation skills are necessary to communicate the message that the community energy group would like to put forward, as well as listening to the community and integrating their views, and negotiating with contractors, authorities and policy makers. As noted by $\mathrm{P} 17$, when starting a project, a group may have "...ten different legal contracts to negotiate, you'd have ten different individuals to explain the idea to ...".

- Collaborative Problem Solving and Innovation, which requires flexibility in thinking and "recognising the intelligences in the room" (P3) is a key strength and another required ingredient of successful community energy projects. Given the volunteer-based nature of these projects and the constrained environment in which they must operate, such mutual respect of contributors and the ability to adjust and the "ability to shift models" (P5) are a necessity.

\subsubsection{Trades Skills for Community Energy subsystem}

Although community groups would not generally be expected to carry out the installations and maintenance work all by themselves, some groups do wish to internalise these skills for their localities. They consider it an opportunity for training the local workforce and also for improving self-reliance of the group and its projects.

- Operational setting up of energy domain hardware (e.g. of solar or wind farms) is also challenging for community groups, particularly for those in "more deprived areas ... because generally they won't have the engineering skills, they don't have legal skills, they won't have experience of running a business ..." (P8).

- Maintenance of generation hardware/infrastructure is required for all community projects, as well as "maintenance operators and ...skilled maintenance managers" (P19).

- Building retrofit for energy efficiency is another basic skill that Community energy groups need in order to support ambitions of energy efficiency, both in providing advice to citizens and in undertaking retrofit effectively (which is supported by the CHEESE project in Bristol).

\subsection{Training needs for Community Energy Subsystem}

The previous subsection details the skills which are in short supply, and so need to have training provision. Next, we highlight some of the key skills training needs.

\subsubsection{Areas of Training Needs}

When considering the successful set up and operation of a community energy group as a (prosocial) renewables-based (or energy efficiency) business, we observe that the training needed for establishing such groups is not different from that of training for any other business set up, although with a deeper "customer base" engagement. Thus, the essential training would include:

- Leadership and confidence, i.e. the ability to communicate, motivate and engage the members of the community with the goals of the community energy group. 
- General Business and Financial Literacy, which includes the abilities to make those financial assessments of "do nothing versus use renewable or energy efficiency solutions" (P2) are essential in members of the community in deciding whether to volunteer for - and champion - the community energy causes.

- Understanding of the Smart Local Energy System, including "what the difference is between the old energy system and the new energy system" (P5), which, in turn, will enable innovation for Developing new Business Models.

- Engaging with Investors both through:

- Fundraising with investors and community;

- Engaging the local authorities as a contributing party; and

- Writing grants and project proposals to obtain funding.

- Whole Life cycle Project Management, whereby the daily activities or developing and maintaining the community energy group and its projects are handled from the start to the end, including:

- Procurement;

- Reading and interpreting contracts;

- Risk assessment and management; and

- Technical project management.

\subsubsection{Modes of Training}

When discussing how training should be delivered, we observe the preference for the more informal, short training opportunities. This is clearly justified, as community energy groups are not considered "professional ventures", yet volunteer ventures instead, with less available time for extensive training. Our respondents noted the following training modes as relevant:

- Training through sharing is delivered by local community energy organisations for the benefit of other community energy groups and individuals. This takes the form of:

- Meeting at local community networking activities, as "the best people to learn from are the people that have done it, so it's that networking amongst community energy groups" (P3) that provides an opportunity to share experiences and identify learning opportunities.

- Online networking events with geographically separated communities with similar interests;

- Open Home events (such as Green Doors) whereby, for instance, energy efficiency or retrofit upgrades completed by some houses are shown to all interested households by the homeowners.

- Questions and Reflection, whereby the interactions and questions between community groups and authorities/other groups lead to "breaking barriers down where oh, you can't do that because we're not allowed ...And just going through that process of getting them to reflect" (P3) builds understanding, mutual learning and provides opportunities for new solutions. 
- Teaching Through Demonstration:

- Informal Demonstration, whereby members of one community see the success of another, and set out to replicate it for their own locality.

- At Formal Demonstration locations, such as the planned Ambition Lawrence Weston's wind turbine's energy learning zone, the learning zone will serve as a place to show and tell to schools and citizens about what the renewable energy projects are.

- Workshops at Community Centres, where community groups/members could bring ideas for project development, and/or learn from other (invited) group representatives about their solutions to common challenges and successes which could be appropriate to replicate.

- Internships with community energy groups or similar organisations (e.g. Centre for Sustainable Energy) are recognised as valuable training opportunities for engaging with citizens as well as developing local talent for expanding the community energy groups' activities. For instance:

- CHEESE project provides internship opportunities for citizens/young people from disadvantaged communities to learn how to undertake energy efficiency audits, while getting a paid-for placement within the project;

- BEN's Energy Champions programme helps to develop an understanding of home energy efficiency, renewable energy technologies and novel solutions (such as demandresponse services) for the volunteer local champions, who, in turn, work with the local communities to educate and engage them with the community energy and retrofit activities.

- Further education colleges are noted as venues where learning about new technologies and practices (such as energy efficiency assessment, operation of community energy generation facilities, etc.) could be taught, particularly to young people. However, it is also noted that some Bristol community groups have "failed in our attempts to talk to ...[colleges about] directing their ...training courses to support our local community in these skills" (P19);

- Apprenticeships, such as a 'Community Energy Specialist' apprenticeship programme, are also suggested as a good opportunity for younger people to acquire skills for community energy, although this is complicated as well. While the local colleges in Bristol are interested in delivering such programmes in general, they " need 12 apprenticeships as a minimum to come through the doors. And obviously each of those apprentices would need an employer to pay for them ..." (P18).

- Learning through Research and Practice with Academia is another relevant avenue as, in collaboration with community energy groups, the universities often support both technical and business innovation development and technical and societal impact evaluation activities.

\subsection{Insights and Recommendations for Bristol's Community Energy Subsystem}

\subsubsection{Risks and Mitigation in Community Energy Projects}

Community energy projects are perceived as presenting many risks. We discuss some of these risks (emergent from our interview study) and suggest mitigation options below: 
- If the community energy groups are new, they have no track record of successful projects, and so cannot prove their trustworthiness as a borrower. This, to some degree, can be mitigated by the trustworthiness of the group members themselves, making sure to demonstrate their professional track record, relevance and credibility of their skills (e.g. "there was someone who'd been in a renewable energy company for 30 years or something. That was very helpful to know [for funding decision]" (P22)). (Necessary skills for CE projects here are: project management, engagement and team building).

- There is little previous evidence of banks successfully funding community energy projects in the UK, which, to the banks, implies higher risk of lending to these groups. Nevertheless, some bank loans have been successful in community energy projects (e.g. "Co-op bank took that risk with the [named] solar project" (P17)). Providing evidence of the successfully funded projects could help to instil more confidence in the prospective funders. (Necessary skills for CE projects here are: research, communication and relationship building).

- Some community energy projects, such as fuel poverty alleviation, are not inherently profitmaking, which makes them unattractive to most funding providers. Although there are some grant funding schemes for such projects, the application is a competitive process which is time consuming and has a low success rate. This issue can be mitigated (to some degree) by setting up a convincing business model, and targeting the funding providers with related interests. For instance, the evidence that retrofit will address fuel poverty concerns could motivate ECO-obliged parties to fund home retrofit projects. Alternatively, combining the fuel poverty alleviation with installation and use of renewable energy generation equipment could pave the way for other business models and funding sources. (Necessary skills for CE projects here are: research and innovation, financial modelling, the ability to develop new business models, as well as communication and relationship building).

- Renewable energy projects tend to have a long (15 to 20 years) repayment plans, while contracts offered within the energy sector are normally assured for much shorter periods (e.g. National Grid's frequency response contracts are for 3 years). This concern could be mitigated through planning for income from several income streams and stacking the finances (e.g. "the battery project for example, we have five different lines on the business case for income to try and pay off that investment" (P18)). (Necessary skills for CE projects here are: creative thinking, financial modelling, the ability to develop new business models, as well as communication and relationship building).

- The small scale of community projects, which leads to dependence on a single income source, can make their business models brittle when faced with change, e.g.:

- change in feed in tariffs can turn a previously profitable project into a loss maker, if the whole project was designed to receive a specific FiT return;

- dependence on a single consumer is risky if the behaviour of the consumer changes, e.g. if a project charges battery use to an organisation, which suddenly outsources all of its ICT infrastructure to a cloud service provider and so does not consume the same level of electricity.

To address these "single point of failure" concerns, the projects would need to build partnerships with other companies/organisations both from public and private sector ensuring that 
they are integrated into a network of mutual support and can diversify their activities, if necessary. (Necessary skills for CE projects here are: partnership building, ability to develop new business models, financial modelling).

- Regulatory uncertainty around renewable energy projects is high in general and even higher for the community energy sector. This uncertainty, to some degree, can be mitigated through working with local governments so that the community energy initiatives are integrated with local government policies and development plans (e.g. as is the case with Devon county at present). The previously noted partnerships and business model diversification activities would also be relevant. (Necessary skills for CE projects here are: partnership building, engagement with policy makers, ability to develop new business models and financial modelling).

\subsubsection{Differentiated Support to Community Groups}

Community Energy groups are not homogeneous; they represent a mix of:

- very well established (nearly professionalised) groups (e.g. “...someone like Plymouth Energy Community, Totnes Rural Energy Community Company, Freco which is Frome, are pretty competent and they have some very good technical knowledge" (P4));

- some small but able-to-succeed groups which focus on one issue at a time as they "have the ability but not necessarily the time to start getting involved in other projects" (P4),

- “...some very small community groups that have some very big aspirations but really don't have the technical knowledge or the ability" (P4).

All groups start with using skills already within the community. As noted by P3: "I didn't know how to build a wind turbine but ...I was able to look at my network and say right, well, [name] is a retired wind engineer. Let's get him involved. And then [name] has just retired, [name] set up the biggest wind turbine company in the world, let's get him involved. ...So yeah, it's recognising the skills that are within people already and how they might be appropriated towards a [community] energy project."

However, they do require some more differentiated support at different levels of their projects thereafter. Thus, the very small and the new groups would benefit most from networking and learning from the opportunities, development processes and requirements that have been faced by more established groups, thus building up their technical know-how, maybe working in "secondment" with the already successful projects.

The small groups with sufficient technical capacity would need support in acquiring start-up capital and project management of their first project.

Finally, the more established groups would benefit from support with business model diversification and growth.

Thus, we recommend that differentiated support in skills types and training modes should be available for the above target group types.

\subsubsection{Skills to be Procured: Challenges and Recommendations}

While many skills can - and are - delivered directly by the community group members to the community projects, it is clear that some skills must be procured from outside. These are either: 
- Professional/highly skilled jobs (such as data-driven management of community energy resources and its integration with the national grid, legal support, etc.), or

- Work requiring specialist equipment use (e.g. cranes for building) and/or qualifications (e.g. electricians).

When community groups go out to procure these skills, they face a number of Procurement Challenges which, we suggest could be addressed through the following recommendations:

- Assuring Quality of Procured Skills: while skills could be available, the community groups are not always aware of how to differentiate the good vs poor service providers. As noted by P8: " there's always somebody out there. It's how well they can do the task and how much they cost, and how you find them as well." Thus, a register of qualified and tested service providers would prove to be very helpful for community groups, if and when they are able to pay for the services.

- Availability of Checking Service: given that small groups have limited financial resources, they often end up doing all kinds of skilled jobs by themselves. However, at times, this leads to them incurring losses if they miss critical issues in completing such skilled work. For instance, P17 recalls that their "project couldn't afford lawyers so we just had to do it ourselves, and we missed a big one ...there was a clause in the contract that allowed the contractor to charge us another 50,000 quid." Thus, a service that checks over the selfcompleted work produced by community groups could be very beneficial.

- Subcontracting without Post-Delivery Responsibilities is another challenge that community groups face when they contract a company and the "companies out there just getting contracts ....and subbing them ...they'll sub it to anybody to get it installed. And the install is poor. The operation and maintenance isn't covered within contractual elements at the beginning, so nobody will come back and fix it" (P4). This suggests that integrating a requirement for post-delivery quality assurance into contracting for community groups could provide a measure of assurance for them on the standard of work procured.

- Access to Consultants by Small Groups is becoming even harder, as noted by P4: "we're having problems getting the right consultants ....and I think around the country, the procurement issue is becoming a key element for us for delivering the rural community energy fund and other bits and bobs, because also a lot of consultants have been snapped up by ... big consultancies who are now hoovering up the knowledge that's out there." While, on the one hand, it is reassuring to see that the renewable energy skills are in high demand across the UK, it would also be useful to ensure that access to qualified services is assured for the community groups as well, e.g. by:

- Stipulating that a consultancy must allocate a proportion of their time to support community groups, if they are to access government contracts;

- Engaging with local academic institutions who can support the projects through qualified engineering/power systems/marketing and other skills either through dedicated funding (e.g. establishing a community group support fund), or as part of training programmes (e.g. through an established community group training fund), or knowledge transfer activities. We should note that dedicated programmes exist with funded PhD 
positions (so called CASE studentships [41]) for research to be conducted with eligible companies. However, there is no such mechanism provided to support community groups, which would benefit from this engagement much more than a company does.

\section{Energy Sub-Sector: Findings from Data Analysis}

\subsection{Factors Affecting Bristol's Energy Sector subsystem}

Drawing on the interview data analysis, we have formulated the causal model of Bristol's energy subsystem, as shown in Figure $14^{15}$, and briefly explained below.

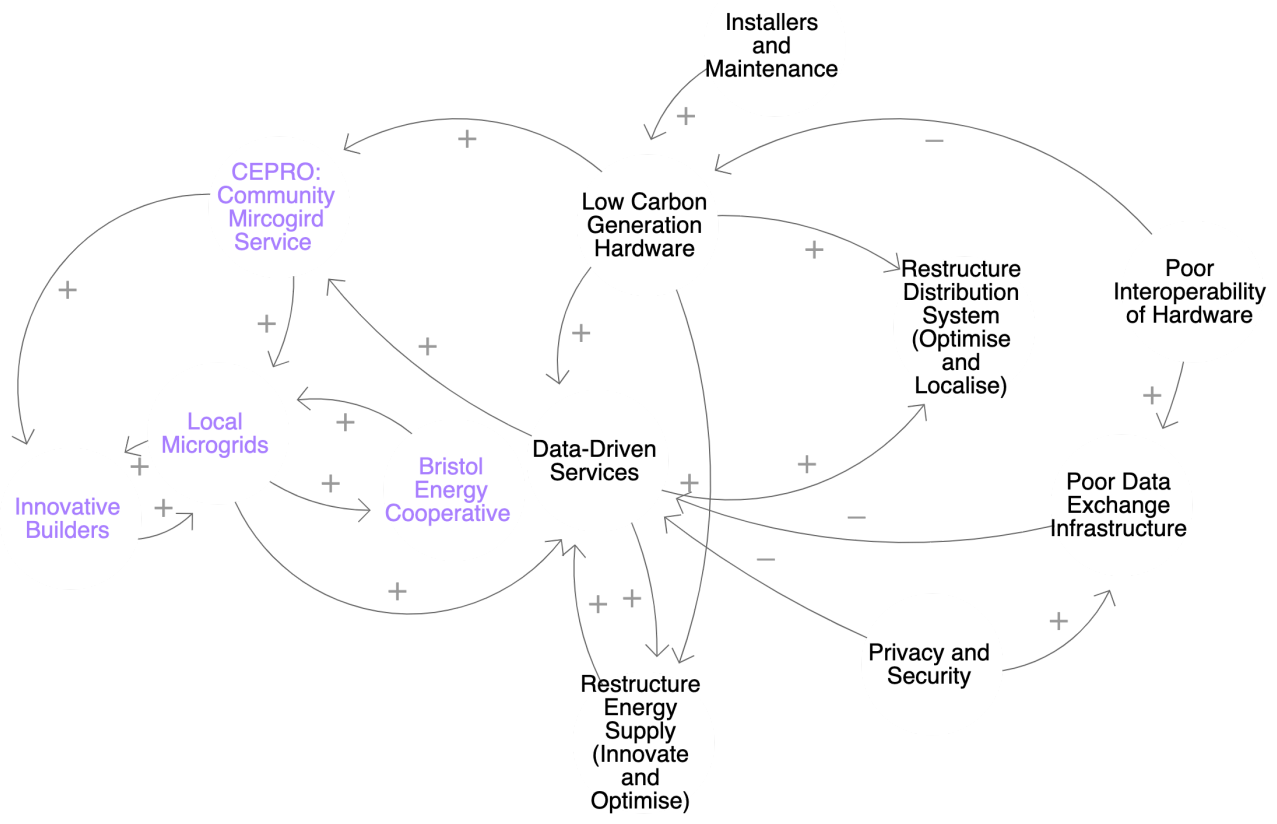

Figure 14: Causal model of Bristol's Energy Subsystem (factors local and specific to Bristol are presented in purple).

The business representatives interviewed from the energy sector in Bristol have demonstrated two key focal factors of transition, both driven by the local and UK-wide carbon reduction priorities, and both leading to the emergence of these new business models: (a) digitisation of energy services and (b) investment into new basic assets.

Figure 14 shows that, as the energy businesses are obliged to diversify from fossil-based generation sources to renewable alternatives (i.e. invest into low-carbon generation hardware), they face the immediate need of engaging with data-driven service delivery. This is necessitated by the:

- Intermittency of generation of these (currently prevalent) non-fossil fuel based sources,

\footnotetext{
${ }^{15}$ This model can be simulated through this url: https://energysystems.blogs.bristol.ac.uk/2021/03/08/ energy/
} 
- Short supply and high price of the current energy storage facilities (e.g. electric batteries, solar to Hydrogen conversion costs), and

- Optimisation opportunities for reduction of upfront investment into the changing infrastructure (e.g. shift household consumption away for peak times so as to avoid investment into reinforcements of distribution lines).

However, given the current lack of dedicated infrastructure for collection, storage, exchange, sharing and monetisation of energy sector data, each company wishing to deliver data-driven services faces the challenge of this type of infrastructure set up. There are many challenges for the setup, as it requires, for instance:

- Installation of various data collection and storage hardware;

- Development of software solutions that enable utilisation and monetisation of data;

- Provision of interoperability between the various hardware components as well as their software interfaces and services;

- Assured checks and balances for regulatory and legal obligations in data use related to both privacy and security concerns, etc.

The above-mentioned challenges of re-investment into assets and tackling the data-driven service delivery issues are leading to a deep re-structuring of Bristol's energy supply sector (e.g. resulting in selling off Bristol Energy as a loss making business by the BCC, as well as the sale of WPD by its American ownership).

On the other side, Bristol has an example of a business emerging whereby the deployment and management of renewable energy and energy efficiency assets drive the business model, without core focus on the additional digitisation services. CEPro [42] - a local microgrid service provider - considers the digital service provision to be a future possibility. Instead, CEPro is focused on integration of renewables-based generation and consumption technologies (e.g. community-level PV array and battery, heat pumps or district heating technology, etc.) into the fabric of the local communal landscape at the construction time. The business then undertakes the management of the energy generation assets, ensuring that the local community benefits from these assets as much as possible, while the excess or shortage in supply/demand is purchased from a partner supplier (in this case, Bristol Energy Cooperative).

It is worth pointing out that CEPro is working primarily with new build communities. Although integration of the same assets into an existing community is also possible, CEPro notes the prohibitively high transaction costs (e.g. due to the need of engaging and onboarding of each dwelling owner to commit to energy efficiency and retrofit at personal cost, as well as agreeing to communal ownership and use of energy resources against new build's working with a single builder and architect).

\subsection{What skills are needed for Bristol's Energy Subsystem?}

The skills deemed relevant by our interviewees to each of the areas of Bristol's Energy sector system are summarised in Figure 15 and are detailed and aggregated into generic types below . 


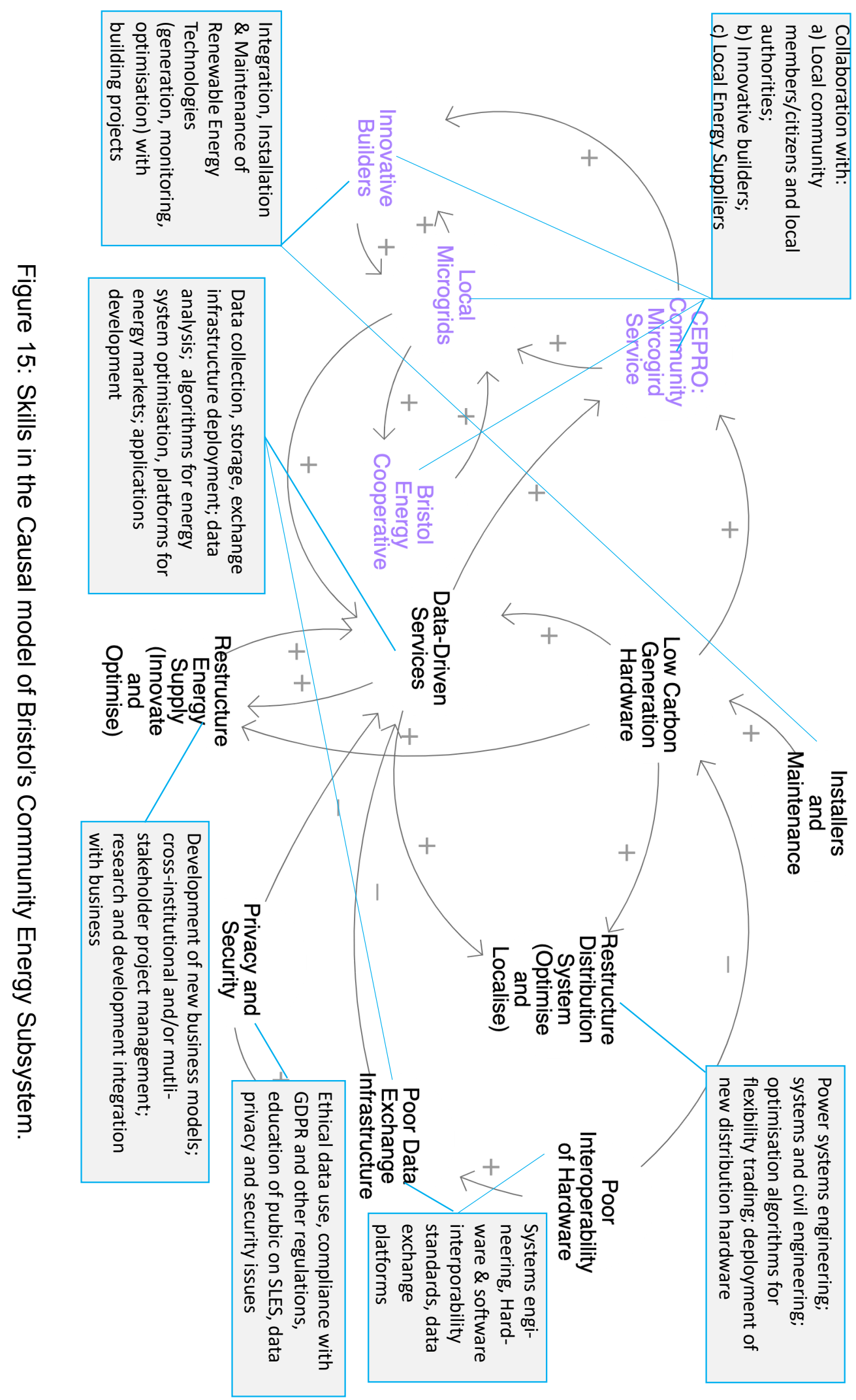




\subsubsection{Engineering Skills for Energy Subsystem}

- Traditional Software Engineering skills are becoming increasingly more in-demand within the Energy sector, as transition to smart systems takes place.

- Algorithms for Energy System Optimisation is an area where " ...there is a lot of sophistication that could be developed for optimisation, trading and improving the value of their hardware" (P2).

- Application Development skills have been in high demand in the energy sector for some time. Since the roll-out of smart meters, many companies have worked to deliver applications which allow their customers to manage their own accounts, view their smart meter data in real-time, and set up the (often mobile) applications as a platform for future new energy services (P9). This trend is set to grow, in line with the increasing need for application development skills within the Energy sector.

- Data-based Systems Management is the underlying aim of the Smart energy system. Consequently, the energy systems move closer to the ICT domain than to traditional mechanical engineering structures. As noted by P9, " ...the more innovative energy companies ....are using IT traditional development type guys ...to work with the data rather than operations." This is reiterated by P24, stating that DSO's "will almost become more of an IT data business than it will an engineering business. ...Most of our issues are sufficient data in the right format, right place, quickly enough, being able to analyse it ..." The specific skills noted include:

- Data Collection is the first essential step for integrating smart behaviour into an energy system. Indeed, the UK has committed to setting up infrastructure for this data collection through smart meters. However, the SMETS1 meters "were all owned and managed individually by energy companies" (P9). Consequently, when a company installed this type of meter at a household, and the household subsequently switched to a new energy provider, the SMETS1 meter data often became inaccessible. Thus, the skills of upgrading SMETS1 to SMETS2 meters are necessary, as are the skills to connect to and undertake data collection from SMETS1 meters; interfacing with the Data Communication Company and Elexon for regulated data submission and access. Moreover, for real time access to data, skills for additional hardware installation (e.g. consumer access devices) may be needed, as well as skills for engagement with customers in compliance with the data-related regulations.

- Exchange of Data between customers and the energy sector companies as well as between the various companies themselves is a necessary, albeit challenging process. On the one hand, the customers must support the "data requirements" (P24) of the companies, as they "both send them data and they can send us data and information ...getting them to actually properly interface with us is the harder bit." On the other hand, the data often underlies the business model of a SLE company, and so providing access to that data for other businesses could undermine their own competitive advantage. Meanwhile, at the same time, for the SLE SoS ecosystem to operate as a whole, the data must be exchanged across all of the system stakeholders. Thus, knowing which data to share, what and how to aggregate and anonymise, is another key emerging skill.

- Cross Domain Data Integration is seen as the necessary step in harnessing the smartness of the energy system. The energy sector notes that "...lots of data is already 
gathered in areas that we'd want to bring ...together: ...energy city-based data, so traffic for instance, air pollution, ...mobile data ..." (P9). The sector needs skills both to integrate these datasets and also to define models that optimise how the subsystems from which these data come could best work together.

- Data Analysis and Machine Learning are noted as the key "...skillsets we really need" (P24) in the traditional energy sector. Such analysis is often supported with statistical and mathematical data handling skills. In particular, the DSO's are "...just starting down that path of machine learning yes. I would say we're in the baby steps of that area at the moment." (P24).

- Currently Data Security is "a big area ...to research further" (P9) for the energy sector stakeholders. This is because energy data protection and use is regulated, and, even more significantly, because all new energy services are centred around data. Thus, securing data storage in both hardware and software, controlling access to it, and monetising its use in a secure way is one of the key challenges within the energy sector.

- Ethical Use of Data is mandated through various regulations (such as the GDPR) and enforced by "Ofgem, who would be sense-checking whether we [the companies] were doing that ethically." (P9). To support this, consumer rights and interest protections must be engineered into the data management systems, and engineers must have a sound understanding of what and how to implement, as well as knowing how to set up a clear data governance structure and plan.

- Platforms for SLE are emerging as the markets for SLE service delivery, data purchase/sale and customer relationships management develop. For instance, WPD uses this type of platform for flexibility contracts trading, while Bristol Energy (in collaboration with Eliq) was considering a mobile platform for potential customer data management and new service provision.

- Delivery of the in-house platform is an open challenge for the energy companies, as presently most energy companies use platforms "provided by a third party". However, they "... will look to bring that in-house in the next couple of years". This is the practice used within the traditional energy companies who "...do that with most things in terms of when it's a new area, we might well use an outsource provider to start with, but we look to bring it in-house as rapidly as we can" (P24).

- Interoperability of Systems and Models, with its integration into the SLE platform is another challenge, as "... a lot of research is required from ....an interoperability perspective" and "... lots of data is already gathered in areas that we'd want to bring everything together. But it's kind of managing those systems on a systems by systems basis" (P9) that remains to be handled. This brings along many challenges, such as the granularity of the data collected (e.g. some parties may have one reading every 30 minutes, others collect data on a per-second basis), reliability of data sources, compatibility of various models, hardware, software languages, measurement units, etc.

- Power Systems Engineering remains a keystone in all energy systems engineering and transition, yet some areas here are noted to be of concern, such as:

- System Behaviour Analysis and Control (i.e. understanding of the "... behaviour of networks, behaviour of system protection, behaviour of generators connected to the net- 
work" (P24)) is a traditional Power Systems Engineering skill, which remains in high demand in the energy sector. However, "...there is a smaller number of universities that still teach those areas. And equally, even those universities that teach it, they tend to be options so therefore the number of graduates which take those options is smaller as well" (P24). Thus, the traditional energy companies see skills shortages arising in this respect.

- Electrical Hardware Integration skills are also in high demand for the new kinds of hardware technologies that need to be integrated to form SLE systems. While the "...hardware is mostly off the shelf with top-enders like Tesla or Solar Edge", the engineers may need to have skills for "...developing glue to link all the hardware" (P2), focusing on power systems aspects of integration.

- Systems Engineering skills underline the need to consider the energy systems as a whole, including the interconnections of hardware, software and human aspects within this large and complex system-of-systems.

- Hardware Integration skills underline the need to integrate various energy systems devices, for example, from solar water heaters to $\mathrm{PV}$, ventilation within a single home to district heating systems and transmission and distribution networks of the national grid. Here, the Mechanical and Electrical engineering skills and power system engineering skills must come together with construction and retrofit.

- Software Integration skills relate to the need to integrate various software solutions into a joined-up system of monitoring and control, for example, from smart meter and battery charging data viewing apps for households, to EV charging stations and weather forecasting applications to help set right electricity prices in real time and charge/discharge EV batteries, etc.

- "There is a real lack of Interdisciplinary Skill-sets", whereby " all the pieces are there but the weak spot is the interdisciplinary trade of being able to assemble it" (P2). This refers to the ability of the engineering disciplines to work together, as well as with the non-engineers in delivering an integrated, well-functioning system-of-systems for SLE.

- Research and Development is one of the priorities within energy businesses, as innovation is seen as the only way to remain competitive. While all businesses are undertaking innovative projects across the whole spectrum of SLE SoS, with the engineering skills discussed above needed for all these projects, a specific skill noted to be missing for R\&D projects is:

- Back Office Integration with Innovation Projects. This is essential for the success of innovation projects, yet "...lots of people overlook those boring aspects of innovation projects when they're very integral to the successful delivery" (P9).

\subsubsection{Trades Skills for Energy Subsystem}

- Installation skills are not always rare, but are often lacking in quality. For instance, even for smart meters, "installing smart meters is still a relatively new thing for installation engineers" and the energy companies "...have to work with a third-party and we don't pay them enough for them to give us the good installers, so we've had a lot of problems with ...installing" 
(P9). Given that the volumes of installation of renewables technology must scale up, and it is a relatively new technology, ".... what we really need is just lots of deployments of more advanced systems" (P2) to bring the skills levels up, as well as to establish clear supply chains for the technologies. The specific installation skills mentioned in our interviews are listed below, though other renewable technology installations are equally relevant:

- Charge Point Installation;

- Heat Pump Installation;

- Heat Network Installations;

- Smart Meter Installation.

- Skills for Construction for Net Zero are also still in short supply. These are relevant for the delivery of smart energy services, though building itself is not carried out by the Energy sector. These include both specific skills such as Building to Passive House Standards and skills for Systems Integration: "So the electricians can do the electrician thing and the heating people can do the heating thing and the architects can do the architects thing. ...So I think it's like all the pieces are there but [again] the weak spot is the interdisciplinary trade of being able to assemble it." (P2).

\subsubsection{Managerial Skills for Energy Subsystem}

- Managing New Business Models, while supporting the business transitioning is an implied skill in the whole of the SLE SoS, the new business models (e.g. as outlined under Finance Skills, similar to those based on the value of data or integration of microgrids into the construction fabric of the communities, etc.) require flexible management skills, if they are to succeed.

- Large Scale Project Implementation Management skills are particularly relevant, as the majority of the SLE projects are large scale, multi-stakeholder and long-term. Although these skills are neither novel nor specifically unique to the energy system, they are still at a premium, as they require well-qualified and experienced professionals to undertake:

- Cross Institutional Management, whereby several businesses may be collaborating or even joining together to deliver a project (e.g. Bristol's City Leap project creates a joint venture between the city and the net zero delivery partner(s)).

- Setting Up Common Systems and Processes is a particularly relevant skill where multiple stakeholders/organisations must collaborate across their specific platforms, which are likely not to be accessible to each other. The project manager must then find a way for the parties to share information and collaborate, despite the platform incompatibilities or access restrictions (e.g. "I kept everything in a Google Drive that everybody could access and [even] that was actually really difficult, getting everybody from different organisations to be able to access the same systems so that they could see data." (P9)).

- Skills of setting up Cross-Team Collaborations are also in short supply, as "teams don't work well enough together. They're very siloed in their ambitions and their project planning" (P9) and it is the project manager's (often ignored) responsibility to bring these teams together. 
- Preservation of Historical Knowledge is another skill which has suffered from underinvestment, yet it is essential in long-running projects, as those working on (and newly joining) the project need to understand the reasons and evidence for past decisions, as well as the progression towards the set goals, especially if projects (like SLE developments) last for several years.

- Stakeholder Management skills in multi-stakeholder projects (e.g. with over 10 stakeholders engaged into a newly built microgrid development) cannot be over-emphasised, as all stakeholders must be involved, communications channels set up and progress monitoring and support established.

- Research and Development management skills are particularly relevant in the current energy systems, as they undergo whole-scale transition. Some of these skills are:

- Working towards Roll Out of Innovation Projects for adoption within the company. If not accordingly propelled by a champion (e.g. manager), an innovation project with promising results may never be rolled out if it is considered to be "ahead of its time", or benefits are likely to be received directly by the customers, rather than the company (P24).

- Aligning Innovation with Business Priorities to foster the likely roll out of the innovation project, as well as increasing the chances for the project's success. Without this type of alignment, the innovation projects would likely fail as they will clash against "other priorities that just couldn't be moved" (P9).

- Sharing R\&D Leanings Across the Company, so "...that learning and those skills" obtained from focused project work by a small team "would go back into the business" and "become part of how the business works" $P(9)$.

\subsubsection{Energy Skills for Energy Subsystem}

The energy company interviewees in our study did not flag many concerns about skills specifically related to the Energy domain (beyond the engineering and other skills discussed previously). The only notable exceptions were skill shortages in district heating and flexibility engagement of community energy groups.

- "District Heating more generally has quite a lot of skills gaps in the UK" (P9). This is not surprising as the UK has not been actively using this technology until very recently. Thus, BCC is looking for commercial partners (e.g. Eurovia [43] and Vatenfall) from outside of the UK to deliver Bristol's district heating projects.

- Engagement of Community Energy Groups in Flexibility Services is hampered as "...their skill levels are quite low" in delivering and using flexibility services and "...they're not as fleet at foot as some of the commercial organisations" (P24).

\subsubsection{Finance Skills for Energy Subsystem}

- Skills for Development of New Business Models, including, for instance: 
- Business Models Based on Value of Data, whereby real time data is becoming central for managing the energy businesses (e.g. data on "...24/7, 365 operation" and skills to "...look at that and can decide what is needed when" (P24)). Thus, the data suppliers (e.g. " ...car manufacturers or possibly aggregators, .... with portfolios of electric vehicles ...trade in terms of both location and volumes of energy" or "suppliers or aggregators ...[who] contract directly with the customer and then provide the service ....at a more aggregated level" (P24)) need to be identified and integrated into the business models, along with the costs and benefits of these arrangements.

- Business Models Based on Building Dwellings with Integrated Microgrids, whereby either the new build or retrofit projects are designed so as to integrate community level generation, storage and heat systems, which supply the needs of the given community, as well as delivering additional services (as necessary) to the wider grid. Here the community level aggregator (such as CEPro) acts as the energy service manager as well as the initial financier of the project.

Irrespective of the business model selected, the finance skills needed are:

- Raising funds for the projects;

- Financial modelling for the projects;

- Comparing the Net Present Discounted Value of alternative renewable-based projects.

\subsubsection{Legal Skills for Energy Subsystem}

- Contracts Preparation skills are needed whereby the legal professionals are able to account for the real (rather than perceived) risks brought about due to the renewable technologies and new business models. (e.g. contracts are to be set up between energy companies and 3rd party data providers, such as, aggregators, EV car manufacturers, charge point operators, community microgrids, etc.)

- Handling Data under Data Protection Regulation, as well as with the protection of own business interests while also allowing for the SLE ecosystem to operate, is a challenging task. Overprotection of data prevents other stakeholders from new service delivery, as well as the data owners from value creation on the basis of their data (e.g. "So having access to the data that they [WPD] CAN share with us if they want to was quite difficult" (P9)). However, over-sharing could lead to business losses too. Balancing these priorities is a skill which is currently missing across all of the SLE SoS subsystems.

- Regulation of Heat is currently only voluntary, thus, "... a lot of existing heat networks don't really worry about regulation". However, this "...will become compulsorily regulated eventually" (P9), thus, energy companies should upskill in working under the regulated heat conditions.

\subsubsection{Policy Skills for Energy Subsystem}

- Local Authorities SLES Delivery Skills, in particular when engaging with the challenge of handling the distribution network constraints, are noted as lacking for BCC. As noted by P24: "The ability of Bristol City Council to deliver has never been that great, has been our experience ...I don't know whether it's budget constraints or resource constraints within Bristol of 
actually converting that aim and desire into reality, which is the problem, or not. But something makes it slow in Bristol." It was suggested that having "sufficient funding, and a permanent project team who don't change their personnel too often" charged with the responsibility to deliver the specific net zero objectives would foster a better delivery at BCC.

- Setting Policy on Subsidies for Renewables "has been a mess for years and it remains a mess now" (P2). This, in turn, prevents larger deployments for SLE. Skills for clear, longterm policy making in various areas of renewables (akin to solar FiT) are much desired.

- Skill in Local Authority for Future SLE SoS Scenario Planning is currently lacking in many local authorities. The distribution companies, such as WPD, could provide support for this to the local authorities (e.g. "...help almost hand hold to some extent on how to produce some of these plans" (P24)). However, the national regulator must decide if DSO's are to take on this role: "...questions for our regulator in terms of, do they want us to do that process of helping local authorities get these plans in place to help deliver overall net zero? Or do they see that as someone else's role ..." (P24).

\subsubsection{Soft Skills for Energy Subsystem}

- Collaboration across Teams within an Organisation is a missing skill in many 'established, traditional' companies, which precludes successful innovation and change. (For example, as commented upon by P9: "our plan was to essentially bring a load more data into the company and we didn't engage with the smart metering team who would have to gather that data. And we didn't engage with the IT team who would have to process that data before we planned this. It got worked out and we resolved some of those issues but we didn't make friends to begin with and that's a really important thing to do.")

- The skills of Engaging Citizens into the innovation projects undertaken by the energy sector are particularly relevant to the energy utilities (like Bristol Energy), but are also necessary for other energy sector companies, as their innovations need to be grounded in what the customers need/want.

- Educating households/ general public on topics of SLE SoS for them to:

- Overcome fear of Smart Systems and Data Sharing, as “...the fear of smart and the fear of data and the fear of big brother is huge and massively outweighs the benefits that people see" (P9), which prevents SLE adoption;

- Gain Financial Literacy on Costs and Benefits of Renewable Energy Alternatives, so that householders could make informed "assessments of do nothing versus ...[renewable installation] pathways forward" (P2).

- Understand the Uses of New Technology so that they can "change behaviour", e.g. about their car use or EV charging patterns (P24). 


\subsection{Training needs for Energy Subsystem}

\subsubsection{Areas of Skills and Training Needs}

The key areas where skills and training are considered to be particularly necessary in Bristol's energy sector are:

- Power Systems Engineering with new technology integration. Where the traditional Power Systems skills are still essential, training on integrating and utilising new technologies (such as microgrids, hydrogen supply, etc.) is still limited.

- Software and Systems Engineering for Energy Sector as the energy sector is transitioning from a largely mechanical system to a software-intensive socio-technical one. Thus, hardware deployment with connectivity to data collection and transmission networks is necessary, along with (presently often) custom-based hardware to support such networking availability (e.g. even smart meters are to be augmented with consumer access devices). On the software side, the industry needs reliable data analysis and service delivery platforms, applications for user engagement and information, along with algorithms for assets utilisation optimisation. It must be noted that training for all of these skills is currently delivered within the Networking and Computer Science/Informatics disciplines. The key challenge is in attracting well-qualified individuals into the energy sector.

- Data Scientists for Energy Sector also need to be trained, as data is fast becoming the key driver of innovation in SLE as well as the essential ingredient for collaboration across the SLE subsystems.

- Installation needs for various renewables and low-carbon technologies, such as charge points, heat pumps, heat networks, and even smart meters is continuing to accelerate. Thus, training for new installers is becoming critical, if a bottleneck in skills availability is to be avoided.

- Managing multi-stakeholder, large scale implementation projects is another aspect where training is beneficial. This is because the SLE projects both require the participation of many stakeholders, and tend to last for a long time, with stakeholders often progressing with their semi-independent agendas. Managing such projects requires skills in integration, knowledge sharing, coordination, and the creation of a long-lasting project identity with shared goals, outlasting individuals/stakeholder participation.

- Developing, Trialling, and Roll Out of New Business Models is another area that should be support with training provision, particularly within the incumbent energy players. Given the long history of slow change within the traditional energy sector, many incumbents find the current fast-paced changes challenging. To avoid business breakdown (which came to pass in the case of Bristol Energy Co., for instance) innovation in service delivery with various models must constitute a core daily part of the energy business. Thus, training in formulating sound business models, trialling, and rolling successful cases out to the wider business is a very relevant need.

- Training in Handling Energy Data is relevant to engineers, managers and the larger public. Here, skills in data protection, aggregation, sharing, and monetisation need supporting. 
- Policy \& Regulation for speedy and supported transition is the skills area needed within local and national authorities. Here, it is paramount to have long-term policy stability for new technologies stimulation, funding support and regulatory enforcement.

\subsubsection{Modes of Training}

When discussing how training should be delivered, the respondents noted a variety of relevant training modes:

- Universities are noted as particularly relevant for engineering and technical education (e.g. the undergraduate and graduate degrees in Power Systems, ICT, and Maths were pointed out as the most relevant by WPD). However, the energy sector has other close engagement and training collaborations with the universities, including:

- Training through the IET (Institution of Engineering and Technology) Academy, whereby the "IET actually looks at the universities in terms of the courses they provide in power engineering and their suitability for the sorts of roles and jobs we're looking for." (P24). The Academy also mediates as companies "...sponsor students through their university degree as part of that process looking to recruit them at the end of that", and also delivers "summer vacation training ...they [students] get a bursary plus they get paid over the training periods ...during the summer" (P24);

- MSc Projects, with " students ...coming each year to do Masters theses" (P2) based on the ongoing and completed innovative SLES systems (such as the Owen Square microgrid of CEPro);

- Joint Research Projects with companies submitting joint research bids with the universities to undertake new research.

- Apprenticeships: "rather than just looking at the graduate intake ...[the companies] are also looking at the more technician type level" (P24) through apprenticeships in "traditional skills, line build, cable jointing" and more recent "schemes for cybersecurity and for IT type areas" (P24).

- External Training Providers (such as ETAL) are often employed to help employees (particularly the newly employed recruits) to provide the "detailed knowledge that they need" for specific job roles.

- In-Company Training is also used, particularly where the training is expected to be "...benefiting the company for a longer period of time" (P9). In such cases:

- Trainers/Consultants would be hired "to come in and do that training for us" (P9). In the longer term, the companies would often "...look to bring it [i.e. skills and 3rd party platforms supported by those skills] in-house as rapidly as we can." (P24).

- On the Job training would be used, in particular, when new roles and responsibilities are emerging for the first time. For instance, when WPD were to move from a DNO role to a DSO, they "...took people and effectively they learnt on the job in terms of what was needed for those areas” (P24). 
- Sharing Experience Across Organisations is carried out through pilots/demonstrators, or presenting/discussing their own experiences at conferences and workshops:

- Pilot and Demonstrator Projects are a valuable source of evidence on what and how the new technologies can deliver. Unfortunately, "There aren't really a lot of pilots around. ...So we're not really seeing the outcome of those pilots yet" (P9). These, nevertheless, are useful for all SLES stakeholders: from general public to policy makers and energy companies themselves.

- Conference Attendance is also used for energy companies, e.g. P9: "We attended quite a few conferences ... attending as much as possible from a learning perspective".

- Online Courses are also noted as a possible training method, however, these are only relevant as "Maybe a starting point" (P2), as more practical skills needed within this sector cannot be acquired without hands-on engagement.

- Public Awareness raising is also a model of training, though it is aimed at the general public (not workers within the energy sector per se), informing the public about new technologies, SLE services, and their benefits and impacts. This can be done through the usual channels used by the companies for marketing and advertisement. However, it can also be supported with " visiting sites where they [renewable technologies] are installed more often and being more exposed to that kind of technology" (P2).

- School Education is suggested to have a key role in setting up the foundations for the training needed for working in the energy sector, as it provides the basic knowledge of:

- STEM Subjects, which are key for the SLE engineers;

- Renewable Technologies, that must make up the SLE, and notions of it

- Systems and their Interactions, which relate to the SLE SoS subsystem components and their inter-relationships.

\subsection{Insights and Recommendations for Bristol's Energy Subsystem}

\subsubsection{Digital Innovation Drive}

As previously noted, digital innovation and data-driven service delivery are becoming critical requirements within Bristol's energy sector. Thus, we suggest an update to the training provision for those aiming to work within the energy sector in Bristol and its surrounding region (as well as nationally) to provide additional training opportunities with a focus on digital technologies. For instance:

\section{Expanded Power Academy Provision}

During this case study we observed that the University of Bristol was not part of WPD's Power Academy training provision, and we have already initiated the process of joining the Academy.

Moreover, building on the Power Academy initiative, and working with the local universities (e.g. UoB, Bath and UWE), we suggest establishing training provision, through the IET Power Academy, specialising in: 
- Digital Services (e.g. working with the UoB's departments of Computer Science, and Networking and Communications);

- Data Analytics (e.g. working with the UoB's Al and data analytics doctoral training centre);

- Privacy and Cybersecurity (e.g. working with the UoB's Cybersecurity Research Centre, as well as the doctoral training centre on Security of Critical Infrastructures)

\section{Student Projects and Internships}

The local energy sector has the opportunities to both invigorate its own innovation and to attract young people into their companies through a wide set of activities engaging with the local universities, e.g. via

- Posing projects to undergraduate, MSc, and PhD students (working with the departments of the Energy Management, Computer Science, Networking and Communications, Mathematics, Cabot Institute for the Environment, etc.). (It is worth noting that some companies, e.g. CEPro, already actively participate in such projects, although they tend to focus on working with a single university/department, and so broadening their engagement would also prove beneficial.);

- Setting up internship projects for students over the summer break;

- Posing research and development competition challenges through the Student Union and/or various student societies (e.g. Computing Society, Women in Engineering Society, etc.).

\section{Funded Research and Development Programmes}

Establish a pipeline of research and development projects with a clear path to rolling out the successful results.

A number of initiatives are in place to apply for funding to run R\&D projects (e.g. UKRI funding has some support for company innovation; WPD's innovation programme is funded through Ofgem, EU Horizon 2020 framework, etc.). Indeed, most interviewed companies noted that they have applied (with various degrees of success) to funding programmes. However, current collaboration between research institutions (such as universities) and companies is weak. Strengthening such collaboration is mutually beneficial for both researchers and industry, as it will both increase the likelihood of successful funding applications, and foster local research and innovation. For this, as an example:

- the previously mentioned student projects and internships can be used to explore initial ideas and build larger research programmes around them and

- direct links between academics and businesses can be set up through networking events and scientific seminars/cafe scientific events, etc.

\subsubsection{Practice of Systems Engineering}

While the previously discussed points would support improvement of training and expansion of $R \& D$, the processes and procedures for the roll-out of successful trials/research results should also be put in place explicitly. This relates to both: 
- developing a set of internal, company-specific processes and procedures (not discussed further below, but some issues are addressed under the Management Skills topic in the above subsection), and

- taking a system-wide perspective on the energy sector, with some points noted below:

\section{Local Energy Service Consortia}

As previously noted, CEPro is already pioneering a new model of community-level power system deployment and operation. This model:

- Is focused on consumer/community level benefit optimisation and emissions reduction, yet it also

- Supports the agenda of the energy distribution companies (such as WPD) by ensuring that the local energy needs are met locally and no wide-scale network reinforcement investments will be required. Furthermore, it

- Provides opportunities for new service delivery models by the energy utility companies (such as Bristol Energy), where digital services can be employed to integrate local microgrids through an electricity trading platform.

This, and similar initiatives, would blossom if a collaboration is established between local energy companies, which can support, expand and build on each other's business. Thus, while WPD can minimise investment needs into its network expansion, CEPro will focus on managing local community microgrids, and Bristol Energy could provide a trading platform for inter-microgrid trading.

\section{Engagement with Local Authorities and Communities}

Given the key roles that both local authorities and communities play in the success of local energy initiatives, we also suggest that the energy companies redouble their efforts in engaging with both of these stakeholders. In particular, while engagement with BCC can be carried out through discussions with the Energy and Innovation teams, engagement with communities would most likely be best carried out through education and demonstration campaigns (similar to what is discussed for the local market orchestration of section 4.4.1).

\section{ICT for SLE Sub-System: Findings from Data Analysis}

\subsection{Factors Affecting Bristol's SLE ICT sub-system}

Drawing on the interview data analysis, we have formulated the causal model of Bristol's ICT for SLE sub-system, as shown in Figure $16^{16}$, and briefly explained below.

Our interviewees note that the key defining feature of the SLE ICT projects are in:

Complexity due to the need to integrate multiple hardware and software interfaces. This emanates form the fact that SLE projects face the need to integrate across multiple energy vectors (e.g., PV, wind, bio fuels) and SLE SoS sub-domains (e.g., transport and mobility, household consumption, community generation, digital elegy services). Each of these vectors and domains (by

\footnotetext{
${ }^{16}$ This model can be simulated through this url: https://energysystems.blogs.bristol.ac.uk/2021/03/08/ict/
} 


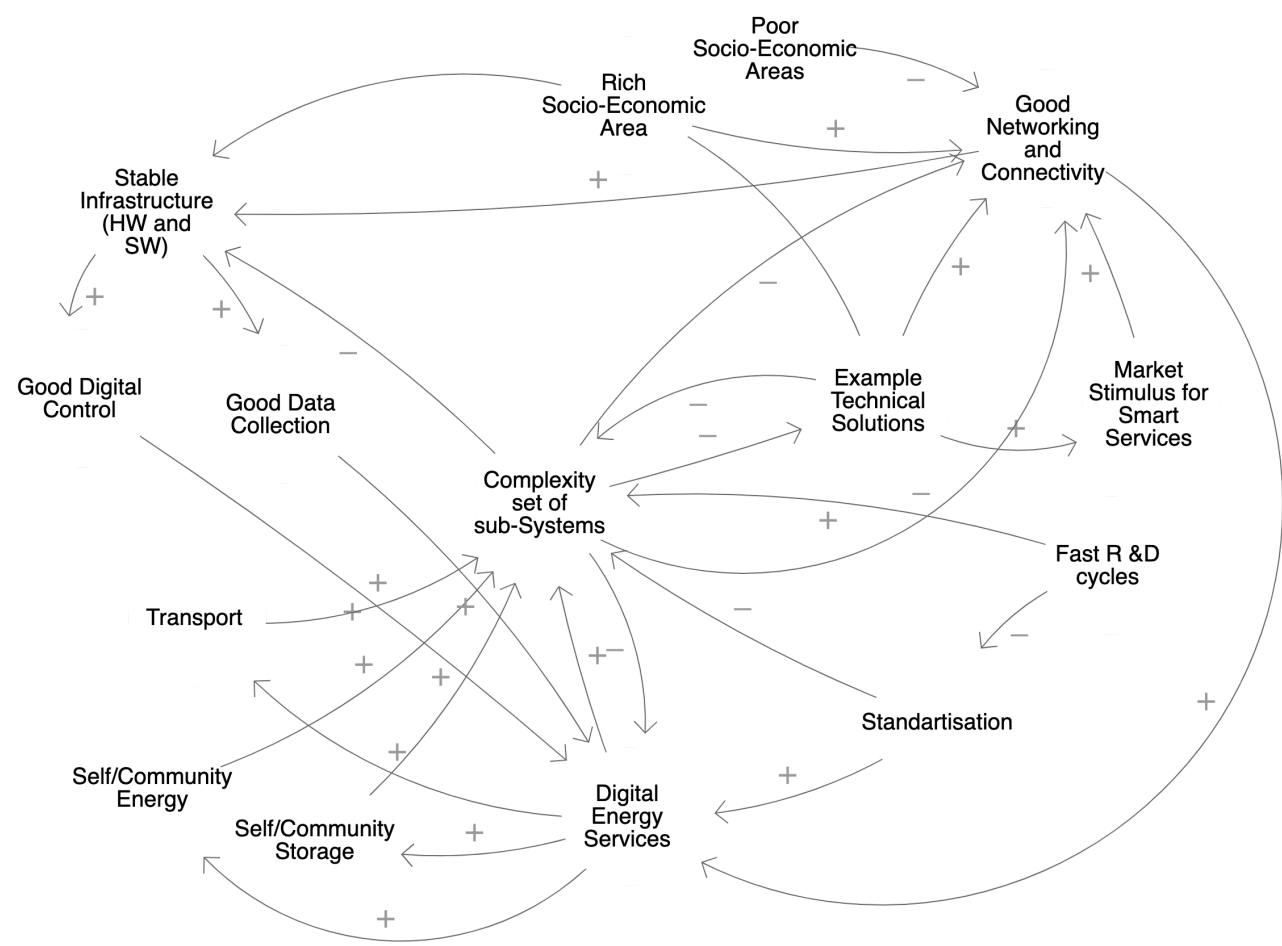

Figure 16: Causal model of the Bristol's ICT for SLE Sub-system.

necessity) is supported with custom hardware and software solutions. Orchestrating a consistent solution across these heterogeneous set of hardware and software solutions is a complex challenge by itself. It is further aggravated by the varied provision of networking and connectivity infrastructure as well as by the fast evolution of the renewable-based technologies with their supporting software services.

The Networking and Connectivity is essential for data exchange for monitoring and control that the ICT solutions are expected to exercise within the SLE. Yet, availability of this infrastructure is uneven across the city of Bristol (as well as UK). In localities with high income and dense economic activity, the networking provision is assured, while in more deprived areas, it is scarce.

Given the unprecedented rate of research and development dedicated to the zero-carbon SLE technologies, it is not surprising that the technological progress leads to the fast cycle of hardware and software obsolescence. This fast technological change, in turn, disrupts convergence to standards and emergence of stable SLE SoS infrastructures.

It is also noted that example technical solutions have a substantial role to play in demonstrating the positive impact and role of the ICT-based SLE (SoS) solutions. This, in turn, allows other organisations/projects to replicate the said solution, thus reducing the complexity that they have to cope with. The growing number of examples also improves the state of connectivity provision: the examples demonstrate viable business use cases and reduced environmental impacts. Furthermore, such viable use cases also motivate policy makers to provide market stimulus to foster replication of such solutions.

In addition, strong technical management of ICT SLE projects (i.e., whereby the project manager is well familiar with the technical issues of the ICT and engineering technologies of SLE) helps 
to reduce the complexity of the project as well as deliver a successful sample solution.

Finally, where the intended user communities are deeply engaged with (e.g., co-designing the prospective digital SLE services), the likelihood of successful adoption and use of such services also increases (as demonstrated by the Replicate project in Bristol, for example).

\subsection{What skills are needed for the ICT Sub-System presently and in the future?}

While the interviewees noted a whole range of skills that are currently in use within the SLE sector, many of them were referred to as available through the traditional education and training providers. Though, for several years now, the ICT graduates have been in high demand across many industries, with demand outstripping supply of available software professionals. This trend is set to continue in Bristol (and likely across the whole of the UK economy). Thus, below we discuss only the specific skills noted as short within the SLE projects, over and above the current competition for the skilled ICT professionals across all sectors. The skills deemed particularly short within the Bristol's ICT ecosystem are detailed below, while also aggregated into generic types.

\subsubsection{Engineering Skills for the ICT sub-system}

- Software Engineering skills:

- Agile Processes and Practices skills, so as the engineers and users from across various project partners can collaborate effectively, e.g., "communication channels between ... preferably an engineering level [are needed] because ... [else] politics generally takes over and you don't have as much focus on what you're actually trying to do" (P1).

- DevOps skills, i.e., continuous collaborative process between the development and operations roles within the SLE projects. While the agile process integrates customers and developers, here the role of operations teams (e.g., systems engineers, system administrators, release engineers, DBAs, network engineers, security professionals, etc.) are considered equally relevant at all stages of software engineering for SLE: from system scoping to development and production support.

- Requirements Engineering skills for SLE (SoS) are critical, as too often, both the customers and partners across the SLE projects have incorrect understanding of what the intended smart solution must do (e.g., "From the beginning the possibilities of demand management were very unclear" (P1)), and what capabilities are available in technology, local environment and infrastructures, regulation and legislation's that would underpin the solutions, and from across the partners themselves (e.g., " ...everyone will have in their mind a concept of what they expect this technology [or infrastructure, or partners, etc.] to do and how they expect it to be going forward" (P20)). So requirements engineers must bring along both system scoping and software engineering skills, and understanding of the energy domain and technologies.

- Programming skills with various environments and languages, including, but not limited to embedded systems and internet of things, using such broad scope of technologies as LoRaWAN, Things network, Kubernetes, DockerC, NodeJ, Python, etc. It is worth pointing out that there is no single language or platform that is considered more relevant 
than others, as each company and product will use a different set. In most cases programmers are able to pick up new technologies and languages as necessary, though proficiency comes with some time delay. Such time delay could prove a challenge in innovative SMEs who need employees to "hit the ground running" (P29).

- Machine Learning and Data Science “....are going to be [needed] more in this space in the future" (P25), where machine learning is used to both optimise the system performances, but also "to begin to understand people's behaviour" (P10) so that better and new services can be delivered.

- Data Engineers are needed to both specify the type and granularity of data to be collected from specific sources (e.g, design data aggregation and dis-aggregation solutions) and routes of data use to enact a desired impact. As per P20: "You need to understand how you're going to make the world better through this data that you've got. And if you don't really have a handle on that initially then you might monitor the wrong things."

- Deployment skills, whereby for a sustainable solution, the software must be integrated with the hardware and deployed in such a way as to avoid additional dependencies on users and environment. For example, "...getting power and comms to something" is a not-trivial task, "...even just deploying something out on the side of a road, it will only work for so long before it runs out of batteries" (P20).

- Privacy and Security delivery skills are also in short supply. E.g., P1: "GDPR is always a big concern with most tech projects" as shared energy data would need to have "a lot of obfuscation" (e.g., changed names and identifiers).

- Robust Hardware/Software Manufacturing skills are essential, for "building robust technology to scale up". This is because the technology is deployment is distributed across many locations (e.g., household premises) and "if you've got a thousand units and they fall over once a month, then by the end of two months all of your devices will have failed because you won't be able to go out to turn them back on again" (P20). Currently the solutions in SLE ICT projects are less than robust.

- Networking and Telecommunications skills relate to the set up of networks for commutation and data exchange between the devices as well as individuals within the SLE (SoS) subsystem (e.g., data on location, speed and charge/fuel level of buses, locations and routes of electric bicycles, excess/shortage of available electricity, etc.). Often the SLE projects suffer, as they expect networking/telecommunications infrastructure, which turns out to simply not be available (e.g., the project expected to "...leverage the software defined networks technology ...but the networks were not available at the deprived areas ..." (P25)). At the same time, the available connectivity solutions (e.g., wifi, $4 G$ and $5 G$ phone networks) tend to be too expensive. As a result, the SLE ICT projects could benefit from skillsets allowing them to set up own networking solutions.

- Systems Engineering skills refer to the ability to inter-connect the software and hardware components within and across the various sub-systems of SLE SoS, for this the following skills are noted:

- Systems Architect skills to oversee the "complex web of different partners doing different 
things" (P29) with " different technologies and background ITs" (P28) and put these together into an integrated, working system.

- Considering Scalability of the system-to-be is another key skill. Often trade-offs would need to be made, for instance, between the level of control that can be exercised over a solution (e.g.: implement everything in-house from scratch) and the convenient, readily scalable technologies (e.g., AWS for data storage); security vs speed of system response, etc.

- Multidisciplinary Engineering requires that engineers within SLE SoS are able to either collaborate closely, or draw on more than one engineering discipline. This is because electronics, civil, mechanical, software and other engineering disciplines are often expected to be applied together, as solutions are often multidisciplinary "....in how they're put together so you might be a mechanical engineer but you're also working in software electronics" (P21), or needing to install sensors along with software solutions (P20) and so on.

\subsubsection{Energy Domain Skills for ICT sub-system}

- Understanding of the Fundamentals of Power Systems and Renewable Energy is considered to be relevant for the ICT in SLE. Though this is not novel knowledge per-se, it is relevant for ICT professionals working with the SLE solutions.

\subsubsection{Trades Skills for ICT sub-system}

- Installation engineers are noted as necessary for "installing stuff into people's homes" (P20) and elsewhere, over which an ICT solution could be developed. Though installers are not currently in short supply from the ICT domain's perspective, it is noted that the scaling up of the SLE activities will require proportional scaling up of the trained installation providers as well.

\subsubsection{Managerial Skills for ICT sub-system}

A critical point to note is that an ICT project manager must have sound understanding of the ICT technologies. The specific skills noted as short within Bristol's ICT SLE projects are:

- "Technical project management is ...definitely desperately lacking from [SLE ICT] industry" (P20). Yet, the SLE projects that succeed are generally those where "...the engineers were also the project managers".

- Systems Integration Management, whereby the manager would ensure that the team members:

- have a clear understanding of the capabilities of the chosen technologies; these technologies must work together, across the organisational boundaries, for the integrated system to function;

- build collaborative relationships between project team (which could often be distributed across several organisations); 
- provide the "coordination clout" that enables the team work while maintains "oversight to critically appraise" (P29) the progress.

Without this there is a risk making "code a complete mess" due to needing to "switch technology" midway through the project (P30).

- Team Management with Remote Working has been a skill utilised in ICT teams for a while, and now"should be an area of focus" (P1) even more, due to the COVID-19 impact.

- "Research Skills ...in terms of being able to find out what else is out there and bring that in" is considered particularly relevant under the "fast moving pace" (P29) of SLE.

- Procurement is another skill that drives the capability of the project to deliver, and the project manager must ensure that the groups that undertake procurement for SLE projects have "...ICT representation on" and have clear understanding of how and what the obtained hardware/software will be utilised for the smart monitoring and control.

\subsubsection{Finance Skills for ICT sub-system}

The key shortages around finance within the ICT sub-system are not in ICT finance per se, but in using the capabilities delivered through ICT, thus:

- Skills for Planning Commercialisation Pathways are noted to be in short supply, as most SLE projects lead to an ICT-based system development, but with no thought thorugh commercialisation pathways. This, in turn, results in disused solutions, for which " ...example being Smart City platform. Another example being the energy management system. None of those ...have had a clear commercialisation plan throughout" (P29).

- Similarly, skills to Utilise Data for Business Improvement could be very valuable, particularly for small businesses, where data might be available, but the business owners “...don't themselves have either the opportunity or the knowledge to use it" (P20).

\subsubsection{Policy Skills for ICT sub-system}

Policy skills discussed within the ICT-related projects are centred on the policy skills that would support the delivered ICT solutions, e.g.,

- "People who have Insight into Markets Overseas" (P10) are very valued within the smart mobility sector, as they can help inform the local policies improvement based on the other countries experiences.

- Skills for Lobbying Regulators, are also noted as particularly relevant, e.g., for (de-)regulating various aspects of the SLE sub-systems, e.g., ability to purchase from multiple suppliers and sell small quantities of electricity for peer-to-peer trading solutions, or selling electricity stored within a battery, etc. 


\subsubsection{Soft Skills for ICT sub-system}

- Engineers with skills to Engage Citizens with SLE projects are in short supply. As a result, in many cases "engagement seems to be completely decoupled from the engineering and ...[the projects] end up with just a gap in the communication" (P20).

- To Manage Public Expectations of Technology, the engineers need to be able to convey exactly what the technology is and what its limitations are, so as the pubic can have a realistic expectations of the gains and pains they would encounter, rather than starting with overexerted expectations that result in disappoint in SLE overall.

- Fundamental ICT Skills and Understanding of Engineering Technologies in Public are necessary as presently the SLE projects "can't really expect people to be IT savvy or even [know] the basics really", which impedes their participation in the SLE projects (P27).

\subsection{Training needs ICT sub-System}

\subsubsection{Areas of Training Needs}

The key areas for training in ICT sub-system are primarily focused on Engineering and Technical Management, including:

- The Software Engineering set of skills, form requirements elicitation to algorithms development, systems programming, and deployment. This is not surprising, as any software development project is critically dependant on all these skills;

- Data collection, storage, exchange, standardisation, interpretation, analysis and management is another critical area, as all decision making is SLES SoS (and so the services delivered by the ICT sub-system to this SoS) are based on the results of the (nearly) real time data analysis.

- Systems Integration Engineering is an area where the SLE projects are somewhat more diverse (i.e., require integration of heterogeneous hardware and software APIs, across differently networked (and sometimes with missing network access) localities with differing additional constraints (e.g., on telecommunication network's bandwidth availability, etc.). Despite these characteristics, we note that the SLE domain is not the only one with these very demands, but so is, for instance, any domain that relies on Internet of Things architecture. Thus, the combination of Software and Embedded Systems/Electronics Engineering skills training would be particularly popular in the SLE domain at present (or until the telecommunications infrastructure is modernised, standardised, and stabilised across the UK.

- Installation Engineering (i.e., installing PV/wind turbines, EV charge points, etc.) is another area of training needs, as the ICT solutions are to be developed for the hardware that is installed across the SLE sub-systems to support "smart" optimisation of energy and resource use.

- Technical management skills, along with the ability to manage very large projects with a multitude of stakeholders is not a new challenge for the ICT sector, but is still open and equally relevant for the SLE. 


\subsubsection{Modes of Training}

When discussing how training should be delivered, the respondents noted that:

- University education (or equivalent) is a clearly assumed expectation for most entrants into the ICT area. Yet, they note that this is (necessary but) an insufficient level of training to work within the SLE ICT sub-system, as many skills are not "...skills that someone would get as a computer science degree. It's usually experience that you'd get from ...working with this kind of scale of software" (P1). Thus, practical training top up is considered essential.

- Apprenticeship "is a good opportunity of obviously training ..." (P31) through apprenticeships tend to be more used by larger organisations.

- On the Job training is considered particularly relevant, as given the wide range of new contexts and projects that arise, the employees are "pushed me to learn a bit more" (P26) while working. This is often done through online code repository searches and reading, as well as through peer-learning. Most importantly, as noted before, the practical skills around handling projects of very large scale and interacting with many stakeholders and collaborators from across various organisations can only be acquired through such on-the-job experience.

- Peer-training capacity is often accounted for during the hiring process as well, as the company would "need a couple of key people and seniors who have that background experience that could be training and upskilling people from other backgrounds" (P1) to help them gain the practical skill, such as, for instance, handling production scale platforms and projects.

- Doctoral Training is another method mentioned for both algorithms development and networking areas. These skills are relevant particularly at present because most SLE projects come with a large Research and Development component since much of the required work is new with no pre-set solutions to draw upon. Interestingly, the research for SLE does not seem to require any other that "traditional ICT" research and development skills, e.g.: "I think a couple of postdocs were recruited, networking and embedded systems people so we didn't deviate from the typical ICT skillset that we would recruit on a technical project like this" (P28). Though Maths degree graduates are also well regarded for algorithm development work (P10).

\subsection{Insights and Recommendations on Bristol's ICT for SLE Sub-System}

\subsubsection{Reduce SLE Project Complexity through Good SE Practice}

As noted in section 10.1, the ICT sub-system in Bristol's SLE SoS suffers from the complexity due to need to integrate multiple heterogeneous devices and interfaces, coupled with the fast technological change and evolution of the physical and software components of these devices. Moreover, many of the SLE projects are intended as trials with the real users of new SLE solutions and services. Thus, our interviewees noted the need to reduce this complexity in SLE projects as much as possible, which can be done by:

- Plan for Flexibility in Work Process: given that the hardware and software planned to be used within the SLES are likely to evolved within the project lifetime, it is only prudent to expect this change, and so a methodology which incorporates co-design and iteration cycles would 
suite such projects best. Moreover, "putting a bit more co-design ... and not having [the work plan] really fixed" (P27) also allows for better integration of end user concerns, as the project progresses.

- Minimised Technology in Trial: SLE projects expect to integrate a large set of technologies and devices. Yet, when trailing a solution, it is essential to start with the bear minimum, as trials of the full set of intended technologies together are likely to fail both due to technology immaturity within some components, and evolution of others. Thus, P30 suggests to "...start with the minimum amount of failure points" in a skeleton solution, and only then add one aspect of technology at at a time (e.g., "an insecure VPN-less architecture for a start" P30).

- Small Number of Initial Users is also helpful in complexity reduction, as this too reduces the number of "failure points" both in communication with the users, and in setting up the technical solution within the situated use environment. To illustrate this, one of the failure points in Bristol's Replicate Smart Home trial was the need to " install several pieces of hardware which were supposed to be kept connected to the mains" however, as trial participants at times wanted to use the power outlets for other purposes "the hardware was often disconnected" (P26). Given that the solution was rolled out to 150 households without an initial limited trial, the project wasted a vast number of person hours chasing trial participants and asking them to re-connect the equipment to the mains sockets.

- Use Mature Technology where available, as that would help reduce complexity due to the technological flux.

- Engage Experienced Systems Integration Engineer as practical experience is particularly helpful in quickly identifying and addressing integration and inseparability challenges.

We observe that all the above noted practices have also been proposed within the agile software development paradigms in the the "traditional" ICT sector [44, 45]. We observe that the project management and decision making within the SLE projects is often not led by a professional Software Engineers, and so the good practice within the software engineering domain remains unknown and unavailable to members of such multidisciplinary SLE projects. Thus, as an implication to the skills, we recommend that the technical management as well as the development teams across all areas of the SLE projects be introduced to agile development and management practices.

\subsubsection{Scale Up Considerations}

While considering the prospect of scaling up the ICT solutions for SLE we note the following recommendations, based on our Bristol study:

- The principle to consider for a successful adoption of new technology is to ensure that it "Fits into other people's business as usual" (P20) as much as possible. This is not surprising, as the alternative is to engendered conscious behaviour change, which requires that the indented users/participants are reached, informed and on-boarded with the change programme and rewarded and motivated to carry it out - all of which requires large time, effort and cost commitments. While, if it is “ very simple, very easy ...to be part of the trial ...people don't have to worry too much about it" (P26), then participation and engagement is much easier to achieve. 
- Using Mature and Robust Technology makes scaling up much easier. This is because it allows for the tested and validated hardware and software (e.g., car based monitoring technology for EV monitoring, or cloud-based encryption and storage solutions for securing data (P29)) to be acquired, avoiding high risk and cost of untested or proprietary developments. Here scale up can progress through working with a:

- Specialist Industry Partner as such a partner would already be developing and delivering the required hardware/software technology (e.g., as Trakm8 for car monitoring boxes) and removes the need for production/development process set up;

- External Skilled Professionals, e.g., through consultants or experienced installation parties (e.g., building and retrofit service providers), avoiding the need to develop, finance, and maintain all varied skill-sets internally.

- Planning for Commercialisation Pathways is essential for a successful scale up of a SLE ICT projects, as only a commercially viable solution driven by the interests of (one or several) organisation(s) will maintain momentum in the longer run. Indeed, many good solutions derived through SLES R\&D projects fail to gain a momentum when there is no dedicated industry partner(s) driving this (prospectively lucrative) commercial interest.

- Finally, the Regulatory Compliance of the proposed solution must be (reasonably) achievable, else even the most promising technologies fail to scale up. For instance, this currently is the case with the peer-to-peer electricity trading platforms. While these platforms are technically viable [46] and prospectively profitable, given that a household can have only one supplier at any given time, the local electricity trading remains impossible.

\subsubsection{Capacity and Expertise}

- Capacity to create value from data: Within the SLE ICT sub-system there is an implicit assumption that once data for a particular area of SLE SoS is available, the business that owns that data will be able to derive additional benefits by creating value form this data. This, however, is not always the case, as often the businesses working within a specific domain have neither the capacity, nor the skill-set for such value creation.

Such capacity is often missing in small and medium sized companies, which, despite utilising SLE technology, are not focused on SLE SoS activities for value creation per-se. For instance, a car rental company may have to move away from fossil to electric vehicles, yet continue to see its key business in renting out vehicles, rather than charge/discharge optimisation and battery use. Indeed, the customers would rent and return the vehicles with the set 'fuel' levels (be it battery charge or petrol in the tank). And through the company would, by default, be able to aggregate the vehicle tracking data, as noted by P20, the company may not be "that interested in looking far and wide for other possible applications of tracking data when basically they think they've got all the value that they can get".

To address this issue, we recommend that opportunities for value creation from SLE technologies are explained and provided to all SLE technology users across all SLE sub-systems. For instance, by having a choice of monetising access to own or aggregated business data, etc. The first steps towards this are already taken through the recommendations of the Data Task Force and their implementations across the UK R\&D funding providers 
[47]. This, however, also needs to be scaled up and integrated at the technology distribution points (e.g., at the point of EV sale) allowing the buyer - business or citizen - to choose a value from data creation options.

- Given the quickly evolving technological scene in SLE, and even faster evolution in its ICT sub-system, it is difficult to maintain an up to date technical expertise across the SLE SoS ICT sub-system. This is particularly relevant to project managers, who are not themselves technical developer's, but need sound knowledge of the current solutions and opportunities.

To address this, we suggest that the projects and businesses undertaking funded SLE ICT projects should periodically report their findings at open forums, rather than at by invitation only only events.

- Finally, we observe that the SLE ICT SMEs are often reluctant to employ new graduates, but aim to hire professionals with proven track record and past industrial experience with similar technologies, as they have no capacity for training provision, but need people who can "hit the ground running".

This issue can be addressed thought wider use of 'with industry' projects at the universities, as well as through 'year in industry' schemes and internships, aiming to provide a hands-on practice opportunities for all of the university graduates.

\section{Skills Across SLE SoS Sub-Systems: Architecting through Inter- faces}

This chapter considers the cross-subsystem skills for the SLE system of systems, drawing on the case study of the Bristol City's SLE (as represented by the views of our study participants).

\subsection{Challenges of SLE as a SoS}

As discussed in section 1.2.1, SLE SoS comprises a number of semi-independent subsystems, each operated for its own purpose by a different managerial team, with different project time horizons, technological and professional heterogeneity and evolutionary paths. However, to act as a coherent SLE SoS, these subsystems must collaborate towards a common goal.

Given that these subsystems, due to their quite independent evolutionary developments, have relatively well established boundaries, the only way of creating a common SoS architecture is by integrating them through common interfaces.

Drawing on the case study of Bristol city through our documentary analysis and interview and focus-group based qualitative study (detailed in [48]), we observe that these interfaces are formulated through:

1. Interfaces with the Energy Distribution and Transition Networks, which refers to the hardware-level interlinking of generation and consumption equipment with the electricity and gas/heat networks;

2. ICT interfaces that integrate data collection, exchange, decision support and control over the various generation, consumption and storage devices located within the component subsystems; 
3. Policy and Regulation that constrains and stimulates various activities within and across these subsystems;

4. Education and Training provision, which fosters the setting of - and working towards - the common SoS goals across the various stakeholders within and across the SLE subsystems.

We discuss the key challenges and their respective skills that the SLE SoS must face, upskill for and overcome in integrating the SLE subsystems through the above interfaces below:

\subsubsection{Challenge 1: Lack of a Holistic View (Understanding)}

As discussed in [48], each subsystem within Bristol city SLE faces their own set of challenges; e.g. the Building and Retrofit subsystem suffers from a lack of professional esteem and public trust (in retrofit) and a lack of incentives to change their building practices (in building); the transport and mobility sector in Bristol is concerned about finding business models that are financially feasible for EV and biogas vehicle fleet operators and their supporting smart mobility service providers, etc. While all subsystems interact through energy supply and demand, none of them has the optimisation of local clean energy production and consumption as its key goal.

A. Setting an agreed common goal is thus the first objective to be tackled in fostering a SoS-level transition. Agreeing upon this common goal would require a wide set of Education and Training activities across all levels of the SoS and subsystems' stakeholders.

Bristol City Council has taken a leadership role in this area and, since 2019, has been supporting Bristol's One City Plan [35] which defines how the stakeholders within the city will work together to create a 'Fair, healthy and sustainable city'. This plan was developed through extensive engagement and consultation with citizens and wider stakeholders and provides a set of mutually agreed goals through a collective vision for organisations and individuals across the city, which stretches beyond just the city council. The City Leap [40] initiative is another development that has flourished alongside the One City Plan. Furthermore, given that Bristol City Council owns a significant amount of property (including schools, libraries, offices and depots) as well as approximately $40 \%$ of the land in the city, it sets a strong trend in defining the essential set of goals that its property operators must address.

The Community and Energy Groups across Bristol have also taken an active role in raising the awareness of citizens about climate emergency and energy transition challenges.

B. Building a Mutual Understanding and a Common Vocabulary is another objective to be addressed through education and training, as the SLE subsystems may not acknowledge relevance of one or several of the other subsystems on the one hand (e.g. Building and Retrofit sector is disengaged from Transportation, as Transportation is from Community Energy, etc.). On the other hand, they will be using different terms to refer to the same subject and/or the same term to refer to different subjects (e.g. citizens 'optimise consumption' by using as much of their own solar energy as possible, while electricity suppliers 'optimise consumption' by shifting the electricity use away from peak demand time).

In order to address this, the local authorities can set up city-wide collaborations and bodies (e.g. a Committee for SLE Transition made up of representatives from a relevant business, the community and a training provider) where the cross-subsystem engagement and cooperation will help to build a mutual understanding and a common (or at least cross-referenced) vocabulary. 
This cross-subsystem vocabulary sharing within the Community Energy sector often happens through collaboration and interaction between groups. For instance, in Bristol, the Cold Home Energy Efficiency Servery Experts (CHEESE) group has engaged with the Ambition Laurence Weston (ALW) community group to support energy efficiency improvements within local homes. ALW also operates a PV array and is currently deploying a wind turbine for the community's use. Thus, the community in the Laurence Weston area of Bristol is actively engaged with learning about retrofit as well as energy generation technologies.

Furthermore, all subsystems must interact with and learn about the electricity (and/or gas) supply distribution networks, as they must all connect their equipment with (at least) the distribution and (often also) transmission networks. This leads to a common understanding, e.g. of the network constraints that a distribution service operator would likely experience, and opportunities for new service delivery (e.g. by shifting away from peak time consumption through EV and/or battery storage/(dis-)charging, etc.

C. General Understanding of Renewable and Clean Energy Technologies: each SLE subsystem is experiencing a technological flux, as all renewable and clean energy technologies are evolving with an unprecedented speed. As a result, it is difficult for those already within the specific sector to keep up with the innovations, and even more difficult for those in other sectors to keep up to date, as, for instance, new batteries and/or chargers are developed for EVs at the same time as new types of heat pump and natural/hydrogen gas-based fuels are emerging across heating and energy supply. Thus, general (and continuous) upskilling is required across all of the SLE subsystems on available technologies, risk management and financial planning for projects.

\section{Skills to Tackle Lack of Holistic View Challenge}

To address this challenge, a number of so-called Soft and Managerial skills must be engaged:

- Communication, to explain to citizens and broader stakeholders what the said goals are and why are they relevant (e.g. via citizen assemblies, an energy champions' programme and business consultations used by BCC);

- Engagement, to ensure that all stakeholders are both generally supportive and also actively engaged with furthering the said goals (e.g. working with citizens and businesses to codesign solutions);

- Partnership Building, to guide the process of engagement towards productive solution delivery (e.g. partnership agreements signed by BCC with community groups, such as the Bristol Energy Network (BEN); tender programme launched for formal joint ventures with businesses for the City Leap).

- SLE Technological Literacy to avoid fears and unfounded concerns about new technologies (e.g. this can be done through workshops with community organisations, peer learning and conferences, such as BEN's annual conference in Bristol);

- Risk Management and Financial Planning with SLE technologies to assess the costs and benefits for business and household engagement for various technologies realistically. (This area is poorly addressed in Bristol presently, and can be integrated within the school curriculum and community/business training activities). 


\subsubsection{Challenge 2: Interconnection and Communication between SubSystems (Integrat- ing)}

In order to operate in a coordinated way, the subsystems within the SLE system must support physical interconnections for energy (e.g. electricity, heat and gas) exchange and data and information exchange for decision support and control in the optimisation of operations.

A. Infrastructure for physical integration, in most cases, is developed along with the renewable technology installations (e.g. solar PVs are integrated with the electricity network at installation time, as are EV change points and heating and ventilation equipment in building retrofit, etc.). However, challenges remain, for instance, where the existing electricity distribution infrastructure requires reinforcement for new EV charge point connections, or the gas distribution network cannot handle the chemical components of the new gas fuels (e.g. if the materials of the pipework have a chemical reaction with the new types of gas fuels, such as hydrogen). While addressing these issues requires coordination and communication across and within the SoS subsystems, such dependencies are explicit, regulated and immediately apparent for any installation project.

\section{Skills to Tackle Physical Interconnection Issues}

The skills needed across the SLE SoS subsystems in this respect are related to the Engineering disciplines as well as Energy Domain Regulation.

- Installations Engineering / trades (e.g. for charge point installations in T\&M subsystem; smart meter for energy supply subsystem, heat pumps in B\&R subsystem, and for local authorities subsystem as they undertake district heating and transition away from gas boiler schemes for BCC-owned dwellings) most (if not all) of which are directly linked up with the electricity supply subsystem as they are either drawing from or feeding into the distribution grid as part of their operation;

- Regulate for Compatibility of Devices and Infrastructures (e.g. on voltage and frequency use by all generation and consumption devices across all subsystems which are legally acceptable within the UK's interfacing with the electricity and gas grids; Energy Efficiency standards of all Building and Retrofit work; regulation of heat networks, etc.)

B. The Communications needs for data and information exchange are somewhat more implicit across the SLE SoS subsystems, yet poor communication for interactions between the subsystems will negatively affect the efficiency of the SoS operation and its evolution (e.g. greyouts or blackouts due to poor coordination of peak time electricity demand and EV fleet charging, etc.). Notably, the collection and interchange of such data may not be a key requirement for the subsystems themselves. However, it is primarily a requirement of the SoS as a whole. Thus, coordinated investment into the data collection and control infrastructure (such as installation of telecommunication networks, development of software platforms and APIs for data exchange and support for external control functionality) would be required at the SoS coordination level. In addition, policy and regulatory constraints around data and control must be defined, monitored and enforced.

Skills to Tackle Communications and Information Exchange Needs

Thus, the list of relevant skills here includes: 
- Software Engineering and Algorithm Design, as, for example, smart buildings and controls are expected to take a more central role with the automation of energy systems, because "...to guarantee the performance, you need much more detailed monitoring and controls than are typical" (P12). Energy trading platforms are required for accounting for the transactions from community- and citizen-owned generation equipment as well as for their consummation, and for the use by EV charging and returning stored excess electricity during peak demand times into the distribution grid, etc.

- Data Analysis and Machine Learning skills are relevant both within and across subsystems (e.g. in monitoring the state of the subsystems and SoS as a whole and supporting decision making for local authorities, energy supply subsystem, transport and mobility, ICT and smart energy, as well as for informing citizens and community groups).

- Data Protection, Ethical Use and Security skills within and across all subsystem of the SLE SoS, e.g. in ensuring compliance with GDPR, using encryption when sending data across networks, etc.

- Networking and Telecommunications skills, to ensure that the equipment and appliances are able to exchange data and control instructions, for which hard-wired or wireless communication infrastructure needs to be in place.

- Regulations and Standardisation skills are essential for the utility of the exchanged data and usability of the software platforms and services APIs (which is relevant to all subsystems).

\subsubsection{Challenge 3: Governance of the SLE SoS in its Entirety (Operating)}

While each subsystem will be managed by its respective management structures, there is a need for an additional governance mechanism that accounts for the holistic SLE SoS, along with the impacts that interactions between the subsystems could cause. These interactions may result in, for instance, privacy impacts from the cross-subsystem aggregation and the sharing of householders' data, exacerbated inequalities (e.g. if the well-off and so well-networked areas of the city can acquire new digital energy services, which are not accessible to less affluent areas). Another possible impact is stifling of business opportunities, for instance, if one subsystem, say the EV charge operators, refuses or lacks networking infrastructure to share its data with the others (e.g. energy suppliers) who therefore cannot deliver new services (such as demand response management), etc. These challenges could be addressed through the following:

A. Set up of a Cross-Subsystem SLE SoS Coordination body to Identify and Address Emergent Properties. While there is no such mechanism in place presently for the SLE SoS at Bristol, this is not entirely unfamiliar ground. For example, this cross-subsystem impact consideration is taken by BCC through the Health and Wellbeing Board in the Joint Strategic Needs Assessment [49] for identifying and addressing the impact of fuel poverty on health.

The task of this body would be to consider inter-dependencies, and emerging impacts that subsystem-specific-behaviours could cause in deviating from the agreed upon goals and vision (as discussed in Challenge 1) of the intended SLE SoS. For example, is optimising traffic flow for EVs acceptable for the Citizen's subsystem? Also, can community energy groups support their 
communities better by collaborating with local charge point providers for EVs?

B. Develop a Framework for Conflict Resolution as conflicts can emerge both from incompatible goals and worldviews between stakeholders (e.g. a goal to optimise traffic routes for smart mobility providers may conflict with a community group's goal to minimise through-traffic; wind turbine installations goals may conflict with biodiversity preservation, etc.).

Similarly, technological solutions across various subsystems may often lead to conflicting implementation requirements, e.g. distribution network operators may wish to minimise network reinforcements, while EV charge point providers require such reinforcements for operating within a given locality, or data may need to be shared for optimisation of electricity network management, yet this may conflict with the privacy preferences of citizens.

\section{Skills to Tackle SLE SoS Governance Issues}

This challenge is centred around the need to align SLE SoS operation with its subsystems as well as the broader national frameworks. Thus, a variety of skills, inclining negotiation, communication, policy, regulation and standardisation, and processes would have to be employed, with the following list of relevant key skills:

- Building Partnerships skill is necessary to bring the stakeholders along and unite within and across subsystems to identify and address both emergent issues and conflicts (e.g. as noted with respect to partnership with a core trusted team of tradespeople in B\&R, with Industry, Community and local government, etc.)

- Skills to Integrate Evaluation and Assessment into the SoS and subsystems operation is critically important as any emergence is to be observed relatively early and addressed to prevent systemic negative impacts. This could relate, for instance, to cross-subsystem regulations and standardisation, as well as coordinated actions to address cross-subsystem impacts. For instance, the poor retrofit practices in the B\&R sector will undermine the Energy sector's efforts of shifting the consumers' energy demand away from peak time, as well as impede the fuel poverty resolution efforts of the local authorities. Thus, the SLE SoS coordination body could strongly recommend specific quality and qualifications regulations in the B\&R subsystem, as well as agree that the local authorities will motivate retrofit quality improvements by only contracting qualified delivery tradespeople and maintaining a qualified traders' register for citizens to employ on their personal retrofit projects. (The last point has indeed been realised in Bristol through the Futureproof project [28]). This can be supported through both quantitative and qualitative means, e.g.:

- Modelling and Simulation skills for use in SoS optimisation (e.g. system dynamics models)

- Qualitative methods of planning, such as expert panels, Delphi studies, a "what-if" scenario walkthrough with stakeholders.

- Risk Assessment and Management both within and across subsystems, as risks will cross subsystem boundaries and amplify, if not handled, e.g. through integration of responsibilities and mitigation plans into subsystem and SoS delivery contracts (which directly relates to the more generic and equally relevant contract writing skills). 
- Large, Cross-Institutional Project Management skills would play a particularly import role as the SoS needs to integrate and manage a large set of stakeholders, set up a set of common operating systems and processes, foster cross-team collaboration, preserve and utilise historical knowledge in a very dynamic SoS.

- Regulation and Standardisation skills were already noted with respect to the data and API standardisation, yet a broader effort will be relevant for cross-subsystem standardisation as well. For instance, Bristol's regulation in the Building and Retrofit sector stating that at least $20 \%$ renewable energy generation for all new built dwellings must be generated locally has a profound effect on the Energy supply subsystem as well as the citizens and community energy subsystems. Thus, standardising the types of generation equipment used across new-builds in Bristol would facilitate e.g. retrofit quality improvement as builders are familiar with the said type of renewable generation installations; citizens are also more familiar with this technology, and consider it to be less risky for their own use; digital energy suppliers have a homogeneous resource to deliver new services with, etc.

- Stable supportive policy for SLE SoS as a whole is necessary, as in many cases the best policy for one subsystem could be less than optimal for the SoS as a whole. This is best exemplified with the data sharing and privacy concerns; while data exchange is essential for SoS optimisation (and the more data is shared, the better the optimisation algorithms which can be built), such total data availability undermines the fundamental human desire for privacy and security, which undermines the uptake of any of the potential solutions by citizens. Thus, policy making that supports the constituent subsystems, yet allows for optimisation of the SoS as a whole must be exercised.

\subsection{Shaping the type of SLE SoS in Bristol}

There are 4 general types of SoS, characterised by the levels of centralisation and autonomy that the constituent subsystems enjoy within a SoS: $[8,9]$

1. Virtual SoS, have no centralised authority directly overseeing their interactions at all. The interaction of the subsystems and their emergent behaviours occur through indirect and invisible mechanisms (e.g. mechanisms such as interest rates and supply and demand regulate the national economy SoS, the sub-parts of the SoS do not formally agree to collaborate);

2. In Collaborative SoS the subsystems interact on a voluntary basis and collectively decide on how to provide a particular service (e.g. as the internet is composed from collaborating national networks);

3. In an Acknowledged SoS all subsystems acknowledge their common objectives and work through a designated management team to coordinate resource use and plans for achieving the agreed goals (e.g. as is done in disaster recovery SoS);

4. In a Directed SoS, the constituent subsystems are well integrated, are managed by a centralised team/authority, and operate as the subordinates of this central authority; the operation mode is subordinated to a central authority (e.g. as the centralised electricity system has been until recently).

Presently, the Bristol SLE SoS operates as a hybrid type, for instance: 
- the community energy subsystem interacts through a virtual model with the transport and mobility and the local authority subsystems,

- building and retrofit subsystem interacts through a collaborative mode with the citizens and energy supply subsystem and through a virtual mode with the transport and mobility,

- the energy supply subsystem, however, interacts in directed-like fashion with the community energy subsystem, and in collaborative fashion with the citizens, yet virtually with the local authorities, etc.

As elicited both from our interview study and documents on the visions of the city of Bristol [35], the city envisions that its SLE should operate as an acknowledged SoS, with the goal of delivering a net-zero, liveable and prosperous city. For this vision to come to fruition, the challenges listed in the previous subsection must be addressed, and a well-integrated operational framework for the SLE SoS must be established. Such a framework must account for the goals and preferences of the subsystems, as well as the SoS as a whole, and provide transparent governance and participation mechanisms for all subsystems to contribute.

We note that the local authorities in Bristol are well-placed to take the leadership and serve as a core around which the SLE SoS governance would coalesce. They have good relationships with Bristol's citizens, supportive relationships with community energy, and partnership with community groups, as well as commercial partnerships and there has been a set of BCC-driven SLE projects over the past ten years which have developed knowledge and expertise internally.

Finally, Table 4 below presents the list of skills which, according to our study participants, cut across the subsystems and are also relevant at the SoS level itself. 


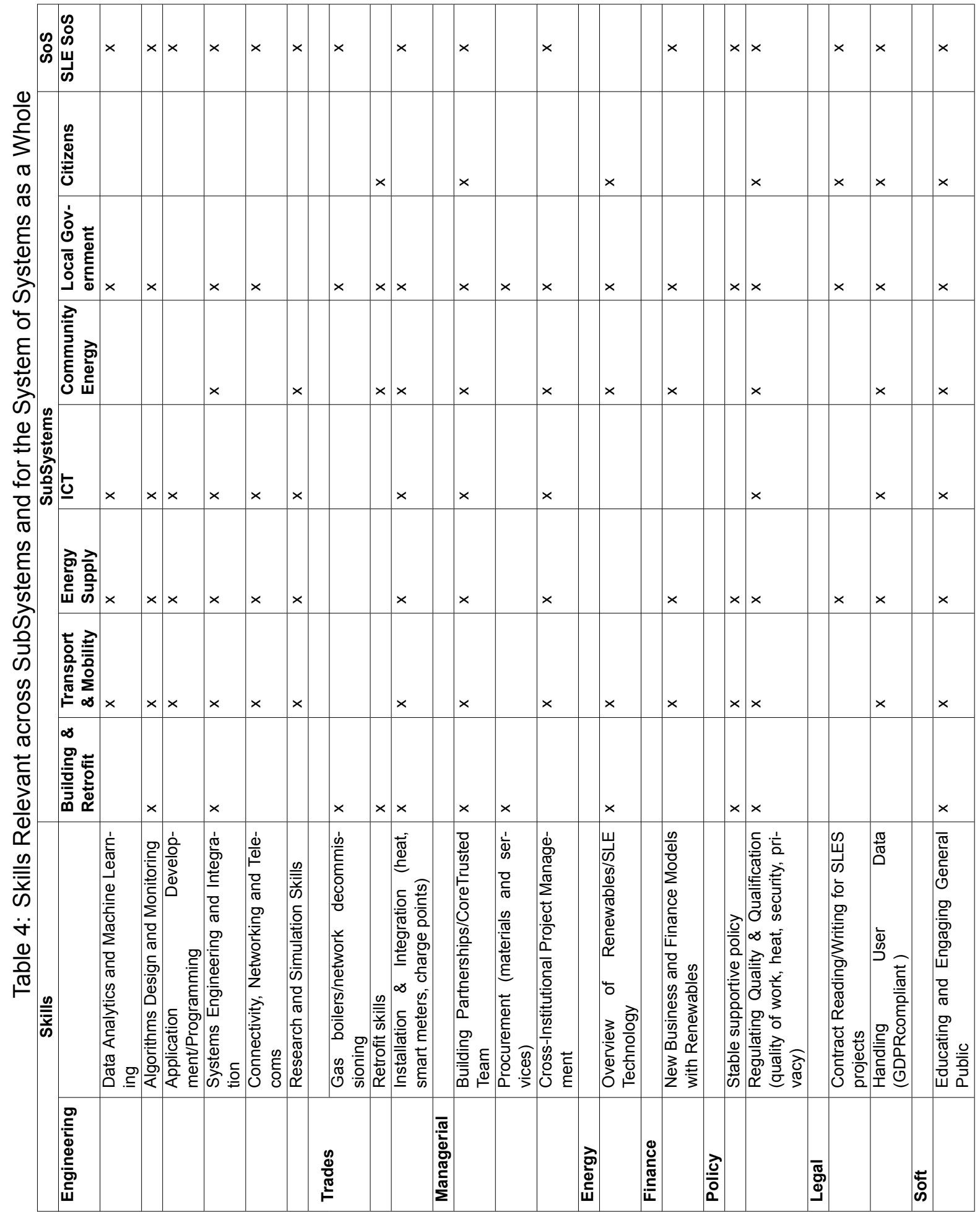




\section{A Appendix: Grounded Theory Method}

Grounded Theory (GT) $[50,51,22]$ is a method for qualitative analysis of data aimed at providing a systematised approach for constructing a theory about phenomena or a question of interest firmly grounded in (i.e. linked to) the collected data (e.g. via observations, interviews, reports, etc.). Here, a theory "states relationships between abstract concepts and may aim for either explanation or understanding" [22] (p. 228). Briefly stated, the key notions of GT [50, 51, 22] relate to:

- Theoretical sampling: a purposeful selection of sources and collection (i.e. sampling) of additional data for analysis which is expected to be relevant to the notions under analysis.

- Coding: the process of examining the data, and breaking it down into small portions (e.g. from individual text lines to a few sentences) and assigning labels (called codes) to each portion.

- Constant comparative analysis: the codes are continuously compared and contrasted, as they emerge when data is examined. As a result of this process, data is collated into conceptual categories, and links/relationships between the categories are identified. Unlike many other qualitative analysis approaches, there is no restriction on what themes/categories are considered as relevant, so all emerging categories are acknowledged and considered. Throughout the analysis process, the reflections of the analysts are recorded into memos.

- Conceptualisation and abstraction: development of theories that emerge from the abstraction and review of the coding results and memos.

Presently, there are three main strands of GT in practice, which differ substantially in a philosophical worldview (e.g. objectivist [50] vs. constructivist [22]) and processes (e.g. could the researcher study the relevant literature prior to data analysis). A recent study by Stol and colleagues has proposed a set of good practice guidelines for GT [52], suggesting that each study that uses GT should detail from which specific strand it draws and how it carries out data collection and analysis, as well as theory building and evaluation.

The grounded theory approach used in this study draws on work of Charmaz [22] and guidelines by Stol et. al [52], whereby the initial research question for the study is set, although it can evolve throughout the study. The researchers had also carried out a full literature review on skills shortages within the SLES, looking both at the models used for skills shortages analysis, [53] as well as various "smart" energy services, such as DSR $[15,54]$ and peer-to-peer energy trading [13].

The interviews (both for stakeholders and for the citizens) were first piloted with a few participants to validate the questions and the process. The feedback from these pilots was used to improve the interview structure and questions. Thereafter, the interview data collection was carried out as full studies (again, for both stakeholder and citizen categories). The results of the interviews were analysed and a set of casual loop models were derived to demonstrate the SLES adoption process within the specific SLES subarea in Bristol, along with the set of skills' requirements. 


\section{B Appendix: Organisations in Bristol SLE Ecosystem}

Table 5: Organisations in Bristol SLES Ecosystem

\begin{tabular}{|c|c|c|c|}
\hline Org. & Details & Scale & $\begin{array}{l}\text { Expertise } \\
\text { and } \\
\text { projects }\end{array}$ \\
\hline $\begin{array}{l}\text { Ambition } \\
\text { Lawrence } \\
\text { Weston }\end{array}$ & https://www.ambitionlw.org & $\begin{array}{l}\text { neighbour- } \\
\text { hood }\end{array}$ & $\begin{array}{l}\text { ALW Solar, } \\
\text { community } \\
\text { wind }\end{array}$ \\
\hline Aura Power & https://www.aurapower.co.uk/projects & global & batteries \\
\hline $\begin{array}{l}\text { Bristol } \\
\text { and Bath } \\
\text { Regional } \\
\text { Capital }\end{array}$ & $\begin{array}{l}\text { https://www. bab-rc.uk Inc. UoB, BCC, } \\
\text { UWE, Voscur, BizWest }\end{array}$ & region & funding \\
\hline $\begin{array}{l}\text { Bristol City } \\
\text { Council } \\
\text { and Energy } \\
\text { Service }\end{array}$ & https://www.energyservicebristol.co.uk & city & $\begin{array}{l}\text { STEEP, } \\
\text { BESST, } \\
\text { Replicate, } \\
\text { City Leap, } \\
\text { SONNET, } \\
\text { etc. }\end{array}$ \\
\hline $\begin{array}{l}\text { Bristol En- } \\
\text { ergy }\end{array}$ & $\begin{array}{lll}\text { Energy } & \text { supply, } & \text { https://www. } \\
\text { bristol-energy.co.uk } & \end{array}$ & national & BESST \\
\hline $\begin{array}{l}\text { Bristol } \\
\text { Energy Co- } \\
\text { operative }\end{array}$ & http://bristolenergy.coop & region & $\begin{array}{l}\text { Community } \\
\text { solar }\end{array}$ \\
\hline $\begin{array}{l}\text { Bristol } \\
\text { Energy } \\
\text { Network }\end{array}$ & https://bristolenergynetwork.org & city, region & $\begin{array}{l}\text { BESST, } \\
\text { Replicate }\end{array}$ \\
\hline $\begin{array}{l}\text { Bristol is } \\
\text { Open }\end{array}$ & $\begin{array}{l}\text { https://www.bristol.gov.uk/ } \\
\text { policies-plans-strategies/ } \\
\text { bristol-is-open }\end{array}$ & city & ICT \\
\hline $\begin{array}{l}\text { Centre } \\
\text { for Sus- } \\
\text { tainable } \\
\text { Energy }\end{array}$ & $\begin{array}{l}\text { Energy NGO https://www.cse.org.uk/ } \\
\text { about-us }\end{array}$ & $\begin{array}{l}\text { city, na- } \\
\text { tional }\end{array}$ & $\begin{array}{l}\text { STEEP, Fu- } \\
\text { tureproof }\end{array}$ \\
\hline CHEESE & $\begin{array}{l}\text { Thermal imaging for building efficiency https: } \\
/ / \text { cheeseproject.co.uk }\end{array}$ & city & $\begin{array}{l}\text { No Cold } \\
\text { Homes, } \\
\text { etc. }\end{array}$ \\
\hline $\begin{array}{l}\text { Clean } \\
\text { Energy } \\
\text { Prospector } \\
\text { (CEPRO) }\end{array}$ & $\begin{array}{lcl}\text { SME } & \text { microgrid } & \text { development } \\
\text { //www.cepro.co.uk }\end{array}$ & city, region & $\begin{array}{l}\text { Owen } \\
\text { Square, } \\
\text { Waterlillies }\end{array}$ \\
\hline Co-wheels & & national & REPLICATE \\
\hline
\end{tabular}


Table 5: Organisations in Bristol SLES Ecosystem

\begin{tabular}{|c|c|c|c|}
\hline Org. & Details & Scale & $\begin{array}{l}\text { Expertise } \\
\text { and } \\
\text { projects }\end{array}$ \\
\hline Ecocetera & $\begin{array}{l}\text { Installers of domestic solar PV, batteries, EV } \\
\text { charging https://www. ecocetera.com }\end{array}$ & region & \\
\hline Esoterix & & city & Replicate \\
\hline Eunomia & $\begin{array}{l}\text { Environmental consultancy, including low car- } \\
\text { bon energy (Bristol) https://www. eunomia. } \\
\text { co.uk/services/energy }\end{array}$ & $\begin{array}{l}\text { Bristol HQ / } \\
\text { international }\end{array}$ & \\
\hline $\begin{array}{l}\text { Garrad } \\
\text { Hassan } \\
\text { DNVGL }\end{array}$ & Wind energy in Bristol office & global & $\begin{array}{l}\text { AWL wind } \\
\text { turbine }\end{array}$ \\
\hline Geneco & Turning waste into biomethane for buses & & \\
\hline $\begin{array}{l}\text { Green Reg- } \\
\text { ister }\end{array}$ & $\begin{array}{l}\text { Non-profit green building training and register of } \\
\text { sustainable construction orgs } \\
\text { https://www.greenregister.org.uk }\end{array}$ & $\begin{array}{l}\text { Bristol- } \\
\text { based }\end{array}$ & Futureproof \\
\hline Greenheart & $\begin{array}{l}\text { Design and build sustainable construction since } \\
2000 \text { https://www.greenheartuk.com }\end{array}$ & Bristol+ & \\
\hline $\begin{array}{l}\text { Knowle } \\
\text { West Me- } \\
\text { dia Centre } \\
\text { (KWMC) }\end{array}$ & $\begin{array}{l}\text { Arts and technology charity since } 1996 \text { https: } \\
/ / \text { kwmc.org.uk }\end{array}$ & $\begin{array}{l}\text { neighbour- } \\
\text { hood, city }\end{array}$ & $\begin{array}{l}\text { Replicate, } \\
\text { Twinergy, } \\
\text { BESST }\end{array}$ \\
\hline $\begin{array}{l}\text { 1World So- } \\
\text { lar }\end{array}$ & $\begin{array}{llr}\text { Renewable energy systems } & \text { (solar, } \\
\text { biomass, heat pumps) since } & 2007 \\
\text { http://www.1worldsolar.co.uk } & \end{array}$ & Bristol+ & \\
\hline OVO & Energy supply - over $1 \mathrm{~m}$ customers & national & \\
\hline Regen & https://www.regensw.co.uk & $\begin{array}{l}\text { SW / na- } \\
\text { tional }\end{array}$ & BESST \\
\hline Severnet & & region & \\
\hline $\begin{array}{l}\text { South West } \\
\text { Energy Hub }\end{array}$ & $\begin{array}{l}\text { https://www.westof england-ca.gov. } \\
\text { uk/south-west-energy-hub https: } \\
\text { //www.swenergyhub.org.uk }\end{array}$ & South West & \\
\hline Sustrans & & national & \\
\hline $\begin{array}{l}\text { Thrive Re- } \\
\text { newables }\end{array}$ & Renewable energy investment & national & \\
\hline $\begin{array}{l}\text { Toshiba } \\
\text { Bristol lab }\end{array}$ & $\begin{array}{l}\text { at the cutting edge of wireless and network sys- } \\
\text { tems research }\end{array}$ & & Replicate \\
\hline Trakm8 & & national & Replicate \\
\hline Travel West & & region & Replicate \\
\hline TUC & & national & \\
\hline
\end{tabular}


Table 5: Organisations in Bristol SLES Ecosystem

\begin{tabular}{|c|c|c|c|}
\hline Org. & Details & Scale & $\begin{array}{l}\text { Expertise } \\
\text { and } \\
\text { projects }\end{array}$ \\
\hline $\begin{array}{l}\text { University } \\
\text { of Bristol }\end{array}$ & & $\begin{array}{l}\text { city, inter- } \\
\text { national }\end{array}$ & $\begin{array}{l}\text { STEEP, } \\
\text { IODiCUS, } \\
\text { Replicate, } \\
\text { Twindergy, } \\
\text { HoSEM, } \\
\text { etc. }\end{array}$ \\
\hline $\begin{array}{l}\text { University } \\
\text { of the West } \\
\text { of England }\end{array}$ & & $\begin{array}{l}\text { Replicate } \\
\text { city / inter- } \\
\text { national }\end{array}$ & \\
\hline $\begin{array}{l}\text { Upside } \\
\text { energy } \\
\text { (Manch- } \\
\text { ester) }\end{array}$ & $\begin{array}{l}\text { pioneering digital solutions that support the } \\
\text { smart energy management systems of the fu- } \\
\text { ture https://upside.energy }\end{array}$ & & $\begin{array}{l}\text { BESST } \\
\text { project, city } \\
\text { hall battery }\end{array}$ \\
\hline Urbane Eco & $\begin{array}{l}\text { Green building / retrofit specialists http:// } \\
\text { urbane-eco.co.uk }\end{array}$ & Bristol & \\
\hline $\begin{array}{l}\text { West of } \\
\text { England } \\
\text { Combined } \\
\text { Authority } \\
\text { (WECA) }\end{array}$ & $\begin{array}{l}\text { Regional layer of local government https:// } \\
\text { www.westofengland-ca.gov.uk/about-us-2 }\end{array}$ & region & $\begin{array}{l}\text { Go Ultra } \\
\text { Low West }\end{array}$ \\
\hline WPD & & $\begin{array}{l}\text { South } \\
\text { West, } \\
\text { national }\end{array}$ & $\begin{array}{l}\text { SoLa, Elec- } \\
\text { tric Nation }\end{array}$ \\
\hline Zero West & $\begin{array}{l}\text { Building a coalition across sectors to accelerate } \\
\text { the transition to net zero across the wet of Eng- } \\
\text { land }\end{array}$ & region & $\begin{array}{l}\text { Go Ultra } \\
\text { Low West }\end{array}$ \\
\hline
\end{tabular}




\section{Appendix: Energy Projects and Initiatives in Bristol}

This appendix summarises some of the energy projects and initiatives in Bristol.

\section{C.1 System projects}

- SoLa BRISTOL, (2011-2016) - WPD, combining PVs and batteries with local DC microgrid and variable tariffs to shift demand in homes and schools.

- STEEP (Systems Thinking for Efficient Energy Planning, 2013-15) - precursor to REPLICATE with the same EU partners (Bristol, San Sebastien and Florence) and EU funding. Bristol's partners were UoB, BCC, CSE and Arup. STEEP aimed to develop Energy Master Plans for districts in three cities, adopting a 'systems thinking' methodology in combination with open data sourcing to achieve carbon reduction targets and overcome the barriers to energy efficiency. http://www.smartsteep.eu.

- REPLICATE (i.e. REnaissance of PLaces with Innovative Citizenship And Technologies, 2016-21), European research and development project in Bristol, San Sebastien and Florence ${ }^{17}$.

REPLICATE is a Horizon 2020 project deploying integrated energy, mobility and ICT solutions in cities. The city of Bristol, as part of a consortium with San Sebastián and Florence (and with a total of 39 partners), was awarded $€ 25$ million in October 2015 to create integrated smart city solutions tackling urban problems such as traffic congestion, poor air quality and unsustainable energy use. The project has multiple elements in its partner cities. In Bristol, the project focuses on the inner-east area of the city to deploy energy efficiency, sustainable mobility and connected smart digital services. It took a systems' approach, looking at smart homes, retrofit and travel solutions, including installation of EV charging points, shared use of EVs through a smart mobility app; installation and use of smart household appliances for a demand-response trial; community engagement and education all connected through the Bristol's Open Data platform.

- Bristol Energy Smart System Transformation ${ }^{18}$ (BESST) project was an Innovate UKfunded PFER pilot research project in 2019. The project was led by Bristol Energy with six other partners: Bristol City Council, Bristol Community Transport, Upside Energy, Regen, Bristol Energy Network and SevernNet. The project focused on the whole system: "looking at technology, commercial viability, regulatory constraints and consumer acceptance and engagement" [B9]. It sought to design a customer-focused way to deploy smart energy and digital technology at scale.

- City Leap ${ }^{19}$ (since 2018) is the City Council's initiative to bring in new investment to meet the 2030 carbon neutrality target. The aim is to form a joint venture between BCC and an external partner to provide services to the Council and substantial investment in delivery of a

\footnotetext{
${ }^{17}$ https://replicate-project.eu/about/, https://www.connectingbristol.org/projects/replicate/

${ }^{18}$ https ://www.regen.co.uk/project/bristol-energy-smart-system-transformation-besst/

${ }^{19} \mathrm{https}$ ://www.energyservicebristol.co.uk/cityleap/, Original prospectus at https://www. energyservicebristol.co.uk/wp-content/pdf/City_Leap_Prospectus $\backslash \% 204-5-18$.pdf
} 
low-carbon infrastructure in the City. This is still at a tendering stage, with changes needed following the sale of Bristol Energy in September 2020.

- Interoperable Open Digital Control Unit System Project (IODiCUS, 2015-2016) - research demonstrating the technical viability and future market for a connected energy network, in buildings with microgeneration, local energy storage and optimised interaction with the electricity grid $^{20}$

\section{C.2 Retrofit and energy efficiency}

- Cold Homes Energy Efficiency Survey Experts ${ }^{21}$ (or CHEESE) is a CIC focusing on thermal imaging to inform householders of low-budget retrofit options.

- Futureproof ${ }^{22}$ - engaging builders and the able-to-pay in retrofitting for energy efficiency.

The Green Register has partnered with CSE on the Futureproof project which aims to support and connect those homeowners who might be up for taking action with suitably qualified builders, thus helping to develop the market and supply chain. It engages with homeowners who can afford to pay for energy efficiency retrofit, yet are not sure where to look or what to do. Simon Roberts of CSE wrote a short paper called, 'Do the Next Million First', suggesting that the most effective approach is to identify who's likely to take up energy efficiency measures and concentrating on them rather than trying to bring in everyone, which then builds the supply chain enabling others to follow. This project builds on the Bristol Green Doors initiative which followed the popular art trail format (where art is displayed in local homes) to exhibit energy efficiency and retrofit processes in domestic homes, enabling visitors to discuss with the homeowner what was done, how, by whom and with what outcomes.

- SONNET ${ }^{23}$ (SOcial iNNovation in Energy Transitions): as stated in the BCC property strategy, the city council's aspiration is that their estate 'leads by example' in the contribution it makes to Bristol's carbon neutrality. The SONNET project is exploring how to help community buildings reduce their carbon footprint, developing templates for audit and engagement and exploring investment crowdfunding mechanisms such as 'Community Municipal Bonds' to fund investable measures with short payback periods. This forms the 'Bristol City Lab' element of the wider SONNET project across six EU cities.

- Schools ${ }^{24}$ : the BCC Energy Service is offering to audit and support schools to improve their energy efficiency with any costs paid for by a zero \% loan which is repaid out of savings over a maximum of 5 years.

\footnotetext{
${ }^{20}$ https : //gtr.ukri.org/projects?ref $=102001$

${ }^{21}$ https://cheeseproject.co.uk

${ }^{22}$ https://futureproof.uk.net/

${ }^{23}$ https://sonnet-energy.eu/portfolio-item/bristol/

${ }^{24}$ https : //www .energyservicebristol.co.uk/business/schools-energy-efficiency-scheme/
} 


\section{C.3 Renewables and Heat}

\section{C.3.1 Microgrids}

Volume housebuilders have been reluctant to embrace new technologies and approaches to making developments more sustainable, so it has been left to smaller developers to make the first moves. Owen Square ${ }^{25}$ - (2016-ongoing) had ambitions to connect rows of existing homes to a private wire microgrid with linked energy efficiency retrofit and domestic solar all connected to a ground source heat pump in the park and solar array on an adjacent community building, working with Easton Energy Group and CEPRO. The (award-winning) project has currently stalled due to a lack of funding.

Bright Green Futures are developing community eco-builds, with their current development of around 50 homes. (Waterlilies ${ }^{26}$ ) planning a crowd-funded microgrid connected to a whole development solar and battery system. CEPRO is working with BEC to take this initiative forward. New developments are seen as less complex for the microgrid approach.

Just outside the eastern edge of Bristol is the site of Hanham Hall ${ }^{27}$, a larger flagship carbon challenge scheme of 186 homes which was completed in 2015. It was judged as the Best Sustainable Development in Britain in the 2014 What House? Awards and was England's first large-scale housing scheme to achieve the 2016 zero-carbon standard. Barratt Homes were the developers working with HTA architects.

\section{C.3.2 Heat networks}

Through the energy service, BCC is developing heat networks across the city centre and beyond. The first map below shows the areas already planning for heat and the second shows a wider area where developments might connect, with the current area forming only a small part of this at present ${ }^{28}$. Currently BCC is aiming at connecting city civic buildings, social housing, businesses and hospital ${ }^{29}$.

\section{C.3.3 Solar}

Bristol Energy Co-operative has been developing community-owned solar on buildings and land since 2010 with a $4.2 \mathrm{MWp}$ solar farm at Lawrence Weston supporting the local community. Low Carbon Gordano also have ground-mounted solar projects with the largest one being in Avonmouth $(1839 \mathrm{~kW})^{30}$.

- Community-led solar farms and roofs - Bristol Energy Co-operative since 2010, also

- Low Carbon Gordano,

- Bristol Power Co-operative

\footnotetext{
${ }^{25}$ https : //www . owensquare.coop

${ }^{26} \backslash$ url $\{$ https : //www.brightgreenfutures.co.uk/projects/water-lilies/\}

${ }^{27}$ https://www.hta.co.uk/project/hanham-hall, https://www.theguardian.com/environment/2007/dec/14/ energyefficiency.energy1, https://www.barrattdevelopments.co.uk/showcase/hanham-hall-bristol

${ }^{28}$ https://www.energyservicebristol.co.uk/business/heat-networks/

${ }^{29}$ https://www.energyservicebristol.co.uk/business/heat-networks/

${ }^{30} \mathrm{http}$ ://lowcarbongordano.co.uk/our-community-generation-projects/
} 
- PROSEU research - mainstreaming renewable energy prosumers, led by Leeds University with Bristol Case studies

\section{C.3.4 Wind energy}

Avonmouth on the Severn Estuary is the site of a number of wind turbines providing power to the port and into the national grid. This coastal, industrial site is ideal for good wind and energy connections to the National Grid in one of the largest dock areas in Europe.

- The first development was of 3 turbines (6MW) in 2007, owned and operated by Ecotricity and the Bristol Port Company on the edge of the estuary ${ }^{31}$.

- There are another 4 wind turbines (8.2MW) located on the land of Wessex Water's waste treatment plant, operational since 2013 in a collaboration between BCC and Thrive Renewables $^{32}$.

- A further two turbines, which became operational in 2013 , are co-located with a solar farm to the south of the Seabank Power Station on BCC land ${ }^{33}$. BCC was the first UK local authority to build and manage its own large-scale wind turbines ${ }^{34}$.

- In 2020, ALW has been developing its own community-owned wind turbine which has received planning approval ${ }^{35}$.

\section{C.4 Storage}

Batteries are another area where Bristol is innovating. The Council $\mathrm{HQ}$ at City Hall installed a $300 \mathrm{~kW}$ battery developed with Upside Energy in 2020, with payback from load shifting and grid services.

In Lockleaze, a 15MW battery, developed by Aura Power with clean energy investors Hazel Capital, provides frequency response to the National Grid. The battery was installed in 2017 after earlier applications for diesel generators were opposed by residents and rejected by planners. At the time, it was thought to be the UK's largest standalone battery storage facility. Aura have another $20 \mathrm{MW}$ battery in development at a site on Feeder Road.

In September 2020 agreement was reached for a new 33MW battery storage facility to be built at Avonmouth, Bristol after a lease was signed between land investor Electric Land and Hallen Energy, part of French renewable energy firm Voltalia SA ${ }^{36}$. Electric Land purchased the 5-acre site to develop 'Avonmouth Energy Park' in 2018, and current plans are for a 49.9MW gas powered generation facility alongside the separate $33 \mathrm{MW}$ battery storage.

\footnotetext{
${ }^{31}$ https://www.ecotricity.co.uk/our-green-energy/our-green-electricity/from-the-wind/ wind-parks-gallery/bristol-port

${ }^{32}$ https://www.thriverenewables.co.uk/projects/avonmouth-wind-farm/

${ }^{33}$ https://www . bristol.gov.uk/policies-plans-strategies/avonmouth-wind-turbines-project

${ }^{34}$ https://www .energyservicebristol.co.uk/about/

${ }^{35}$ https : //www . bristol247.com/news-and-features/news/wind-turbine-150m-could-be-build-avonmouth-lawrence-weston/

${ }^{36}$ https://www.businessgreen.com/news/4019486/giant-battery-storage-project-secures-site-near-bristol, https://www.businessleader.co.uk/tlt-advises-voltalia-on-its-first-uk-battery-storage-venture/ 96845/, https://electricland.co.uk/voltalia-avonmouth/
} 


\section{C.5 Transport and Mobility}

TheGo Ultra Low West (GULW) programme is a $£ 7 m$ project across the West of England authorities to improve access to electric vehicles via public charging networks, rapid charging hubs and electric car clubs. The local authorities are converting a proportion of their fleets to electric. Bristol City Council has taken on the running of the network with a partnership of suppliers (Siemens, ChargePoint Services and Alfen) who plan to install 120 public EV charging points across the region by 2021.

SCIURUS - vehicle to grid with Kaluza / OVO and Nissan, 2018 -2020 (InnovateUK / BEIS / OLEV funding)

Some useful links for these projects:

- https://www.kaluza.com/case-studies/project-sciurus/

- https://www.ovoenergy.com/electric-cars/vehicle-to-grid-charger

- https://gtr.ukri.org/projects?ref=104248

- WPD Electric Nation, trialling V2G smart charging - a national project with SW component 2020-2022

- Go Ultra Low West https://travelwest. info/drive/electric-vehicles/go-ultra-low-west 


\section{Appendix: Stakeholder Interview Questions}

\section{Overview of the EnergyREV research project}

- Aims, process, check reading of info sheet

- Any questions before we start

- OK to record and transcribe?

\section{Interview Questions: Organisation and Role}

1. A brief overview of the organisation (e.g. business area, types of project, number of employees, years of work)

2. A brief overview of the expert:

-What is your role within the organisation?

- How many years have you been part of it?

\section{Interview Questions: Project and Skills}

1. Thinking of a few projects you have worked on:

(a) How many projects have you carried out in this area,(i.e., projects that might fit into the description of a smart local energy system)?

(b) Could you give a few recent examples (names, type, brief description)?

(c) Who are the stakeholders (and skills / professions) involved in these projects at their different stages (e.g. financial, technical, technology, legal, planning expertise, business advice, practical supply chain)?

(d) What do they each do for your projects?

(e) How do you find these skills, and are they within your organisation?

(f) Do you Recruit? If so, from where?

(g) Do you sub-contract, or do you have a partnership? If so, with who?

(h) If not, do you train up your existing workforce?

2. Thinking about the projects, can you reflect on which skills your company needs the most at different project stages? Stages:

- Project Planning/ Route to market

- Legal and regulatory compliance

- Finance

- Installation \& Development and delivery

- Operation \& maintenance

3. What sort of qualifications and skills have you recruited recently? 
4. What are the common issues or trends that arise within projects - e.g., what are the barriers and facilitators to doing this sort of work (e.g., regs, planning, clients, ...)?

5. Do you have any issues finding the right skills, knowledge or expertise? Are there common issues or trends that arise with respect to skills?

\section{Training provision questions}

1. What training provision is currently missing in preparing the workforce for future energy systems?

2. Short courses, university-level degrees, school-teaching?

3. To members of the public or to workforce or to policymakers/users?

4. What sort of training do you think is needed most?

\section{Looking ahead}

1. As the transition to SLES scales up, what skills are we likely to need more of?

2. Are there any skills that are in less demand or are no longer needed?

3. What factors do you think could help to improve the state of the energy (efficiency) sector in the future?

4. If there is a big pot of money to help facilitate faster change in reaching zero carbon: where would you invest it?

THANK YOU! 


\section{E Appendix: Citizen Interview Guide}

Thank you for participating in our study. As you read in the consent form, we will be recording the session so we can review it to make sure that we don't miss any part of our conversation. Your information will be kept confidential and will only be accessed by us. Your name will not be associated with any data we collect. We are interested in how people use energy in their homes and hence what potential there is to shift energy demand away from peak periods. If you cannot or don't want to answer a question, please say so at any time. Do you have any questions?

1. Would you say that you care about or are interested in environmental issues?

- Follow-up: would you say: not at all / a bit / sometimes / quite a lot / very much

2. Are you a member of any green / environmental organisation, or another similar group?

- Follow-up-1: other groups, for example baby, books, community?

[Daily Routines: building a picture of how people perceive their appliances and how they use them currently]

3. What is your daily routine on weekdays?

- Follow-up-1: Is it the same every day?

- Follow-up-2: Are there some days when the house is occupied during the day?

4. How frequently do you use your washing machine,

- Follow-up-1: dryer

- Follow-up-2: dishwasher?

- Follow-up-3: Which of these, if any, are smart?

- Follow-up-4: What other appliances are particularly important to you (e.g., cooker, fridge, shower, $\mathrm{TV} /$ console) - let's pick 3?

[Thinking about these 3 appliances]

5. Can you describe the last time that you used these appliances / 1,2,3 (from listed important appliances)? Is that the normal way that you use them? Where are they in the house?

- Follow-up-1: When / what time of day do you normally use them? Why? e.g. at specific times or varied. Is it different in the winter / summer?

- Follow-up-2: Is the appliance set in a particular way e.g. time delay, eco-friendly, high heat, etc.?

- Follow-up-3: What do you like about this appliance? e.g. speed, looks, effectiveness, capacity, controllability

- Follow-up-4: What do you dislike about this appliance?

6. Do you have any restrictions to when you can use your appliances?

- Follow-up-1: Does anyone in the building object to you using the appliances in a specific way or at a particular time?

- Follow-up-2: Who uses what and when? 
- Follow-up-3: Are there any constraints due to family schedules or noise (e.g., young children, old family members, illnesses, shift workers etc.)

7. Do you have any preferences on how you would like to use these appliances which might be different from how you currently use them?

[DSM Automation:]

Introduction: Use of energy here is particularly high during early mornings (between 7am - 8.30 am) and evening (4pm-8pm). Because of this, the grid needs to set up new generation facilities. However, if people moved their use of energy from these times to other periods in the day, the grid can avoid new generation investments, which cost money as well as cause increased environmental harm. It can also make better use of renewable energy. Because of this, we are looking into automation or management of appliance use in order to move their use out of the critical time periods.

8. What, if some, of the appliances you mentioned could be turned on/off to avoid peak demand time so you would pay less and so that the grid load was more evenly spread. Would you consider some form of automation for some, or all of them?

- Follow-up-1: Would you prefer only automating some appliances over others? Can you explain bit more?

9. How would you choose to automate them? What might work for you?

- What degree of automation limits might you consider for each of the 3 appliances that we have been discussing?

- Would you prefer to actively choose when to run it within only off-peak time limits?

10. How would you feel about having an energy management system which can manage things on your behalf in your household by automating some appliances (within limits set by you)? For example, this is so that you didn't breach an individual energy cap, to move consumption out of peak periods or to smooth energy consumption across a neighbourhood.

- Follow-up-1: What do you think about more of a whole house automation system, integrating and managing your energy usage, or even one that manages your usage alongside other users in your community?

- Follow-up-2: Is personal automation different from a thermostat in the house starting/stopping boiler for temperature controls?

- Follow-up-3: What other examples can you think of (e.g. bread maker, security lights)?

11. What can you foresee as difficulties or problematic issues with the system?

12. What motivations would most help you in changing the time/pattern of use of the appliances 1,2 and 3.

13. How comfortable would you feel for your energy suppliers to have your data on appliance usage?

14. Would it matter to you if your energy consumption data from this system was to be shared various parties?

- Follow-up-1: researchers

- Follow-up-2: energy generators

- Follow-up-3: energy suppliers

- Follow-up-4: other businesses 
15. How would you want this data to be shared with these parties?

16. If you were able to allow only selected businesses or individuals to view your consumption data, to deliver extra services with it, would you be more willing to allow this?

- Please explain your answer.

-Who would you feel comfortable with sharing this information?

17. How does the consumption data compare with other data, shopping loyalty card information gathering?

[Is there anything else that you would like to say about energy use or that this interview has made you think about that I haven't asked you?] [Thank]

\section{References}

[1] Energyrev project. https://www.energyrev.org.uk/, 2021.

[2] Migration Advisory Committee. Assessing labour market shortages: A methodology update. Technical report, Migration Advisory Committee, London, 2017.

[3] Oscar Fitch-Roy, Carlos Albero, Sarah Barber, Beckie Hill, Paul Gardner, Joseph Phillips, Sarah Azau, Zoë Casey, Filippo Gagliardi, Angeliki Koulouri, Jacopo Moccia, Julian Scola, Justin Wilkes, and Adrienne Margoyles. Workers wanted: The EU wind energy sector skills gap. Technical report, European Wind Energy Technology Platform, 2013.

[4] Cedefop. Skills for green jobs: European synthesis report. Technical report, European Commission, Luxembourg, 2011.

[5] Expert Group on Future Skills Needs. Future Skills Needs of Enterprise within the Green Economy in Ireland. Technical report, Forfas, Dublin, 2010.

[6] Mankolo Lethoko. Green economy job projections vs green skills: Is there a link between present skills base and the projected numbers in south africa? International Journal of African Renaissance Studies Multi, Inter and Transdisciplinarity, 9(2):113-132, 2014.

[7] C Martinez-Fernandez, A Ranieri, and SA Sharpe. Greener skills and jobs for a low-carbon future. OECD Green Growth Papers, No. 2013/10, 2013.

[8] Mark W Maier. Architecting principles for systems-of-systems. Systems Engineering: The Journal of the International Council on Systems Engineering, 1(4):267-284, 1998.

[9] I. G. Vargas and R. T. V. Braga. Understanding system of systems management: A systematic review and key concepts. IEEE Systems Journal, pages 1-10, 2020.

[10] Syed Asad Naqvi, Ruzanna Chitchyan, Steffen Zschaler, Awais Rashid, and Mario Südholt. Crossdocument dependency analysis for system-of-system integration. In Monterey Workshop, pages 201226. Springer, 2008.

[11] P. Devine-Wright. Community versus local energy in a context of climate emergency. Nat Energy, 4:894-896, 2019.

[12] Christopher J Brown and Nils Markusson. The responses of older adults to smart energy monitors. Energy policy, 130:218-226, 2019.

[13] Denise J. Wilkins, Ruzanna Chitchyan, and Mark Levine. Peer-to-peer energy markets: Understanding the values of collective and community trading. In Proceedings of the $2020 \mathrm{CHI}$ Conference on Human Factors in Computing Systems, CHI '20, page 1-14, New York, NY, USA, 2020. Association for Computing Machinery. 
[14] Caroline Bird and Ruzanna Chitchyan. Towards requirements for a demand side response energy management system for households. arXiv preprint arXiv:1908.02617, 2019.

[15] Ruzanna Chitchyan and Caroline Bird. Theory as a source of software requirements. In Proceedings of the 28th International Requirements Engineering Conference, RE'2020. IEEE, 2020.

[16] Nick Kelly Graeme Flett and Raheal McGhee. Review of uk energy system demonstrators. https: //ukerc.ac.uk/publications/review-of-uk-energy-system-demonstrators/, 2018.

[17] Richard J Adams, Palie Smart, and Anne Sigismund Huff. Shades of grey: guidelines for working with the grey literature in systematic reviews for management and organizational studies. International Journal of Management Reviews, 19(4):432-454, 2017.

[18] Ian F Alexander and Richard Stevens. Writing better requirements. Pearson Education, 2002.

[19] FabiÃ $i n$ Fuentes GonzÃ $\tilde{j}_{l e z}$, Janette Webb, Maria Sharmina, Matthew Hannon, Dimitrios Pappas, and Margaret Tingey. Characterising a local energy business sector in the united kingdom: Participants, revenue sources, and estimates of localism and smartness. Energy, 223:120045, 2021.

[20] Grants on the web, epsrc. https://gow.epsrc.ukri.org/, 2020.

[21] Bristol City Council. Exploring new technology for smarter streets and homes. https://www . connectingbristol.org/replicate/, 2019.

[22] Kathy Charmaz. Constructing grounded theory: A practical guide through qualitative analysis. sage, 2006.

[23] Patricia Fusch, Gene E Fusch, and Lawrence R Ness. Denzin's paradigm shift: Revisiting triangulation in qualitative research. Journal of Social Change, 10(1):2, 2018.

[24] Council action on climate change. https://www.bristol.gov.uk/policies-plans-strategies/ council-action-on-climate-change, 2021.

[25] Our resilient future: A framework for climate and energy security. OurResilientFuture: AFrameworkforClimateandEnergySecurity, 2015.

[26] The south west energy hub. https://www.westofengland-ca.gov.uk/south-west-energy-hub/, 2021.

[27] Green register. https://www.greenregister.org.uk/, 2016.

[28] Futureproof project. https://futureproof .uk.net/, 2020.

[29] Cold homes energy efficiency survey experts: Cheese. https://cheeseproject.co.uk/, 2014.

[30] Association for environment conscious building. https://www . aecb.net/, 1980.

[31] Simon Roberts. Do the next million first. https://www.cse.org.uk/downloads/file/ do-the-next-million-first-transforming-the-owner-occupier-retrofit-market.pdf, July 2017.

[32] Green open homes. http://www.greenopenhomes.net/, 2014.

[33] Green homes grant: make energy improvements to your home. https://www.gov.uk/guidance/ apply-for-the-green-homes-grant-scheme, 2020.

[34] Retfrofit academy. https://www.retrofitacademy.org/, 2019.

[35] Bristol one city. https://www.bristolonecity. com, Jan 2019.

[36] City leap prospectus. https://www.energyservicebristol.co.uk/wp-content/pdf/City_Leap_ Prospectus\%204-5-18.pdf, 2018.

[37] Core cities uk. https://www. corecities.com/. 
[38] Association for public service excellence. https://www.apse.org.uk/apse/.

[39] Energy service bristol. https://www.energyservicebristol.co.uk/.

[40] Bristol's city leap. https://www.energyservicebristol.co.uk/cityleap/, Nov 2020.

[41] Introduction to industrial case. https://epsrc.ukri.org/skills/students/industrial-case/ intro/, 2021.

[42] Clean energy prospector. http://www. cepro.co.uk/, Dec 2020.

[43] Esme Ashcroft. Council apologises for nine month delay as temple circus roadworks extended. https://www.bristolpost.co.uk/news/bristol-news/ council-apologises-nine-month-delay-1794900, July 2018.

[44] Robert C Martin. Agile software development: principles, patterns, and practices. Prentice Hall, 2002.

[45] Kent Beck, Mike Beedle, Arie Van Bennekum, Alistair Cockburn, Ward Cunningham, Martin Fowler, James Grenning, Jim Highsmith, Andrew Hunt, Ron Jeffries, et al. Manifesto for agile software development. 2001.

[46] Edf launches blockchain solar-plus-storage, p2p trading pilot in south london. https://www. energy-storage.news/news/edf-launches-blockchain-solar-plus-storage-p2p-trading-pilot-in-south-lon 2021.

[47] Energy data taskforce: A strategy for a modern digitalised energy system. https://es. catapult. org.uk/reports/energy-data-taskforce-report/, June 2019.

[48] Ruzanna Chitchyan and Caroline Bird. Skills for transition to smart local energy system of systems: Case of bristol city. ??, Feb 2021.

[49] Joint strategic needs assessment data profiles. policies-plans-strategies/jsna-data-profile, 2020.

https://www.bristol.gov.uk/

[50] B. G. Glaser and A. L. Strauss. The Discovery of Grounded Theory. Aldine Publishing Co., 1967.

[51] Roy Suddaby. From the editors: What grounded theory is not, 2006.

[52] Klaas-Jan Stol, Paul Ralph, and Brian Fitzgerald. Grounded theory in software engineering research: a critical review and guidelines. In Proceedings of the 38th International Conference on Software Engineering, pages 120-131, 2016.

[53] Yael Zekaria and Ruzanna Chitchyan. Literature review of skill shortage assessment models. https://www.researchgate.net/publication/349883872_Literature_Review_of_Skill_ Shortage_Assessment_Models, 2019.

[54] Ruzanna Chitchyan, Palvi Shah, and Caroline Bird. Eliciting requirements for demand response service design to households: A pilot study. In Proceedings of the Evaluation and Assessment on Software Engineering, EASE '19, pages 299-304. ACM, 2019. 